\title{
Will the real R\&D employees please stand up? Effects of tax breaks on firm-level outcomes
}

\author{
Irem Guceri $^{1}{ }_{(\mathbb{D}}$
}

(C) The Author(s) 2017. This article is published with open access at Springerlink.com

\begin{abstract}
This paper evaluates the effect of tax incentives for research and development $(R \& D)$ on $R \& D$ spending and employment of $R \& D$ staff in a quasi-experimental setting. To do this, I exploit an exogenous reform in UK R\&D tax policy, which changed the definition of an SME from firms with fewer than 250 employees to those with fewer than 500 employees. I use the UK Business Enterprise Research and Development Survey (BERD), for which companies do not have an incentive to relabel their ordinary employees or spending as $R \& D$. I find that $R \& D$ tax incentives help to increase $\mathrm{R} \& \mathrm{D}$ spending at the company level; this translates to a user cost elasticity between -0.88 and -1.18 . Further, the additional $R \& D$ generated through the tax relief can be attributed entirely to an increase in the number of R\&D employees in the companies' workforce. Together, these results challenge a common narrative on the role of R\&D tax incentives.
\end{abstract}

Keywords R\&D · Tax credits · Quasi-experiment · Difference-in-differences

JEL Classification $\mathrm{H} 25 \cdot \mathrm{O} 30$

\section{Introduction}

Governments subsidise R\&D in order to reach the socially optimal level of private investment in innovation. ${ }^{1}$ From the government's perspective, one way of subsidis-

\footnotetext{
1 The mechanisms underlying the private sector's underinvestment problem have been laid out in, among others, Arrow (1962), Aghion and Howitt (1992), Jones and Williams (1998).
}

$\bowtie \quad$ Irem Guceri

irem.guceri@sbs.ox.ac.uk

1 Oxford University Centre for Business Taxation, Oxford, UK 
ing private $R \& D$ is to directly fund projects that it chooses from a pool of applicants. From the companies' perspective, R\&D is a risky activity and the companies themselves are better informed than the government to decide on the potential success and economic viability of their R\&D opportunities. Criticisms over the government's ability in choosing the best $R \& D$ projects have led to an increased emphasis on tax incentives to support private R\&D. The USA, France and Japan have offered R\&D tax incentives for decades now, but in the 2000s, the implementation of this policy became ever more prevalent, with France and Japan substantially increasing the generosity of their R\&D tax incentive schemes while some other leading players in R\&D and innovation such as South Korea, China and the UK introduced schemes that later constituted a large portion of government financing for business R\&D in these countries.

In this paper, I explore the channels through which $R \& D$ tax incentives operate to affect firm behaviour. I achieve this by analysing the impact of R\&D tax relief on the real R\&D spending and R\&D employment in a firm. I apply a difference-in-differences regression approach, using the micro-level Business Enterprise Research and Development (BERD) data for the UK collected by the Office for National Statistics (ONS). I exploit a discontinuity in the design of the schemes in order to identify the policy impact.

This paper makes the following contributions. First, the policy reform considered here provides a valuable opportunity to identify the effects of $R \& D$ tax incentives. In a setting where SMEs are eligible for more generous tax incentives, the reform doubles the thresholds that identify an SME, generating a natural control group whose user cost of R\&D capital remains unaffected by the reform, and a natural treatment group composed of firms which experience a drastic reduction in their user cost. Second, the ONS BERD survey includes information on 'total R\&D spending,' and not just spending that 'qualifies' for the relief. It also provides information on R\&D employment which enables me to explore whether the R\&D spending that appears to have been generated by the reform is a result of firms increasing the scale of their $R \& D$ activities, or if the changes are driven by mere price increases that do not affect the R\&D headcount. Third, when collecting the data, the ONS reassures firms that the data on individual companies cannot be identified or used for other purposes than statistical analysis. ${ }^{2}$ This mitigates firms' incentives to lie about their R\&D spending or to relabel ordinary spending as R\&D.

There is an emerging literature that explores the impact of tax incentives on $R \& D$ by exploiting policy discontinuities. ${ }^{3}$ A recent wave of studies use administrative data in a quasi-experimental setup (examples are Agrawal et al. 2014; Guceri and Liu 2015; Rao 2016; Dechezlepretre et al. 2016). These studies generally find a positive and significant effect of tax incentives on R\&D spending by businesses. One main advantage of administrative data is the access to information on the firms' tax positions and whether they benefited immediately from a tax deduction. A disadvantage, on the other hand, is that companies may have an incentive to misreport ordinary spending

\footnotetext{
2 The ONS Code of Confidentiality can be found at https://www.statisticsauthority.gov.uk/ monitoring-and-assessment/code-of-practice/.

3 A review of the earlier wave of structural estimates can be found in Kohler et al. (2012).
} 
as $R \& D$ to obtain the tax credit. Moreover, information in tax return data is usually more limited, for example, to expenditures that qualify for tax incentives.

Wider availability of micro-level data has enabled quasi-experimental work on direct subsidies for R\&D as well. In Bronzini and Iachini (2014), for example, the authors use data on the population of applicants to an R\&D subsidy in northern Italy to evaluate a direct subsidy programme and find that only smaller firms responded to the subsidy by increasing their R\&D spending.

The finding that tax incentives for $R \& D$ may have a positive impact on $R \& D$ spending attracted criticism from two main angles. First, Goolsbee (1998) and Rogers (2010) warned that with the introduction of R\&D support policies, the majority of increased R\&D expenditures may go to higher salaries for scientists and engineers, rather than fund the employment of a larger number of researchers to scale up R\&D activities. Goolsbee (1998) supported this finding by demonstrating that there is a relatively stable supply of scientists, with expenditure on pay rising significantly following increases in government subsidies to support R\&D expenditure by firms. Lokshin and Mohnen (2013) showed firm-level evidence from the Netherlands that there is some wage response to R\&D tax credits. Second, many studies flagged the issue of relabelling ordinary expenses as $R \& D$, even though the extent of the problem has rarely been quantified. Some evidence of relabelling was provided in an early report by the US General Accounting Office (1989), which found that around $20 \%$ of revenue agents were not convinced by the clarity of the definition of qualifying expenses. A more recent US GAO study (2009) identified the main expenditure items which are more difficult to monitor for the tax authority. On the top of their list was the proportion of salaries paid to management-level staff who supervise research activities.

Another strand of the related literature evaluates the effectiveness of public funds, without restricting attention to fiscal incentives for firms in stimulating R\&D and innovative activity. Zuniga-Vicente et al. (2014) and Becker (2015) survey this broader literature, with a discussion of the comparisons between the benefits of direct subsidies and tax incentives. There is some evidence in the literature that young start ups, which are very important for the innovation ecosystem of countries, benefit more from direct subsidies as they incur losses for extended periods of time before switching to profitable positions (Bronzini and Piselli 2016). For these firms, tax deductions or credits have very little value in present discounted terms, especially if they are cash constrained.

The UK system is relatively generous towards loss-making companies, as it offers a cash refund for loss-makers, as well as the option to carry the benefit forward or back (OECD 2010). Most schemes around the world do not offer cash refunds, and some do not even allow the benefit to be carried back or forward in time. The BERD data does not provide information on the tax positions of companies, but it is not unreasonable to assume that firms across the range of tax positions are able to benefit from tax incentives. The treatment of losses for the purpose of the R\&D tax relief is an important design aspect that needs to be considered when benchmarking the findings of this paper with studies based on other countries' data.

The micro-level BERD survey that I use in this study is anonymous, and the data cannot be matched with the tax records due to ONS's legal promise to the respondents. This legal requirement presents an opportunity for the purpose of this study, as companies do not have an incentive to misreport their ordinary spending as R\&D when 
responding to the BERD survey. The other advantage is that the BERD survey has a measure for R\&D headcount within the company, allowing for the study of changes in the firm's R\&D employment.

The composition of R\&D spending stimulated by tax incentives remained an underexplored area. There is evidence that the corporation tax system affects both the quantity and the quality of innovative activity (Ernst et al. 2014). The recent rise in favourable tax treatments of patent income is also of interest given that such incentives may complement or substitute R\&D tax credits. With the OECD-led process to tackle Base Erosion and Profit Shifting (BEPS), there is more of an inclination by governments towards attaching such 'patent box' regimes to real R\&D activity. This paper abstracts away from issues related to international shifting of profits arising from innovative activity (these issues are discussed in detail in Evers et al. 2014). I focus here on the input side of $R \& D$, aiming to identify the quantity effects separately from any relabelling or price effects of tax incentives on R\&D inputs.

Hall and Van Reenen (2000) underlines the difficulty and the importance of finding exogenous variation in the user cost of capital to identify the effect of tax incentive-type R\&D support policies. The UK policy setting provides a suitable basis for exploiting such exogenous variation, using a difference-in-difference methodology with individual fixed effects, as often applied in public policy contexts (for examples, see Yagan 2015; Zwick and Mahon 2017). In the UK, R\&D tax incentives were first introduced for SMEs (in 2000) and then for large companies (in 2002). In 2008, two reforms took place. First the rates for enhanced deduction increased for SMEs from $£ 150$ to $£ 175$ for each $£ 100$ spent on R\&D ( $150 \%$ to $175 \%$ ), and for large firms the rate increase was from 125 to $130 \%$. For the large firms, the increase did not lead to a substantive reduction in the cost of $R \& D$ capital because there was also a reduction in the tax rate. For SMEs, the reform had a more substantial effect. In August 2008, more importantly, the definition to qualify as an SME changed from 250 employees to 500 employees (along with other criteria, which I discuss in Sect. 2). This second reform that took place in 2008 meant a large decline in the user cost of R\&D capital for the mediumsized companies whose definition changed from 'large' to 'SME' for the purpose of the $R \& D$ tax relief. The drop in the user cost of R\&D capital was on average $17 \%$ for this 'treated' group of firms depending on their taxable profit. ${ }^{4}$

I find that the treated firms increased their R\&D spending by around 15-20\% on average in response to the reform. Measuring against the $17 \%$ average reduction in the user cost of R\&D capital, the increase translates to an implied user cost elasticity estimate of around -0.88 to -1.18 (with the latter coming from the preferred sample), which is in the same ballpark as the cross-country finding of Bloom et al. (2002) that used an instrumental variables approach. Without considering the social returns to R\&D through spillover effects, I calculate that the return to each $£ 1$ foregone in corporation tax is between $£ 0.75$ and $£ 1.2$ in $R \& D$ depending on the tax position of claimants, suggesting that the government recovers its cost from implementing the policy.

\footnotetext{
4 The estimates of the user cost of capital are based on Guceri and Liu (2015), since the BERD dataset does not provide information on companies' tax positions and hence on the changes in their user cost of R\&D capital.
} 
This paper pins down a mechanism through which R\&D tax incentives affect firmlevel outcomes. Thanks to the richness of the BERD survey data, in the present paper, I can observe both the R\&D spending and $R \& D$ employment responses, allowing the paper to address the questions raised earlier regarding the impact of R\&D policy in an environment with inelastic supply of researchers. The use of information on total R\&D spending (as opposed to only qualifying R\&D) and the possibility to differentiate between 'price' and 'quantity' effects distinguishes this paper from other recent working papers that use the UK tax returns data on qualifying R\&D. The BERD dataset that I use in this study and the corporate tax returns data cannot be matched due to legal restrictions. Regarding the papers that use the tax returns data, Guceri and Liu (2015) estimates the effect of the R\&D tax relief on R\&D spending that qualifies for the tax breaks and Dechezlepretre et al. (2016) focuses on the patenting behaviour of firms, again referring to the data on changes in 'qualifying' R\&D. Both these latter studies find very high elasticities of qualifying $R \& D$ with respect to its user cost. In fact, comparing the elasticity of total $R \& D$ with respect to its user cost from the present paper $(-1.18)$ with the elasticity of qualifying $R \& D$ with respect to its user cost found in Guceri and Liu (2015) (-2.34), we can infer that all of the impact comes from the qualifying expenditure response, confirming Rao (2016).

In the next section, I present some aggregate trends in the R\&D performance of UK businesses, describe the R\&D tax policy framework in the UK and then outline the conceptual framework. In Sect. 3, I describe the data, and in Sect. 4, I present the empirical approach. Section 5 presents the results, Sect. 6 presents robustness checks and Sect. 7 discusses the implications of the results. The final section concludes.

\section{Background}

\subsection{Trends in the UK private sector $R \& D$ intensity}

Tax incentives for R\&D aim to boost the private sector's R\&D performance. An aggregate measure for a country's private $R \& D$ performance is the intensity of its Business Enterprise Expenditure on Research and Development (BERD), that is, the share of BERD in total value added of the private sector. In the past several decades, the UK private sector's $R \& D$ performance has been sluggish both in absolute terms and in terms of BERD intensity with respect to comparators such as the USA, Germany, France and Japan.

Figure 1 shows that total BERD as a share of this sector's value added has been lower and has been declining in the UK relative to Japan, Germany, France and the USA over the period 1990-2013. Earlier studies [(see, for instance, Van Reenen (1997); Griffith and Harrison (2003)] have shown that this relative decline of UK BERD intensity has been continuing for several decades. At the aggregate level without controlling for any other factors, the introduction of tax credits for R\&D spending in the UK in 2000 and 2002 appears to have had little impact.

Despite the poor relative performance in overall BERD intensity, the UK manufacturing sector BERD as a share of manufacturing sector value added has shown a steady increase and a tendency towards catching up with its peers. This is illustrated 


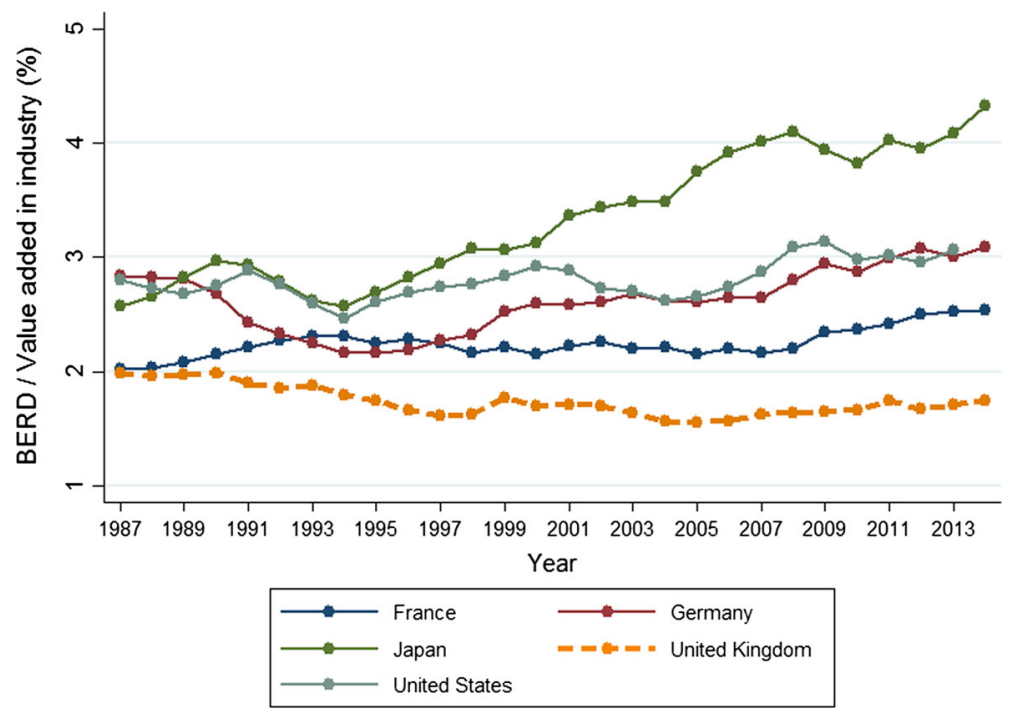

Fig. 1 Overall BERD intensity, UK and comparators. Notes the data are from the OECD Main Science and Technology Indicators (MSTI) Database, series for 'BERD as a percentage of value added in industry,' extracted on 21 November 2016 from OECD.Stat. Original data provides further notes on individual country information

in Fig. 2, which shows that the UK manufacturing sector BERD intensity has been rising over the most recent decade for which this data is available and since the UK R\&D tax credits were introduced. In the 2000s, as the UK manufacturing sector BERD intensity experienced a rise, so did its competitors'; France, Japan and the USA all experienced steep rises, with only Germany demonstrating a rather horizontal trend. Bond and Guceri (2012) noted that these peer trends in neighbouring countries may have been a significant factor in driving the rise in the UK manufacturing sector R\&D intensity, but even controlling for these effects, the UK experienced a steeper rise starting around the time of introduction of the R\&D tax incentives.

\subsection{The UK R\&D tax incentive scheme}

Fiscal incentives for $R \& D$ allow a special treatment of $R \& D$ expenditure for tax purposes and encompass a range of tax incentives for both current and capital expenditures: tax credits, cash credits, enhanced deductions, special depreciation allowance terms, enhanced loss carry backs and carry forwards, to list a few. Tax incentive schemes for R\&D can be of two types: (i) incremental, where firms benefit only to the extent that they exceed some base level of R\&D that they have previously been performing ${ }^{5}$ and (ii) volume-based, where firms enjoy benefits on all their $\mathrm{R} \& \mathrm{D}$ expenditure, regardless of their past level. It is becoming more and more common to introduce or increase the emphasis on volume-based schemes among

\footnotetext{
5 Countries apply different rules regarding the base R\&D expenditure that the firm needs to exceed.
} 


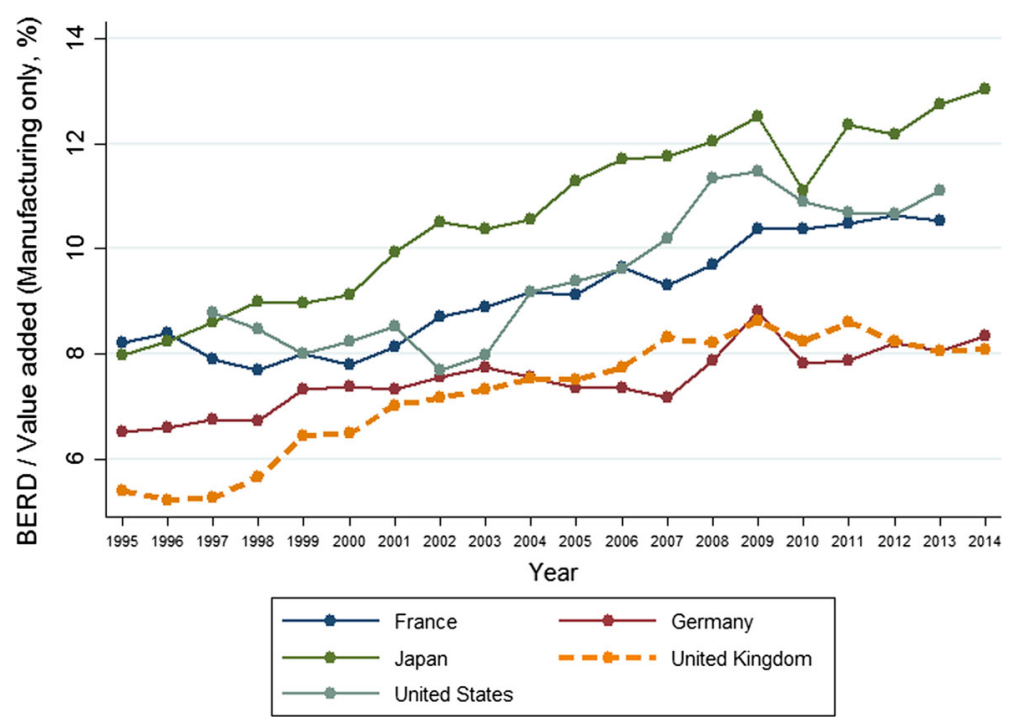

Fig. 2 Manufacturing sector BERD intensity, UK and comparators. Notes the data is from the OECD Structural Analysis (STAN) Database and National Accounts, combining the following series: 'STAN R\&D expenditures in Industry (ISIC Rev. 4),' manufacturing sectors (D10T33) in national currency for the numerator and 'Detailed National Accounts, SNA 2008: Value added and its components by activity-ISIC Rev.4 (Edition 2016)' for the denominator. OECD converts all Euro Zone countries' national currency values to Euros for periods prior to Euro Zone accession, both for R\&D data and in national accounts. The data was extracted on 21 November 2016 from OECD.Stat. For the UK and France, BERD in manufacturing sectors by product field was used, instead of by main activity. For these countries, there is no data available on BERD by main activity for periods earlier than 2007. OECD provides further notes on individual country information

industrialised countries, as the design is simpler and these benefits can be used by a larger group of beneficiaries. Altshuler (1988) outlines issues that arise in incremental schemes.

The UK R\&D Tax Relief for Corporation Tax is relatively generous in the sense that both the SME and the large company schemes are volume-based. The schemes are in the form of enhanced deductions of qualifying current expenditures from taxable income, and loss-making companies can carry forward the benefit indefinitely. France had an incremental tax credit until 2008, and then switched to a volume-based credit, greatly simplifying the design of the preceding policy. The USA provides an incremental tax credit with a 20-year carry forward option, which is a longer time period than that allowed in most countries. Canada provides a volume-based credit, and both Canada and the USA also provide sub-national tax credits [see, for instance, Wilson (2009) for a discussion of sub-national tax credits].

Discussions on a more favourable tax treatment of R\&D in the UK began in the late 1990s. This was at least partly in response to the declining trend in the R\&D intensity of the UK economy overall, which was already at levels below those of comparators such as France, Japan and Germany as demonstrated in Fig. 1. Before 2000, when the first significant tax breaks were introduced, all of current expenditure on R\&D was $100 \%$ deductible against taxable income and a subset 


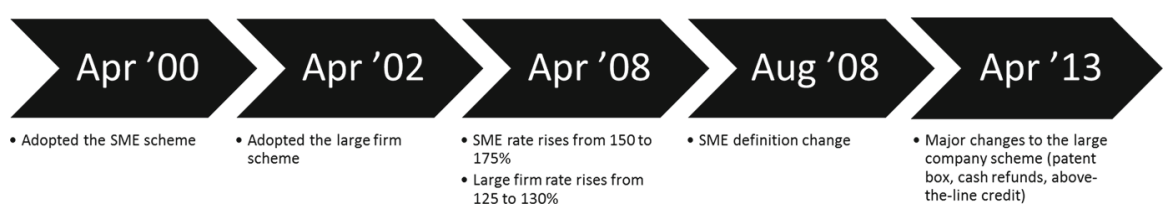

Fig. 3 Timeline of changes to the UK R\&D tax relief schemes

of capital expenditures could be expensed under the Research and Development Allowance. 6

The UK R\&D Tax Relief for Corporation Tax was introduced in two stages. First, the SME scheme was implemented in April 2000 and then later in 2002, the large company scheme was introduced. Figure 3 summarises the developments until and including 2013. The SME scheme was a combination of an enhanced deduction and cash credits, with the former applying to companies with positive taxable profits and the latter to those companies which incurred a tax loss in the reference period. The SME scheme applied to companies which satisfied the SME definition of the EC Regulation 1996/280/EC and allowed these firms to deduct, for every $£ 100$ of qualifying R\&D expenditure, $£ 150$ from their taxable income. ${ }^{7}$ These companies could claim up to $24 \%$ of their R\&D expenditure in cash if they did not have taxable profit. The large company scheme was less generous: it allowed the companies that were above the SME threshold to deduct, for every $£ 100$ expenditure, $£ 125$ against taxable income and did not grant any cash credits. When an SME conducts subcontracted $\mathrm{R} \& \mathrm{D}$ as a result of a contractual relationship with a large company, then the R\&D undertaken by the SME is also subjected to the deduction rates for large companies. In this study, I focus on the 'intramural R\&D expenditure' of companies, which is the component of R\&D spending that is subject to different rates for SMEs and large companies.

Before 2003, there were three separate regimes, first no tax incentives for R\&D, followed by the SME scheme and then the large company scheme (Fig. 3). In 2013, major changes to the large company scheme were introduced, such as an optional switch to an above-the-line tax credit and cash refunds for loss-makers accordingly. In addition, the Patent Box was introduced. In light of these developments, a conservative strategy is to focus on the period 2003-2012. I will show that the main findings do not change, as we move from the 1999-2013 sample to the 2003-2012 sample. If anything, the results are stronger for the 2003-2012 sample.

The enhanced deduction rates increased from 1 April 2008 onwards, and this was followed by a change in the thresholds for defining an 'SME' for tax credit purposes. 8 According to the EU regulations, the SME definition consists of size thresholds and

\footnotetext{
${ }^{6}$ Formerly known as the 'Scientific Research Allowance.' These capital allowances are still available.

7 SME definitions are explained in detail later.

8 The size definition change took place on 1 August 2008, in line with the Corporation Tax Act (CTA09/Ss1119-1121).
} 
also requirements related to owner-subsidiary relationships. ${ }^{9}$ This implies that small firms that are subsidiaries of large companies, which own stakes more than $25 \%$ in the firm, cannot benefit from the SME incentive scheme. To qualify for the SME credit, companies need to satisfy the employment criterion and then either the balance sheet size or the turnover criteria.

During the period of interest for this study, eligibility for the SME tax incentive first required that the company has fewer than 250 employees, and either a balance sheet size of less than $£ 43$ million or turnover less than $£ 50$ million from 2005 . In addition to having satisfied these criteria, the company should not have been owned by a group that exceeds these limits, or the individual subsidiaries, when aggregated, should not have exceeded these thresholds. Ownership in this context refers to more than $25 \%$ of the capital or voting rights. After 1 August 2008, the employment, turnover and asset size thresholds were doubled, allowing companies with fewer than 500 employees and either a balance sheet size of less than $£ 86$ million or turnover less than $£ 100$ million to be able to benefit from the generous SME scheme.

The doubling of the SME tax relief eligibility thresholds allow for a natural treatment group of medium-sized companies that were, prior to 2008, benefiting from the large company scheme and after 2008, from the more generous SME scheme. The reduction in the user cost of $\mathrm{R} \& \mathrm{D}$ capital for the treated medium-sized companies was between $15-21 \%$ thanks to the reform.

The binding thresholds are determined by the total group-level employment of each firm. The Business Structure Database (BSD) covers the population of enterprises and enterprise groups in the UK and has information on employment on these companies. This information can be matched with the BERD dataset to determine which firms are more likely to be treated by the reform.

\subsection{Theoretical framework}

The theoretical background on evaluating R\&D tax credit schemes is influenced by the literature on tax incentives for physical investment, which is based on the user cost of capital as a determinant of investment decisions, first formalised by Jorgenson (1963) and then developed by Hall and Jorgenson (1967). Both their theoretical finding and the empirical analysis point to a significant positive impact of tax credits and depreciation allowance schemes on the firm's capital intensity. Following Griliches (1979), 'R\&D capital stock' or 'knowledge stock' can be considered analogously to the stock of physical capital, and it is possible to establish the same relationship between tax incentives and R\&D capital [as in Bloom et al. (2002) and Mulkay and Mairesse (2013)]. In this section, I focus on the static R\&D spending decision of the firm and abstract away from adjustment costs and the long-term accumulation of knowledge capital, so the model is solved as a static optimisation problem, which depends on the firm's 'knowledge production $\left(R_{t}\right)$ ' in each period, using labour input

\footnotetext{
9 The criteria for eligibility to the SME tax incentive scheme was determined based on the relevant EC Regulation. Depending on the year, these were: 1996/280/EC and 2003/361/EC, with the latter taking effect for accounting periods ending later than 1 January 2005.
} 
(R\&D headcount, $\left.L_{t}\right)$ and other expenses on R\&D $\left(M_{t}\right)$. The firm's optimisation problem is therefore:

$$
\max _{L_{t} \geq 0, M_{t} \geq 0} \Pi_{t}\left(L_{t}, M_{t}\right) \text { subject to } F\left(L_{t}, M_{t}\right)=A L_{t}^{\alpha_{L}} M_{t}^{\alpha_{M}}
$$

where the firm's net revenue function takes into account the taxes paid on corporate profits at rate $\tau$ and tax credits available for inputs into $\mathrm{R} \& \mathrm{D}$ at credit rate $c$. The net revenue function in period $t$ is:

$$
\Pi_{t}\left(L_{t}, M_{t}\right)=(1-\tau)\left[p_{t} F\left(L_{t}, M_{t}\right)-w_{t} L_{t}-r_{t} M_{t}\right]+c\left(w_{t} L_{t}+r_{t} M_{t}\right) .
$$

Prices of R\&D $\left(p_{t}\right)$, labour $\left(w_{t}\right)$ and other inputs $\left(r_{t}^{M}\right)$ are set exogenously in competitive markets. Denoting the optimal labour, other inputs and R\&D output by $L_{t}^{*}$, $M_{t}^{*}$ and $R_{t}^{*}$, respectively, the effects of an increase in the credit rate on total R\&D spending and R\&D headcount are:

$$
\begin{aligned}
\frac{\partial L_{t}^{*}}{\partial c} & =\frac{1}{\left(1-\alpha_{L}-\alpha_{M}\right)}(1-\tau)^{\left(1-\alpha_{L}-\alpha_{M}\right)}(1-\tau+c)^{\frac{\alpha_{L}+\alpha_{M}}{\left(1-\alpha_{L}-\alpha_{M}\right)}} \kappa_{L} \\
\frac{\partial M_{t}^{*}}{\partial c} & =\frac{1}{\left(1-\alpha_{L}-\alpha_{M}\right)}(1-\tau)^{\left(1-\alpha_{L}-\alpha_{M}\right)}(1-\tau+c)^{\frac{\alpha_{L}+\alpha_{M}}{\left(1-\alpha_{L}-\alpha_{M}\right)}} \kappa_{M} \\
\frac{\partial R_{t}^{*}}{\partial c} & =\frac{\alpha_{L}+\alpha_{M}}{\left(1-\alpha_{L}-\alpha_{M}\right)}(1-\tau)^{\left(1-\alpha_{L}-\alpha_{M}\right)}(1-\tau+c)^{\frac{-1}{\left(1-\alpha_{L}-\alpha_{M}\right)}} \kappa_{R}
\end{aligned}
$$

where $\kappa_{i}$ are constants for $i \in\{K, L, R\}$, given input and output prices are set in competitive markets. Assuming decreasing returns to scale in the 'production of knowledge,' the partial derivatives in Eqs. 3-5 are always positive. Therefore, an increase in the tax credit rate would be expected to increase the R\&D spending by increasing the $R \& D$ headcount in a competitive labour market for R\&D employees and the amount of other inputs. The empirical specifications in Sect. 4 can be thought of as estimating the factor demand equations derived in this model, with the term that captures taxes and tax credits represented by a dummy variable in a difference-in-differences specification.

In this simple standard model, in response to an increase in the rate of tax credits for $R \& D$, we expect to observe an immediate increase in R\&D headcount, materials spending and knowledge production. The assumptions of this framework, such as decreasing returns to scale in knowledge production, and exogenous price setting in competitive input and output markets, are also useful for illustrating the potential reasons why we may expect different responses to increased generosity of tax incentives. For example, if R\&D employees have some bargaining power over their compensation, we may then observe a setting where $w_{t}$ increases in response to an increase in $c$, and this may affect $R_{t}$ without increasing the R\&D headcount. In Sects. 5 and 7, I explore the effects of an increase in the rate of $R \& D$ tax credits on total $R \& D$ spending of a firm, as well as its $R \& D$ headcount. The empirical specifications in this paper are influenced by a simple model as the one depicted in this section; however, the quasi-experimental research design is not reliant on any particular theoretical model. 


\section{Data}

\subsection{Available data sources}

The Business Enterprise Research and Development (BERD) survey is conducted by the ONS, with the purpose of collecting the aggregate and sectoral UK BERD statistics. The micro-level BERD data has recently become available under secure conditions for approved research projects. ONS follows the Frascati Manual (OECD 2002) methodology to collect the statistics on BERD. ONS uses stratified sampling to select the enterprises which will receive a BERD questionnaire form each year. All questionnaire forms include at least questions on total R\&D spending (in-house and contract R\&D) and R\&D employment. The micro-level BERD dataset contains all the reporting unit-year observations that were identified by the ONS as performing R\&D in a given year. The observations that are left outside of the stratified sampling have imputed values for the questions that are not answered, using the mean values of the variable as a share of employment in the size band-sector cell. To avoid introducing measurement error, I do not use these imputed values in the regressions. Further information is presented in 'Data description and cleaning' Appendix and in Guceri (2015). ${ }^{10}$ I merge the micro-level BERD dataset with the other relevant ONS datasets; the ABS and the BSD to obtain firm-level characteristics used as controls in this study. Even if a firm is not sampled for BERD in a given year, BSD allows us to obtain its employment value at the enterprise and the group levels. This is crucial for identifying the treatment and control groups.

The large company scheme was introduced in the 2002 fiscal year, with 2003 as the first full calendar year of implementation. In 2013, a new tax credit was introduced for large companies, along with the Patent Box regime, rendering an estimation sample that is unaffected by other changes than the 2008 policy reform to cover the period 2003-2012. ${ }^{11}$ I first use the whole dataset available, then refine the years to obtain the preferred results on this more restricted sample.

Real expenditures on $R \& D$ is obtained by deflating the nominal intramural $R \& D$ expenditure from the BERD dataset using a weighted deflator with $50 \%$ weight on researcher salaries and 50\% weight on the GDP deflator. Intramural R\&D here means the in-house R\&D carried out by the company by its own employees. The researcher salaries component of the weighted deflator is taken from the Annual Survey of Hours and Earnings (ASHE) tables on gross annual pay for science and technology professionals (Table code 2.7a, job code 21). The GDP deflator is obtained from the OECD Economic Outlook 'pgdp' series (base year 2008). In the R\&D literature, this kind of weighted deflator is commonly used to reflect the fact that around $50 \%$ of R\&D investment goes to the salaries and wages of research staff [ (see, for instance, Bloom et al. (2002)].

\footnotetext{
10 From Centre for Business Taxation Working Paper 15/11.

11 The datasets used in this study were made available by the Office for National Statistics (ONS) and the Secure Data Service (SDS).
} 


\subsection{Assignment to treated and control groups}

Assignment to treatment and control groups is based on the threshold for eligibility to the SME Tax Relief. The BSD contains information on ownership and employment for all UK firms. ${ }^{12}$ The binding threshold to determine eligibility to the SME scheme is the employment threshold, subject to limitations on ownership by larger groups. ${ }^{13}$ Before merging the employment information to the reporting unit-level R\&D data, I aggregate employment over enterprise groups (including their non-R\&D members) in the BSD to check whether each reporting unit satisfies the group-level employment thresholds.

In this paper, I use an intent-to-treat approach. In the main set of regressions, I present the results based on a treatment group defined according to the 2007 employment status. I take this approach to ensure that treatment status is not endogenous to the reform. If the firm has 250-500 employees in 2007, then it is allocated to the treated group, and if it has more than 500 employees, it is allocated to the control group. Firms with fewer than 250 employees experienced a rate increase in 2008 leading to a reduction in their user cost of $R \& D$ capital. I therefore do not use these smaller companies' data in the analysis.

The reporting period for BERD is the calendar year. ${ }^{14}$ The definition change for determining an SME was introduced in August 2008, which is eight months into calendar year 2008. I therefore ignore each firm's status in 2008 for the purposes of both the allocation into treated and control groups and also in the estimation stage when evaluating the response to the policy.

\subsection{Comparability between treated and control groups}

Figures 4 and 5 present the trends in the two main outcome variables of interest in the largest available dataset. In Fig. 4, the mean level of the natural logarithm (log) of R\&D spending in the treated (medium-sized) and control (large) companies follow common trends, as should be expected for the two comparison groups to satisfy the identifying assumption for a difference-in-difference strategy.

The regression samples are based on a panel of non-imputed observations of BERD variables on medium-sized and large companies. For companies that were present in the dataset between 1999 and 2013, and have performed positive R\&D at least once before and once after the reform, the sample contains 270 unique treated firms and 663 control firms. Restricting the sample to the 2003-2012 period, when no substantial reforms took place that would affect $\mathrm{R} \& \mathrm{D}$ spending by companies (other than the reform of interest), the sample size is a little smaller but there are still 238 treated

\footnotetext{
12 Turnover information is sourced by the VAT records and this is only available for firms that are above the VAT registration thresholds.

13 For example, an enterprise may itself have 200 employees and satisfy one of the turnover or the asset size thresholds. Then, the group-level check involves aggregating the employment numbers of each member in the whole group and then assessing whether the group as a whole remains below the thresholds.

14 If the reporting unit does not have the record covering the calendar year, for instance year $t$, then the record for a business year that ends between April 6th of period $t$ and April 5th of period $t+1$ is reported for the expenditure in year $t$.
} 


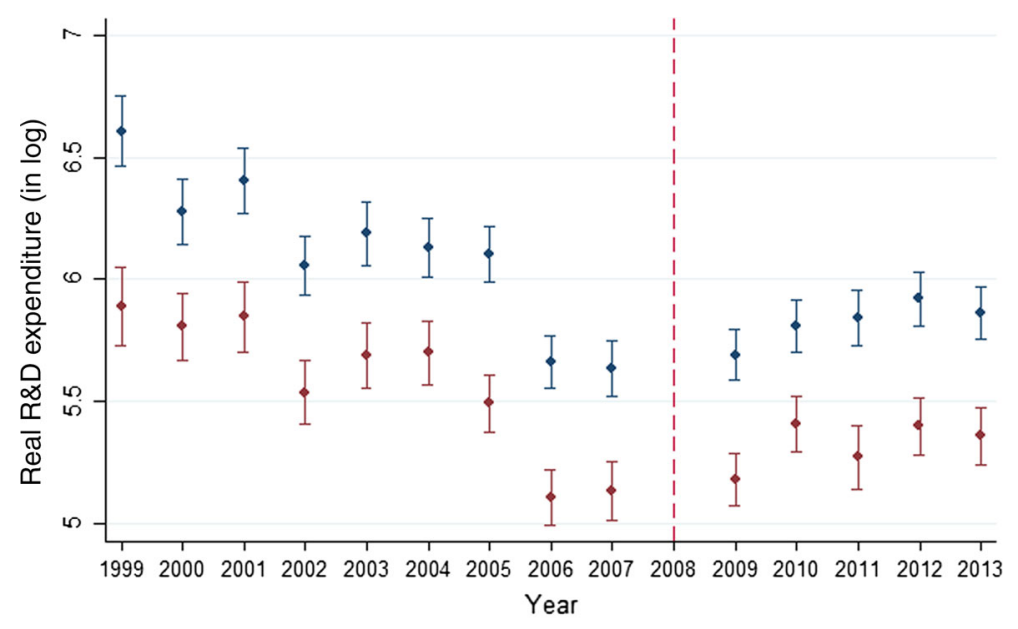

$\longmapsto$ Large $\longmapsto$ Medium

Fig. 4 Trends in R\&D expenditure (natural logarithm, constant GBP), means across treated and control groups. Notes the figure shows the pre- and post-treatment trends in the mean of the main outcome variable (log R\&D spending in constant GBP). The blue dots represent the control group (large companies) mean values and the bars represent the upper and lower bounds of $95 \%$ confidence intervals. Similarly, the red dots represent the treated group (medium-sized companies) mean values, with the bars representing 95\% confidence intervals. The reform was introduced in August 2008. We therefore do not use information from 2008 in any analysis (Color figure online)

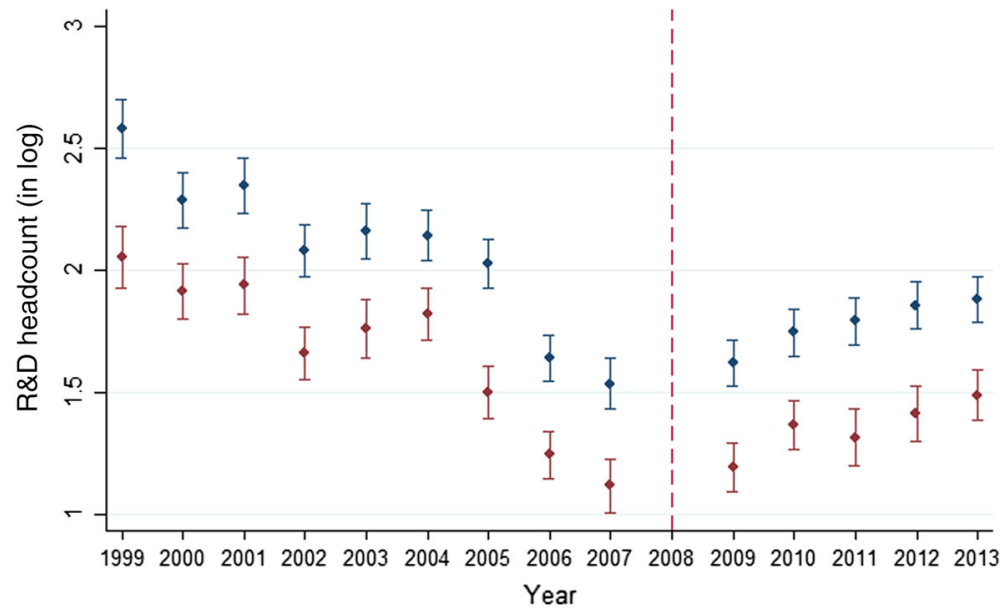

$\longmapsto$ Large $\longmapsto$ Medium

Fig. 5 Trends in R\&D headcount (natural logarithm), means across treated and control groups. Notes the figure shows the pre- and post-treatment trends in the mean of the main outcome variable (log R\&D headcount). The blue dots represent the control group (large companies) mean values and the bars represent the upper and lower bounds of $95 \%$ confidence intervals. Similarly, the red dots represent the treated group (medium-sized companies) mean values, with the bars representing $95 \%$ confidence intervals. The reform was introduced in August 2008. We therefore do not use information from 2008 in any analysis (Color figure online) 
firms and 607 control firms. Within the universe of non-imputed observations, in a representative year (2007), around $42 \%$ of observations had more than 250 employees, representing more than $80 \%$ of total $R \& D$.

I present detailed descriptive statistics on the regression samples in Tables 1, 2 and 3. These tables show basic descriptives for the values of the main regression variables and the levels of the outcome variables of interest. ${ }^{15}$

Two observations are of importance in these tables. First, despite some discrepancy in raw means, the mean values for the middle $90 \%$ for both the treated and the control groups are very similar. Second, in Table 3 (as in Table 2), the differential increase between pre- and post-treatment periods for the treated group relative to the control group is clearly visible. For example, in the 2003-2012 sample, this statistic for log R\&D spending only increased from 7.41 to 7.43 for the control group, whereas the treated group experienced a rise from 7.30 to 7.36. For the control group, the level of the R\&D headcount was roughly stable, dropping from 43 to 42 , whereas the treated group saw the same statistic rise from around 38 R\&D personnel to around 44 . Finally, the R\&D spending per R\&D worker, which may indicate a price effect of tax incentives, experienced parallel increases for both the treated and control groups, and does not show a differential rise in either group in the post-treatment period.

On regression samples, I formally test the differences in pre-treatment dynamics of the outcome variables of interest using $t$ tests (Tables 4 and 25). I cannot reject the null hypothesis that the changes in the outcome variables between the beginning and the end of the pre-treatment period are the same across treated (medium-sized) and control (large) firms. Figure 6 shows the kernel densities of the differences in $\log$ real R\&D spending for the treated (medium) and control (large) groups (for the 2003-2012 period). 'Additional $t$ tests for pre-treatment dynamics between treated and control groups' Appendix provides additional tests with different base years as a robustness check. These figures visually demonstrate that the distribution of the time changes are similar between treated and control groups.

The sectoral compositions of medium-sized and large firms between pre- and posttreatment periods are roughly similar, as can be observed in Figs. 7 and 8. In the figures, the blue line represents reporting units that belong to medium-sized firms and the red line represents reporting units that belong to larger firms with 500-1000 employees. In Figure 7, I present the pre-treatment period shares of observations in each of the sectors for medium-sized and then large firms. ${ }^{16}$ Figure 8 traces the changes in the sectoral compositions between pre- and post-treatment periods across the two groups, and apart from the 'Food' sector, the changes between pre- and post-treatment periods in the number of observations seem to have the same sign between the medium-sized and large groups.

\footnotetext{
15 Mean of the middle $90 \%$ has been chosen as a measure for central tendency that is unaffected by outliers. Publication of percentile values, including the median, are not allowed due to data confidentiality requirements of the Secure Lab/Office for National Statistics.

16 The medium-sized and large firm groups that are presented in these figures are broader than the treated and control group samples used in the regressions. In the final regression samples, the number of observations in a few sectors fall below the ONS disclosure thresholds and therefore I present these statistics in the larger samples, which provide a similar picture as the treated and control groups in the final regressions.
} 


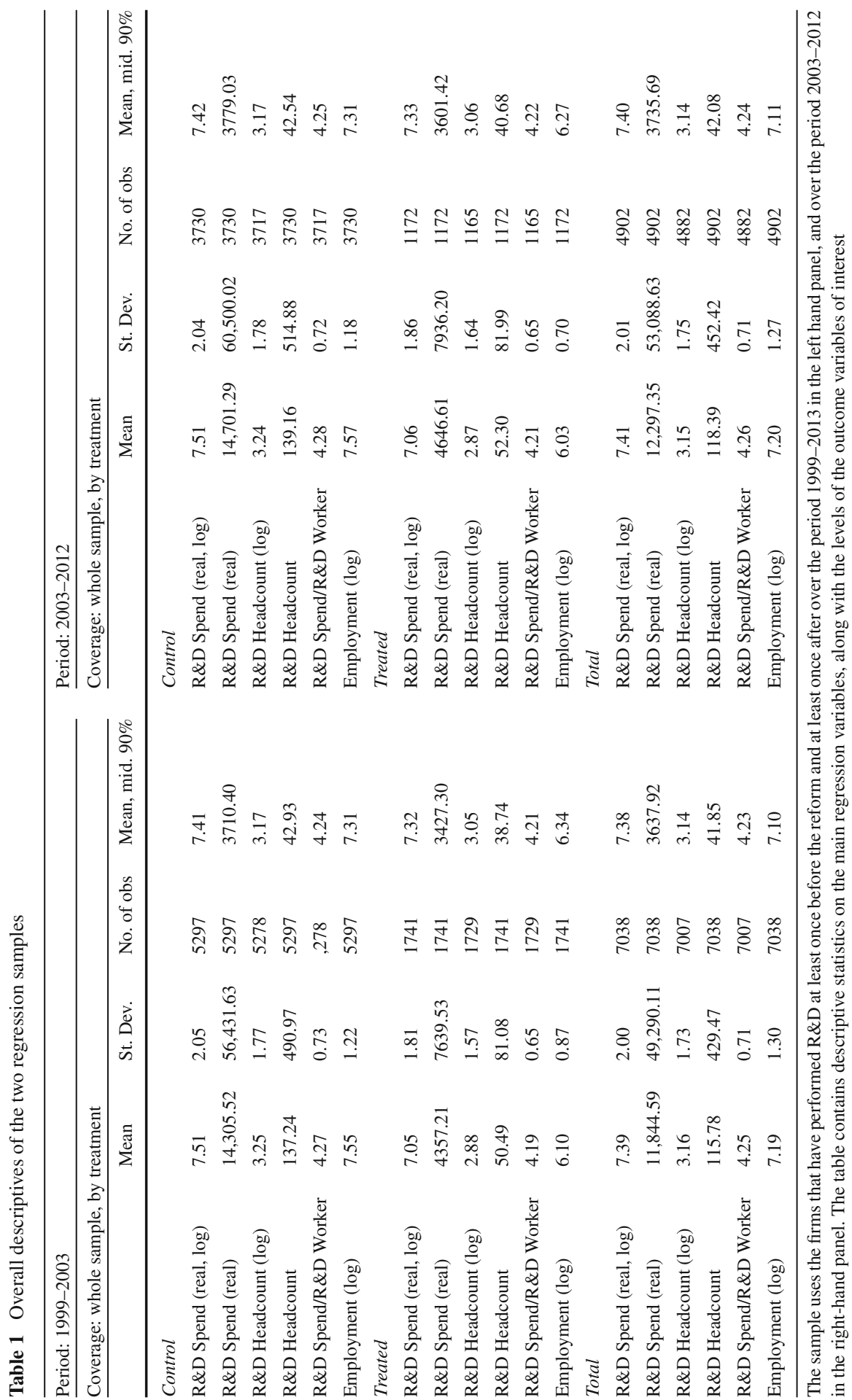




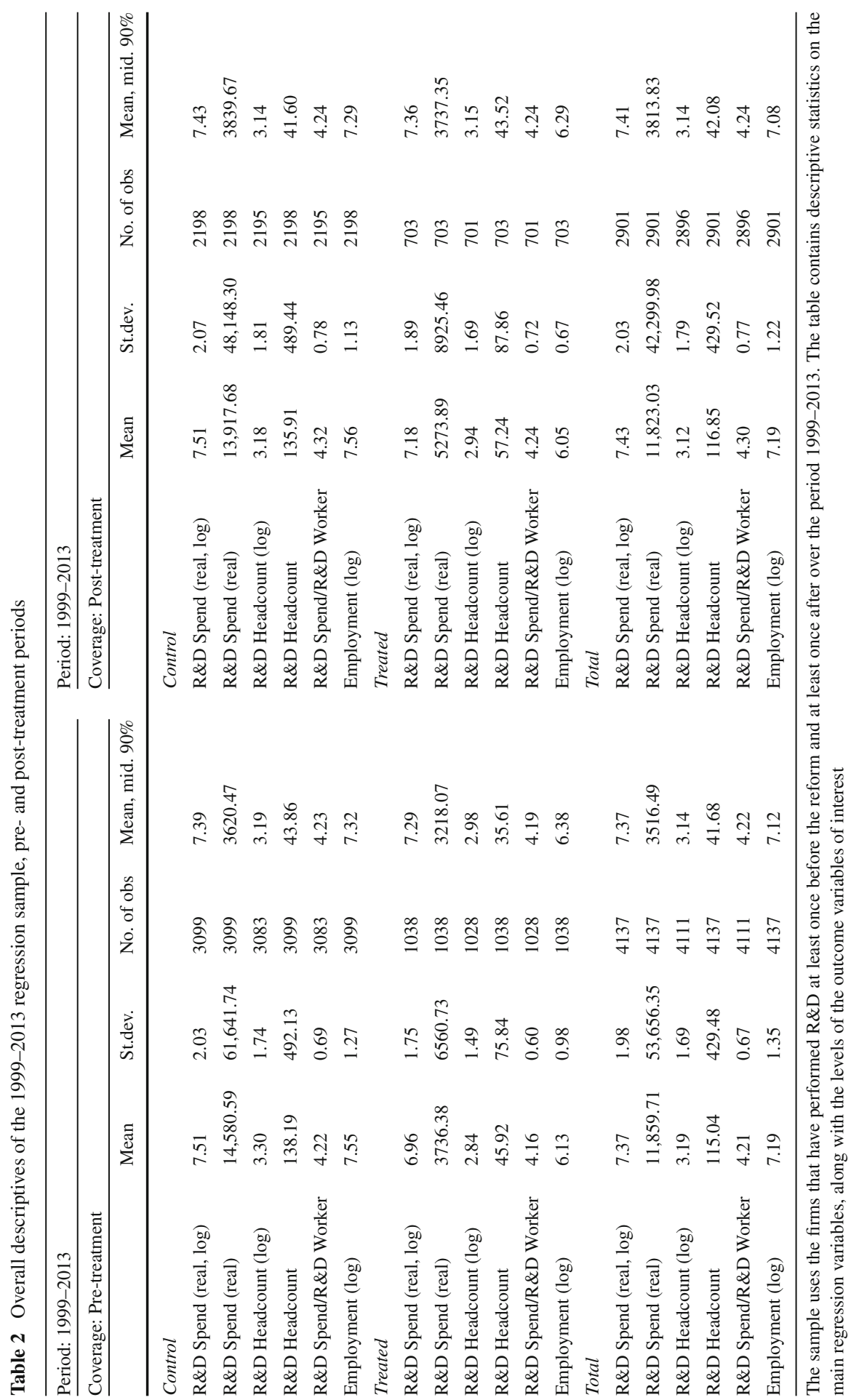




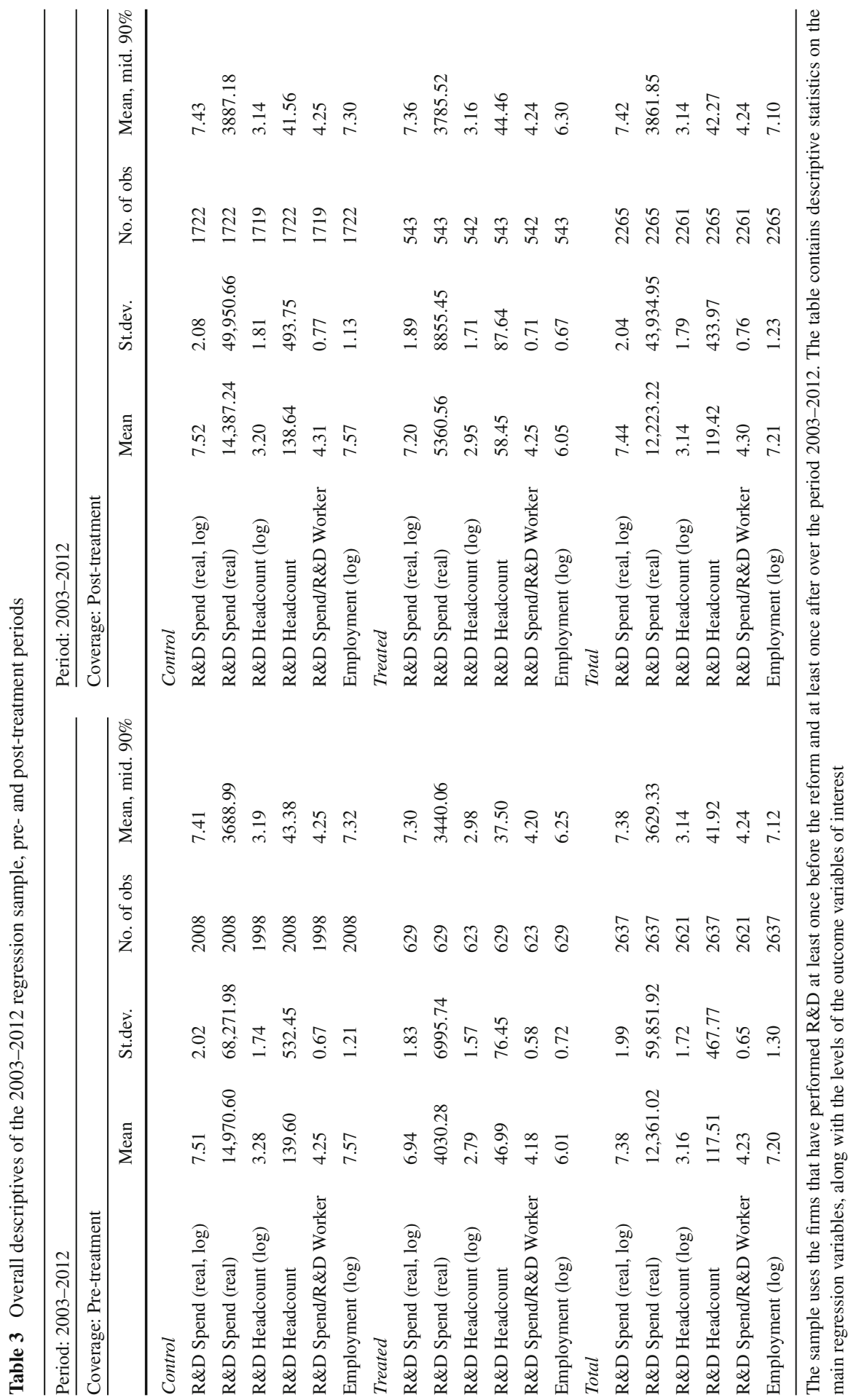


Table 4 Pre-treatment dynamics for key outcome variables, $t$ test for the null of equal dynamics between treated and control groups

\begin{tabular}{lll}
\hline Outcome & $\log ($ Real R\&D) & $\log ($ R\&D Headcount $)$ \\
\hline Mean value (control) & 0.016 & -0.090 \\
Mean value (treated) & -0.070 & -0.010 \\
$p \_$value & 0.389 & 0.924 \\
No. of obs (control) & 322 & 319 \\
No. of obs (treated) & 100 & 100 \\
\hline
\end{tabular}

The table presents the mean values for the change in indicated outcomes between the beginning and the end of the pre-treatment period. Beginning of the pre-treatment period is marked by the periods presented in the table. End of the pre-treatment period is the 2007 value. ' $p \_$value' is the $p_{-}$value for the $t$ test of the null hypothesis that the means of the two samples (treated and control) are equal to each other. The number of observations is smaller than the whole sample since all the firms were not sampled in the period both the base year and in 2007

\section{Empirical approach}

As the difference-in-difference specification, I estimate the following base model:

$$
r_{i t}=\gamma+\delta_{I} D_{i} T_{t}+\delta_{T} T_{t}+\mathbf{x}_{i t}^{\prime} \beta_{x}+\eta_{i}+v_{i t}
$$

where $r_{i t}$ is the natural logarithm of R\&D spending of reporting unit $i$ in year $t$ in 2008 prices, $D_{i}$ is a dummy that takes on a value of 1 for treated observations, 0 for the control group, $T_{t}$ is a dummy that takes on a value of 1 for post-2008 and 0 otherwise. ${ }^{17}$ The coefficient $\delta_{I}$ on the interaction term $D_{i} T_{t}$ thus captures any differential change in $r_{i t}$ between the pre- and post-2008 periods for the treatment group compared to the control group, and the null hypothesis of no impact of the introduction of more generous tax incentives for medium-sized firms corresponds to $\delta_{I}=0 . \eta_{i}$ are reporting unit fixed effects. I later drop $T_{t}$ and include a full set of year dummies. $\mathbf{x}_{i t}$ is a $K \times 1$ vector of controls, which, in different sets of results, include sector dummies, year dummies, lagged employment (in log), employment growth rates (in log) and a quadratic term for lagged (log) employment. I use Poisson and negative binomial count models to estimate the difference-in-difference specifications with R\&D headcount as the dependent variable. In specifications with R\&D headcount as the dependent variable, I use the levels of lagged employment, its square and growth rate as controls.

Identification with the difference-in-difference estimator requires that the common trends assumption be satisfied; that is, in the absence of treatment, we should expect the change in the outcome variable between pre- and post-intervention periods for the control group to be similar to the change in the outcome variable for the treatment group. I discuss the comparisons for pre-reform time differences in treated and control outcomes in Section 3.3. These comparisons support that there are no significant differential trends between treated and control groups in other years than the treatment

$\overline{17 \text { In regression tables, the dummy variable } T_{t} \text { is labelled as Post2008. }}$ 

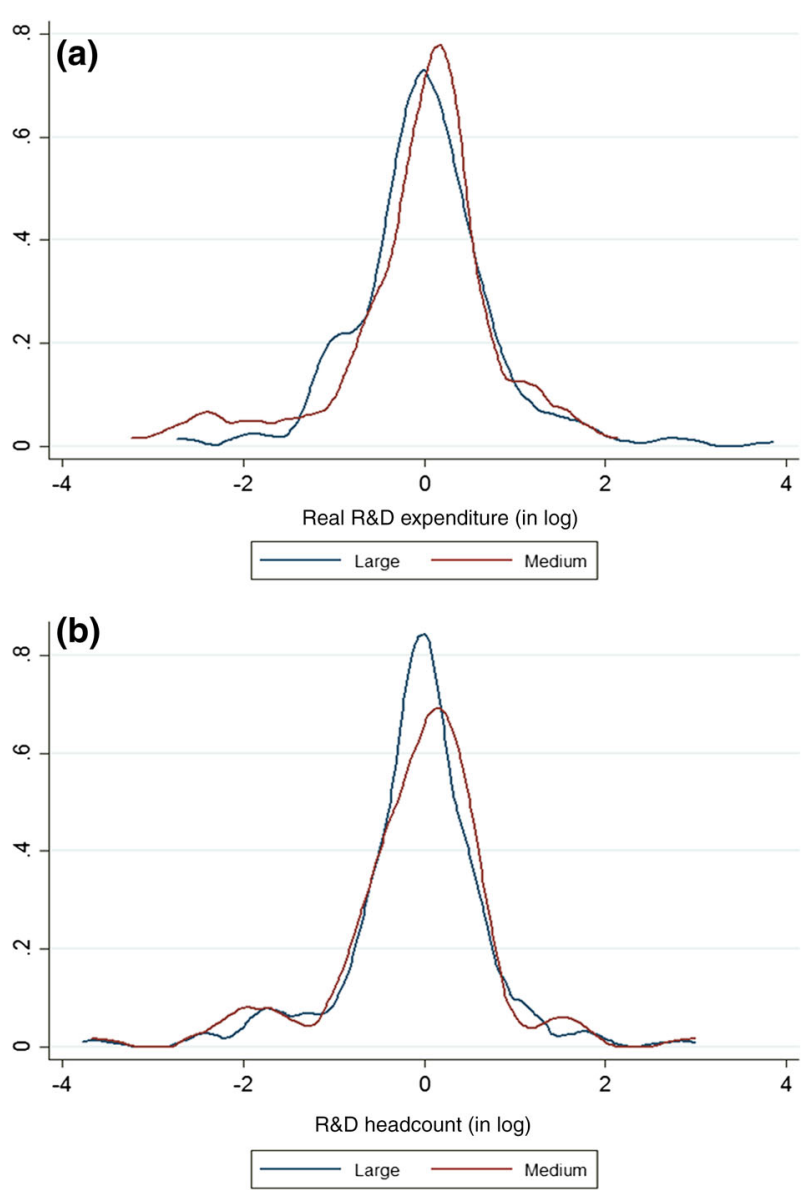

Fig. 6 Kernel densities, differences in pre-treatment dynamics of R\&D expenditure (log, constant GBP) and R\&D headcount $(\log )$. a Real R\&D expenditure $(\log )$. b R\&D headcount $(\log )$ Notes the figures present the density of the changes between the beginning of the pre-treatment period and the end of the pre-treatment period in key outcome variables. a shows the kernel density of the changes in the R\&D spending variable in the treated and control groups. b shows the kernel density of the changes in the $R \& D$ headcount variable in the treated and control groups

year. In Sect. 6, I present results from regressions with placebo reforms in earlier years than the policy change.

\section{Results}

I focus on the impact of the reform on two main outcome variables to capture whether tax incentives increase R\&D spending by firms at the intensive margin, and if so, whether an increase in price or quantity drives the observed effect. These variables are real R\&D spending and the R\&D headcount. An observed increase in R\&D spending, with a similar increase in headcount employment may mean that quantity effects 


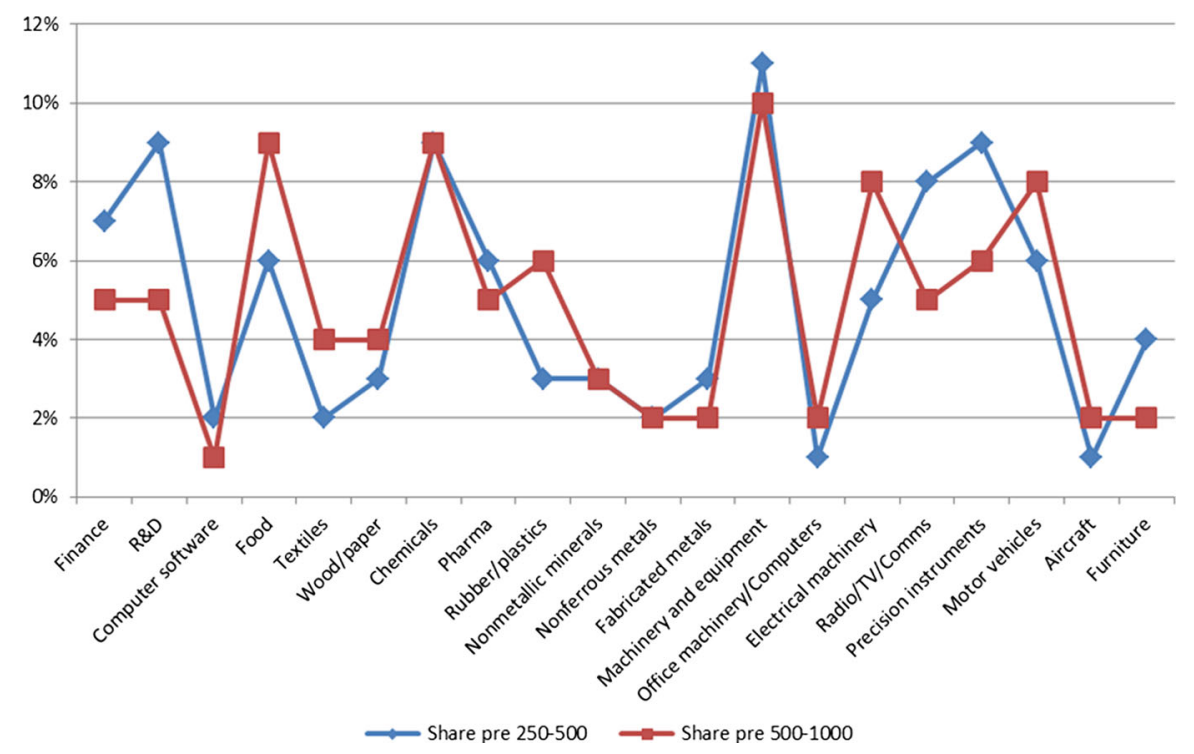

Fig. 7 Sectoral distribution of medium-sized and large companies in the pre-treatment period

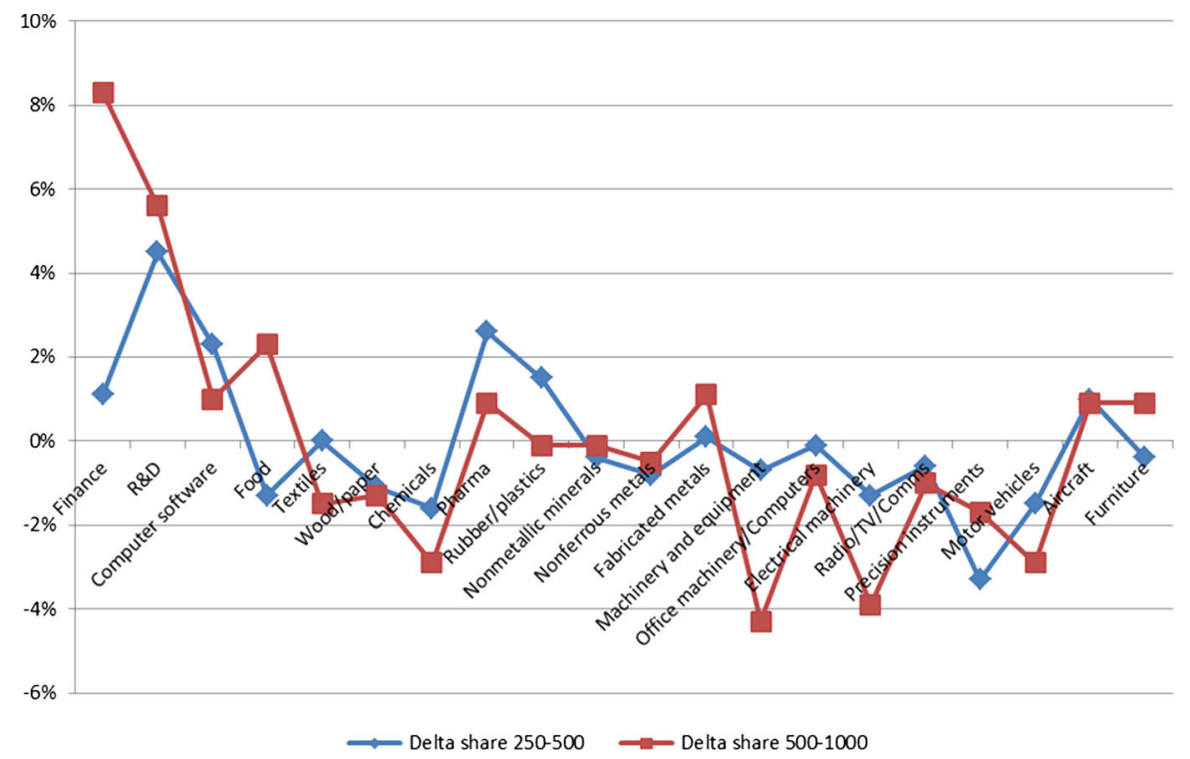

Fig. 8 Change in the sectoral distribution of medium-sized and large companies in the post-treatment period

dominate. This may in turn indicate that firms hire a larger number of R\&D employees, possibly as a result of a larger uptake of new $R \& D$ projects, which is the intended first order effect of the policy. We can then also examine the effects on the $R \& D$ spending per R\&D worker, which may give information about the price effects as well. A wage 
increase for researchers would lead to a significant increase in R\&D spending per $\mathrm{R} \& \mathrm{D}$ worker.

\subsection{Effect of the reform on $R \& D$ spending}

Columns (1)-(5) of Table 5 present the difference in difference (diff-in-diff) regression results from the largest possible sample that covers $1999-2013 .{ }^{18}$ Standard errors are clustered at the reporting unit level. Column (1) presents estimates from the model in Eq. 6 without any controls. The positive effect of the policy is captured by The coefficient labelled 'Treatment x Post2008' (diff-in-diff), and the estimate has a magnitude of around $15 \%$ which is statistically significant at the $95 \%$ level. In Column (2), the 'Post2008' dummy is replaced by year fixed effects and two digit sector dummies are also included in the model. In Column (3), I include a control variable for firm size, which is lagged level of employment. Firm size and growth rate variables are all lagged by one period to avoid potential issues due to the simultaneous determination of total employment and R\&D spending. In Column (4), I include a control for the lagged growth rate of the firm along with the lagged level of employment, which turns out to be a significant control variable, and together the control variables drive the magnitude of the diff-in-diff coefficient upward by 2 percentage points relative to Column (1). Finally, in Column (5), I add the full set of control variables including a quadratic term for the firm size measure. In the preferred specification (estimated in Column (5)), the diff-in-diff estimates indicate a positive and significant effect of the policy on treated firms, with a magnitude of around $15 \%$.

Columns (6)-(10) of Table 5 restrict the sample to a period where no substantial policy changes took place except the 2008 reforms. To be included in this sample, a firm needs to have performed $R \& D$ at least once before and once after the reform, and the pre-reform period covers 2003-2007, the post-reform period covers 2009-2012. Column (6) starts with no time dummies or size controls. Control variables are added the same way as in Columns (2)-(5) from Column (7) onward. In Columns (6)-(10) of Table 5, the diff-in-diff coefficient is consistently estimated to be around 20-21\% and highly significant.

The estimated effect of the reform is remarkably stable across all specifications, and all show a large and significant effect. In the preferred specification (reported in Column (10)), the estimated magnitude is $20 \%$.

\subsection{Is the measured effect driven by price or quantity?}

Next, I explore the mechanisms that drive the increase in R\&D spending. First, I examine the effect of the policy on the R\&D employment of treated companies. Goolsbee (1998) argues that, due to the inelastic supply of scientists and researchers, R\&D subsidies only boost the salaries of researchers instead of driving firms to take on new

18 The Business Structure Database (BSD) data begins in 1997. Lagged employment growth rate controls require the two-period-lagged level of employment. The sample starts at 1999 to enable the inclusion of lagged controls that are sourced by the BSD. 


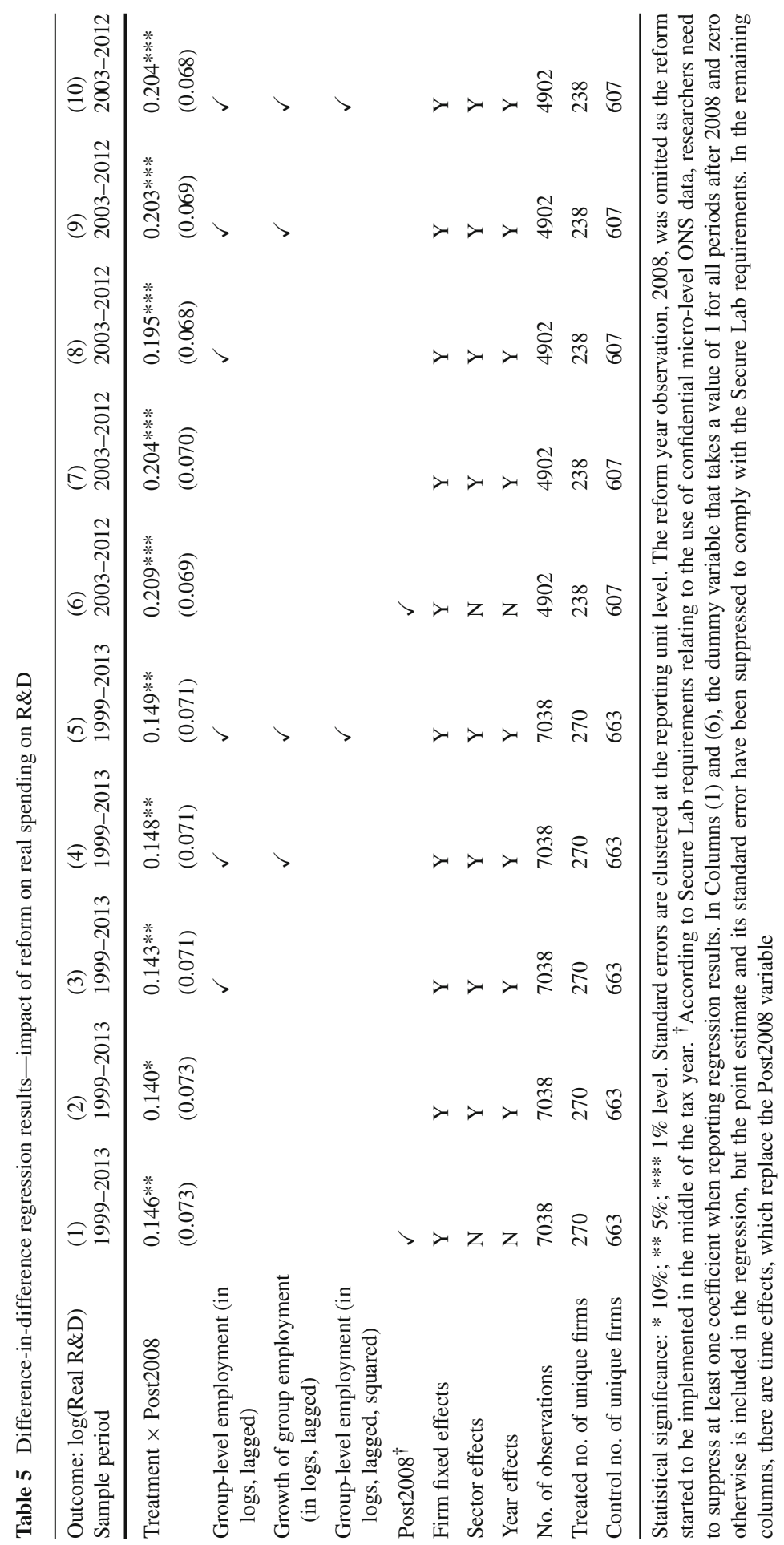


$R \& D$ projects and therefore increase their R\&D efforts. In light of this argument, I explore whether the price or quantity effects drive the increase in firm-level R\&D. In the BERD data, there is non-imputed information on the R\&D headcount that may help explain this effect. Because R\&D employment is a count variable, I use Poisson and negative binomial regressions with reporting unit fixed effects to evaluate the impact of the reform on the R\&D headcount. Table 6 presents the results from Poisson regressions with $R \& D$ employment as the dependent variable. In robustness checks, I report similar results using negative binomial regressions. As before, the first column does not include additional control variables, and Columns (2)-(5) gradually add time dummies and sector dummies, followed by size controls in Columns (3)-(5). Columns (6)-(10) repeat the exercise for the more conservative 2003-2012 sample. The table provides evidence in support of a positive effect of the policy on the R\&D headcount, with a magnitude of around 17-19\%. Estimates for the diff-in-diff coefficient in Table 6 are statistically significant, and the magnitude of the coefficient is consistent across the different columns.

In order to compare this 'quantity response' with a potential 'price response,' finally, I estimate the effect of the reform on R\&D spending per R\&D worker in Table 7. If there are significant effects of the reform on this variable, then it would be more difficult to argue that quantity effects dominate. The interaction terms in all the columns of Table 7 support that the per worker spending in R\&D has not been affected significantly by the policy reform, suggesting that the quantity effects are driving the result on R\&D spending.

Finally, I test the impact of the policy change on firms' spending on 'extramural R\&D,' which includes R\&D that is subcontracted to external parties by the firm. There is a small number of firms that report positive extramural R\&D in the survey, and perhaps unsurprisingly, I do not find any significant effect of the reform on this variable. Additionally, we would expect extramural R\&D to remain unaffected by the reform, since these expenditures are not eligible for the more generous SME deduction rates.

\section{Robustness}

\subsection{Results using a more comparable control group}

How comparable are medium-sized companies that have between 250 and 500 employees, and large companies that have more than 500 employees? All else held constant, we would expect companies which have only slightly more than 500 employees to be more similar to the medium-sized firms in our sample. In this section, I examine the changes in results when I use information only from observations that are close to the 500-employee threshold in the control group. I discuss results that restrict the control group to firms with fewer than 800, 750 and 700 employees and then also restrict the size of the treatment group to include more than 300 employees, in the spirit of a regression discontinuity design.

Table 8 presents the results from regressions that restrict the employment size of control group firms to 800 . This is apparent in the reduction in both the number of 


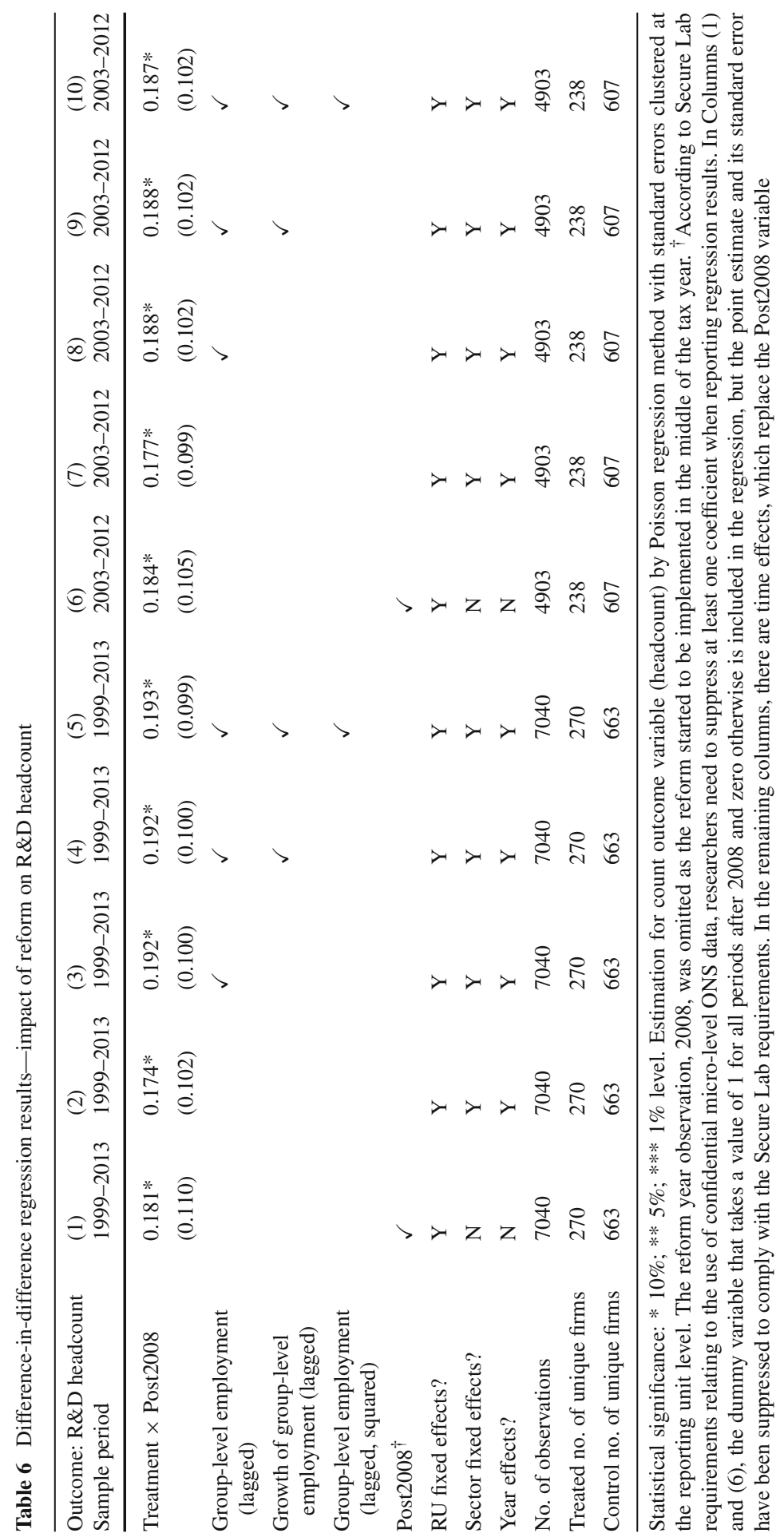




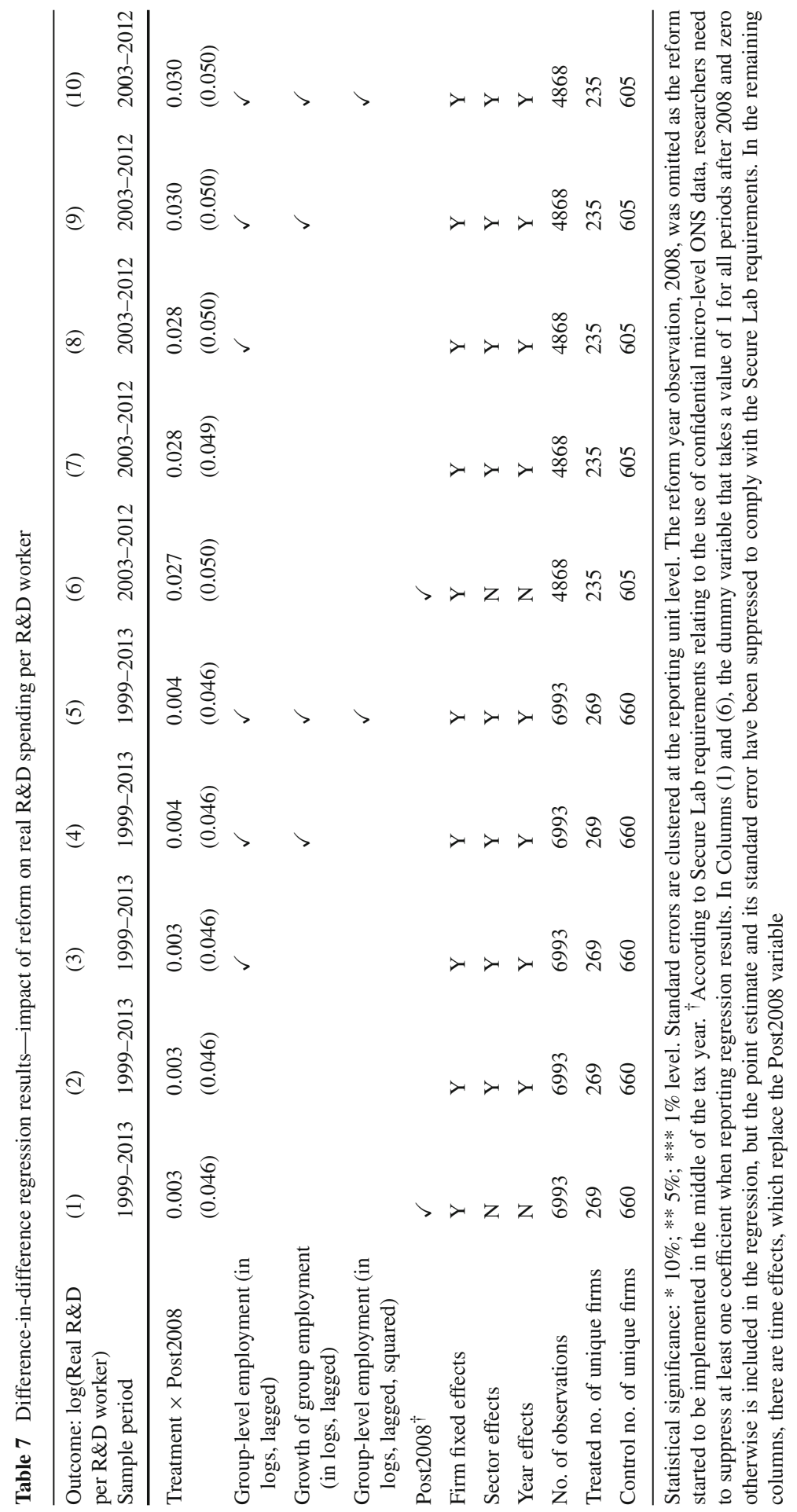


observations and the number of unique firms in the control group, which dropped from 607 in Table 5 to 137 in Table 8. The regression results are similar to the original results from Table 5. If we focus on the most restrictive specification with all controls included in the 2003-2012 sample (Table 5, Column (10)), the diff-in-diff interaction term is significant with a very similar magnitude in the corresponding Column (10) in Table 8. Table 9 then confirms that the effect is driven by an increase in headcount R\&D employment for the similarly restricted sample with employment less than 800 in the control group.

Further restricting the control group employment size threshold to 750 in Tables 10 and 11 does not lower the magnitude or the significance of the diff-in-diff estimates. In fact, there are a few percentage point increases in the magnitude of the diff-indiff coefficient for the 2003-2012 sample, and an even larger increase for the 19992013 sample. ${ }^{19}$ The results that restrict the control group firm size to 700 employees (Tables 12,13) demonstrate similar coefficient magnitudes.

The results that I present in Tables 14 and 15 combine the diff-in-diff approach with a regression discontinuity design. These results are based on a more restrictive sample, with the treated group constrained to firms that include more than 300 employees and the control group constrained to firms that include fewer than 700 employees. Even with much reduced sample sizes, these estimates support that the differential effect of the policy on R\&D spending was significant, with a magnitude of at least $23 \%$. I find that the differential effect of the policy on R\&D headcount was also significant, with a magnitude of at least $25 \%$. The results are once again stable across different slices of data and specifications.

\subsection{Other robustness checks and placebo tests}

In this section, I check the robustness of the results to the presence of outliers and different estimation methods, and then I explore the presence of differential pre-reform movements in any of the pre-treatment periods through placebo reforms. In the posttreatment period, if there are very large jumps to high outlier values in treated group outcomes, or very large jumps to low outlier values in control group outcomes, then the average treatment effect will appear to be large, but the result would be misleading. There may also have been very low pre-treatment outcomes in the treated group, which then rise to normal levels, or very high pre-treatment outcomes in the control group, which then stabilise to normal levels in the post-treatment period. To ensure that such observations do not drive the main findings, I winsorise the top and bottom 5 percentile values for each of the outcome variables and report the results in Table 16 for R\&D spending and in Table 17 for R\&D headcount. The results are robust to winsorising the top and bottom 1 percentile, as well as trimming instead of winsorising (I present these latter results in 'Further robustness checks to test for the effect of outliers' Appendix).

19 The increase in coefficient magnitudes for the 1999-2013 is a few percentage points higher than that for the 2003-2012 sample. These small changes in the point estimates seem to be driven by just under 60 firms. 


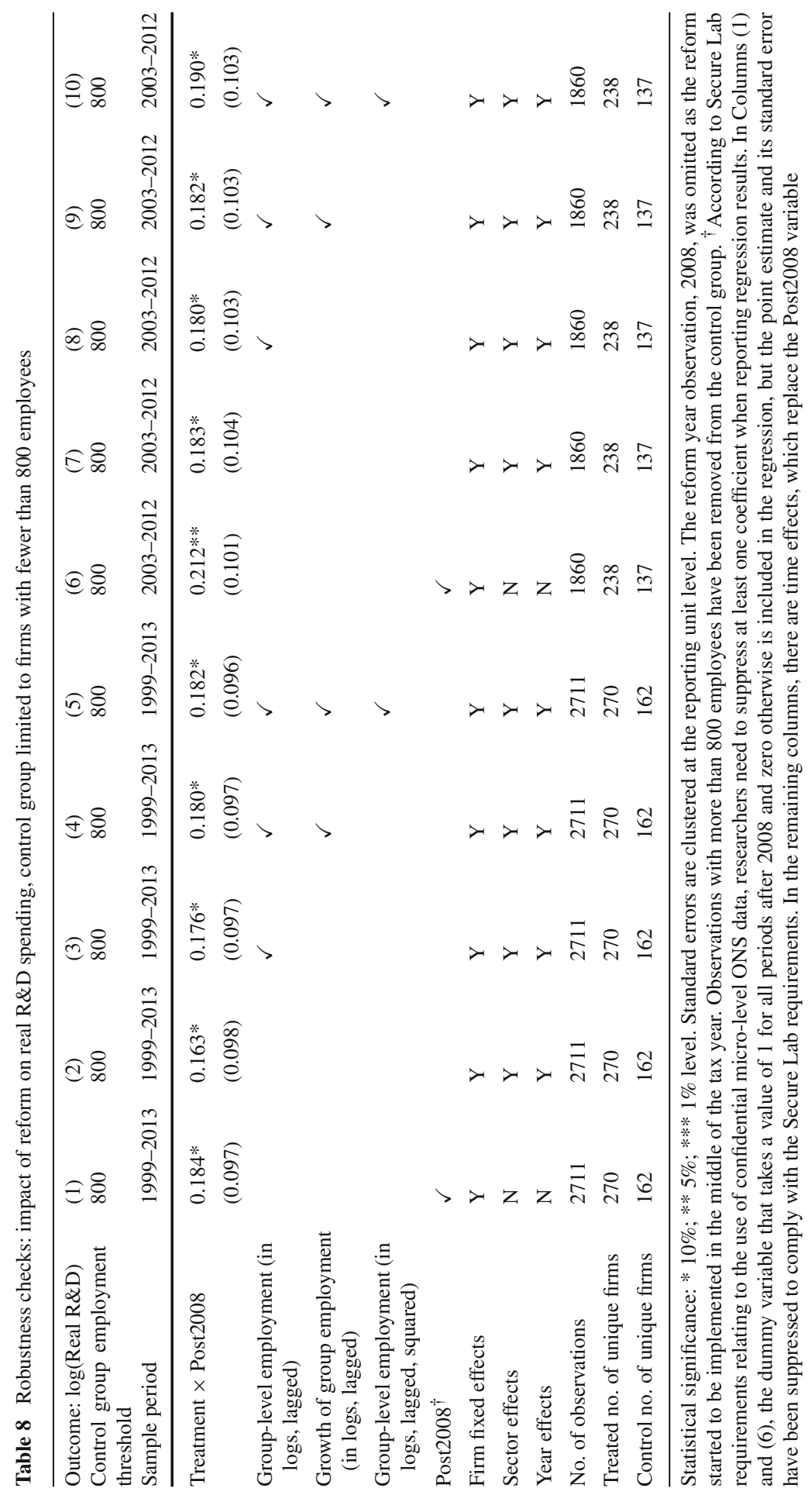




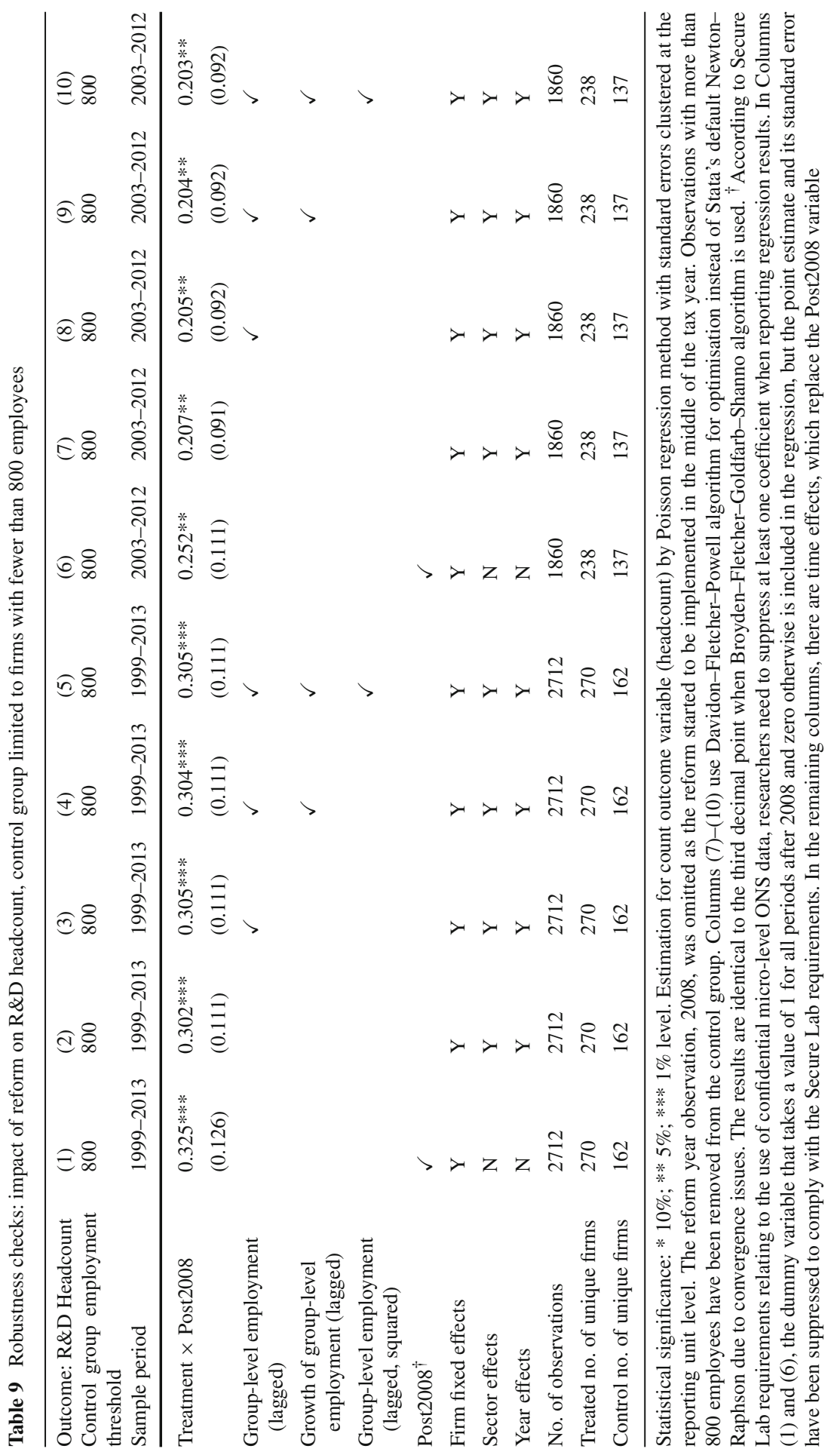




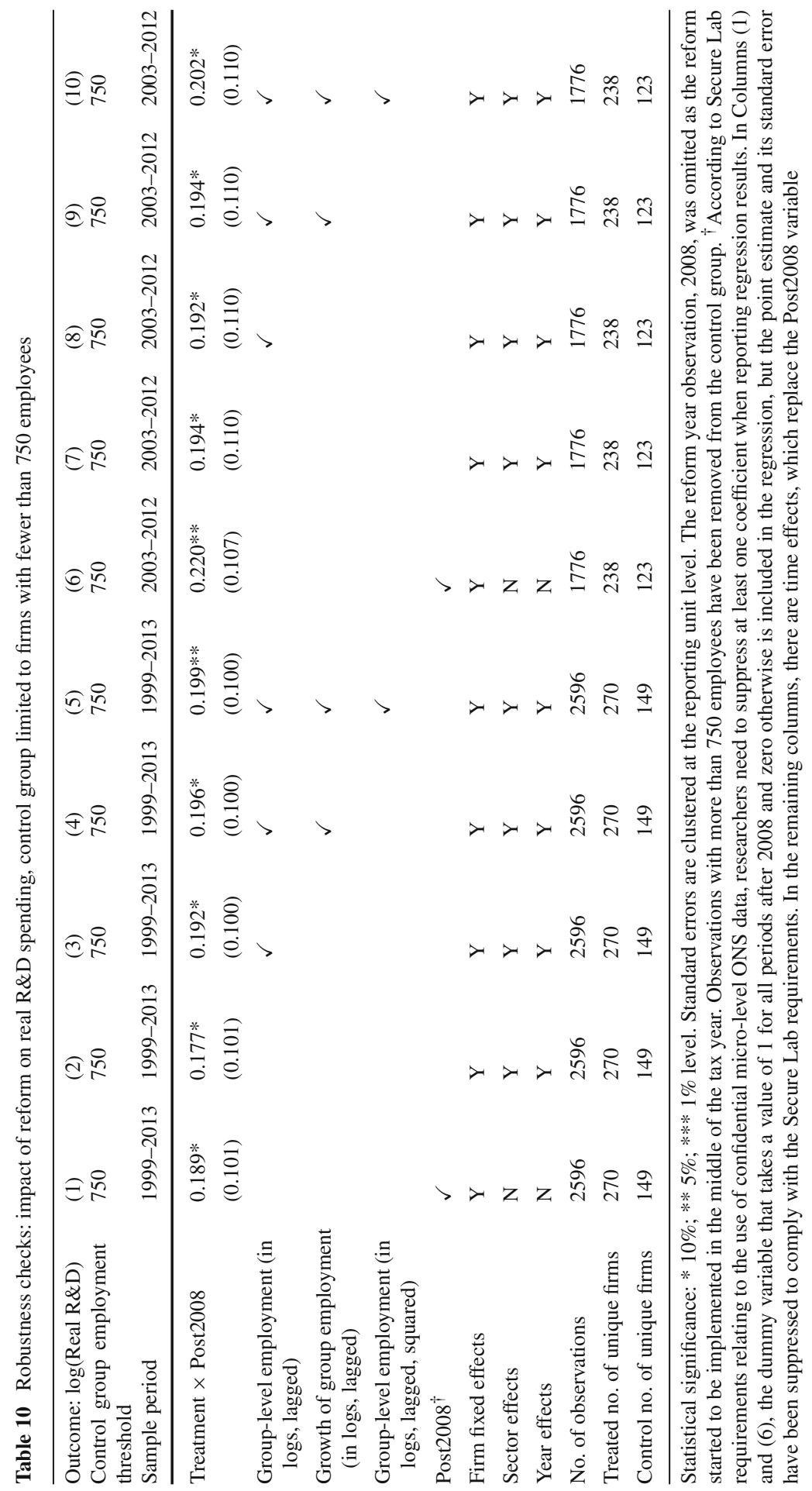




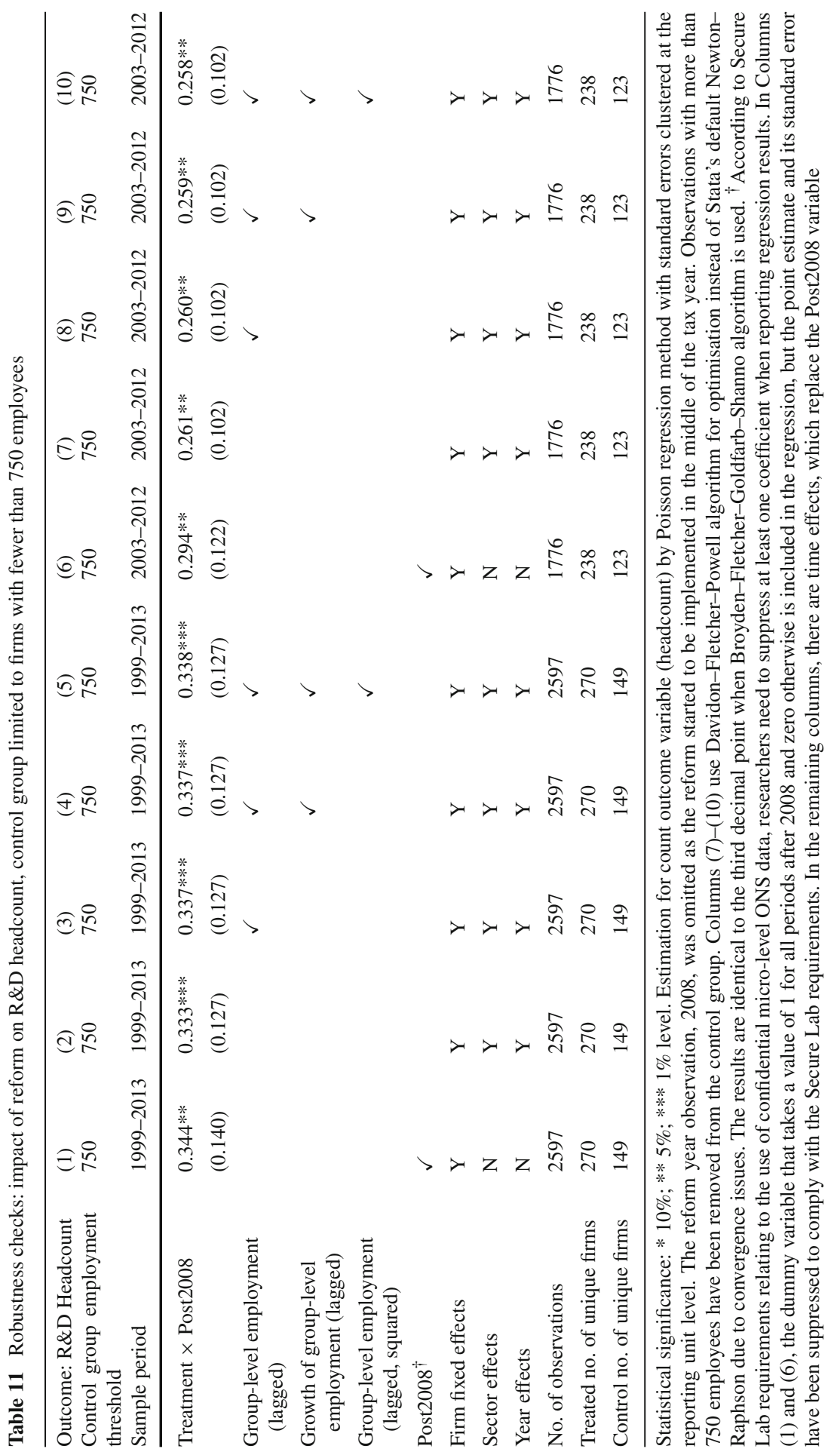




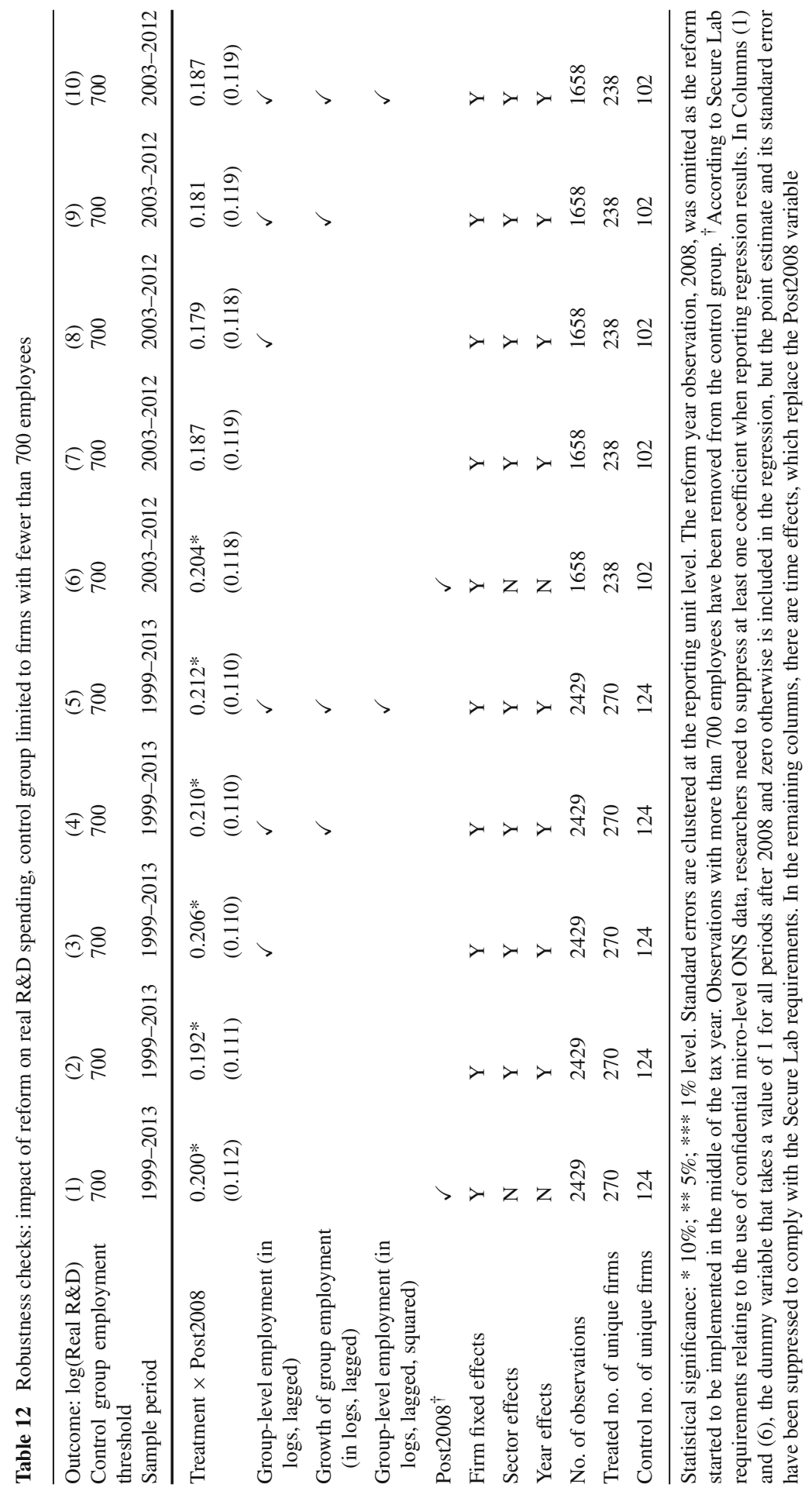




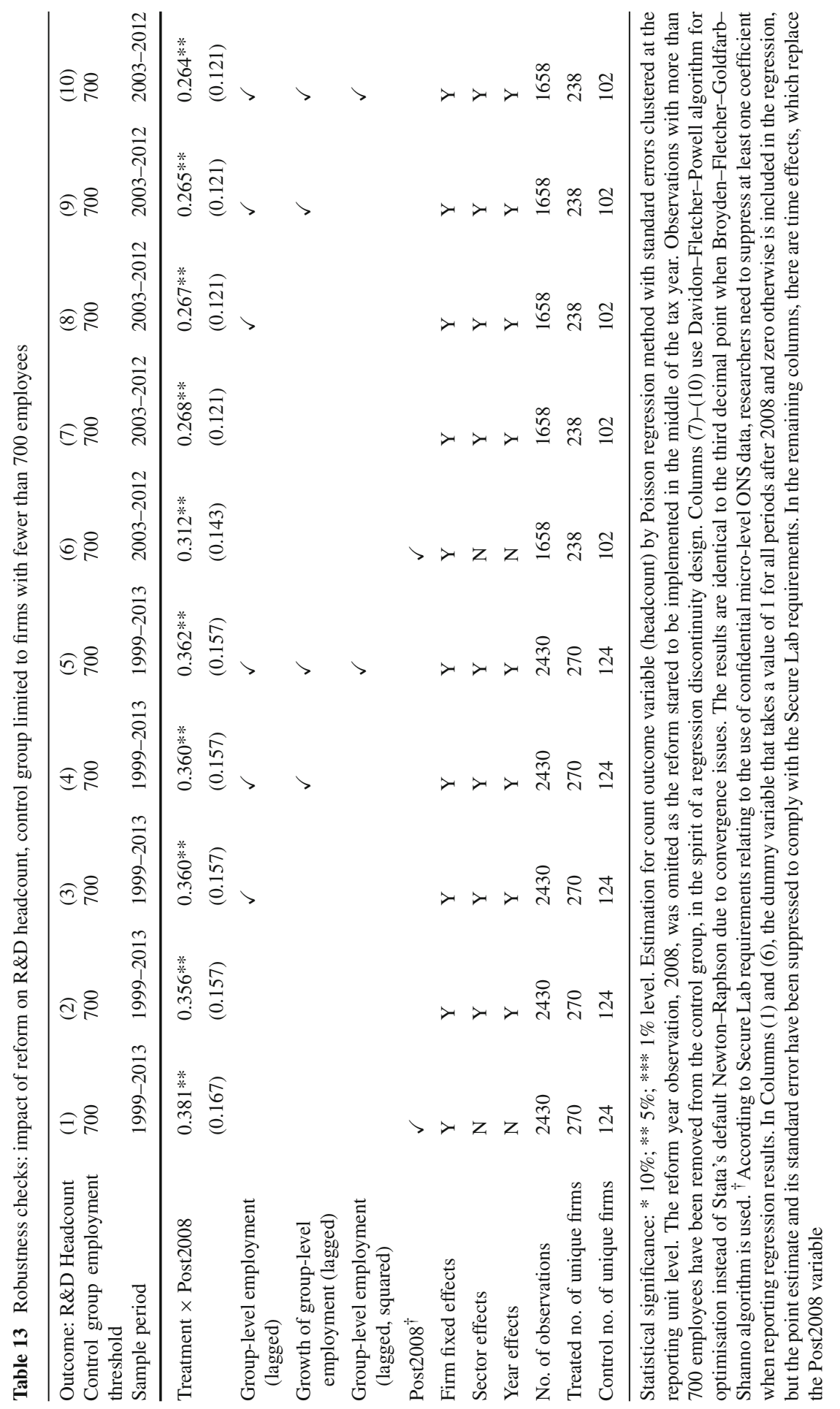




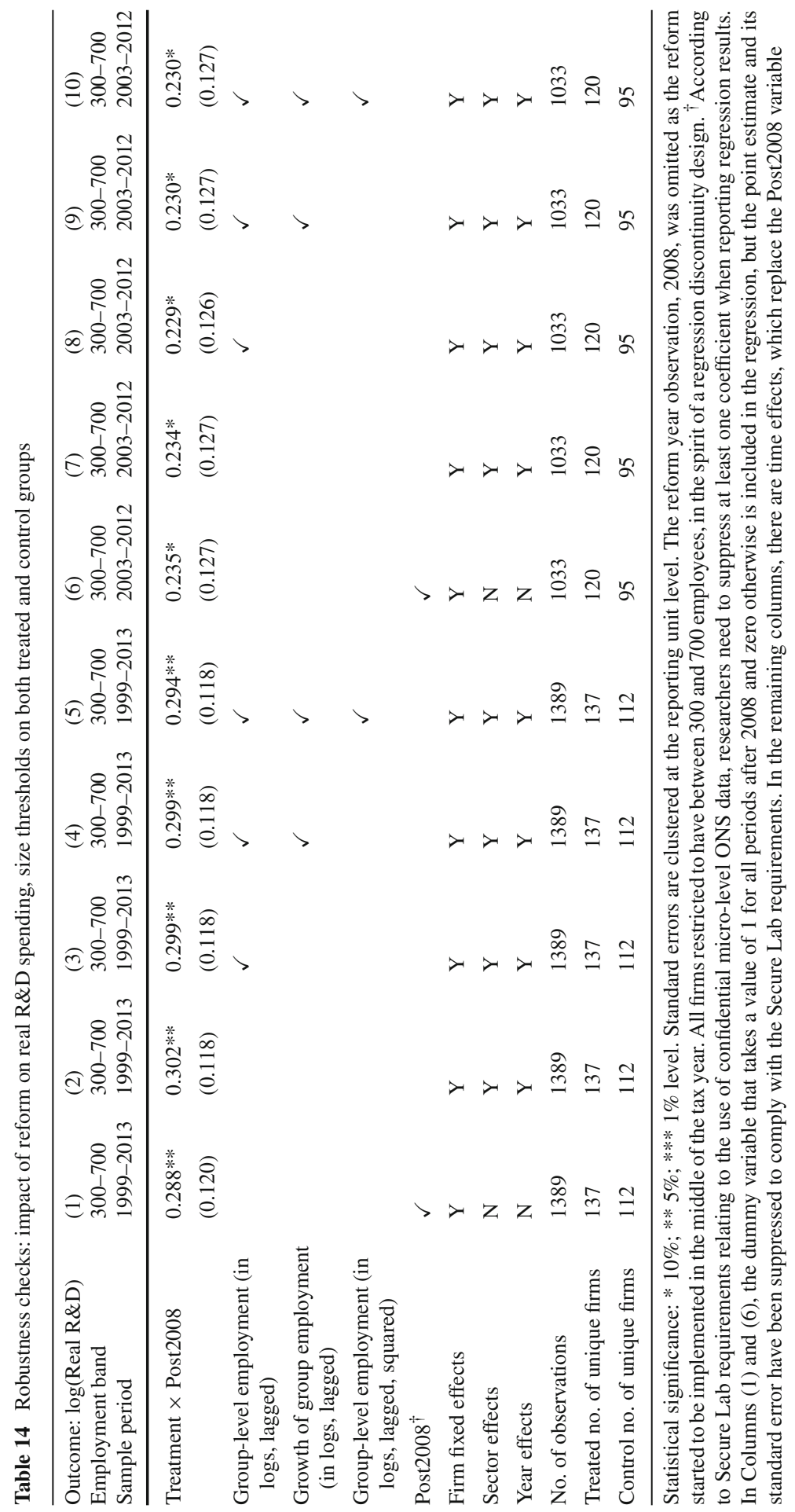




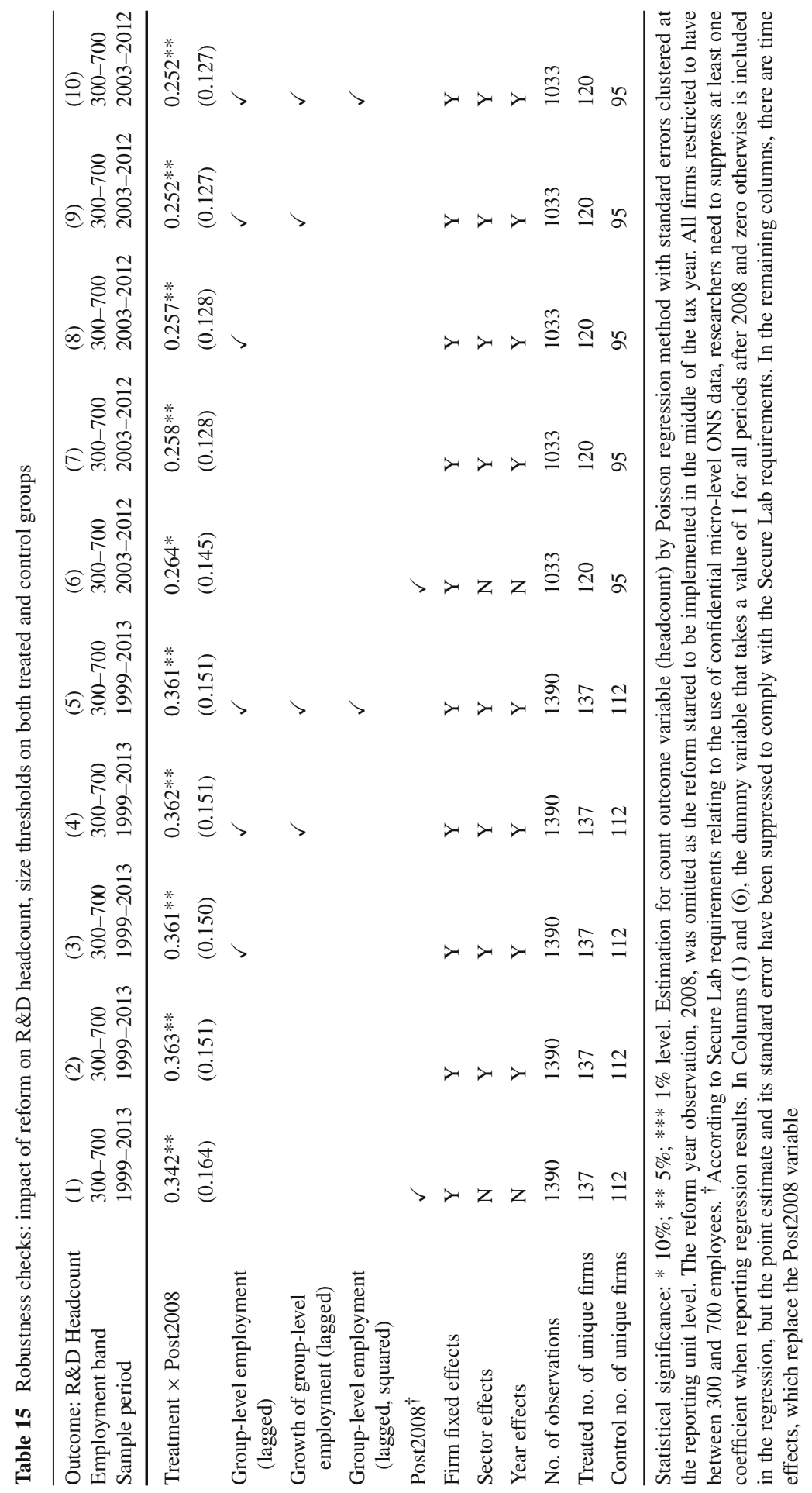




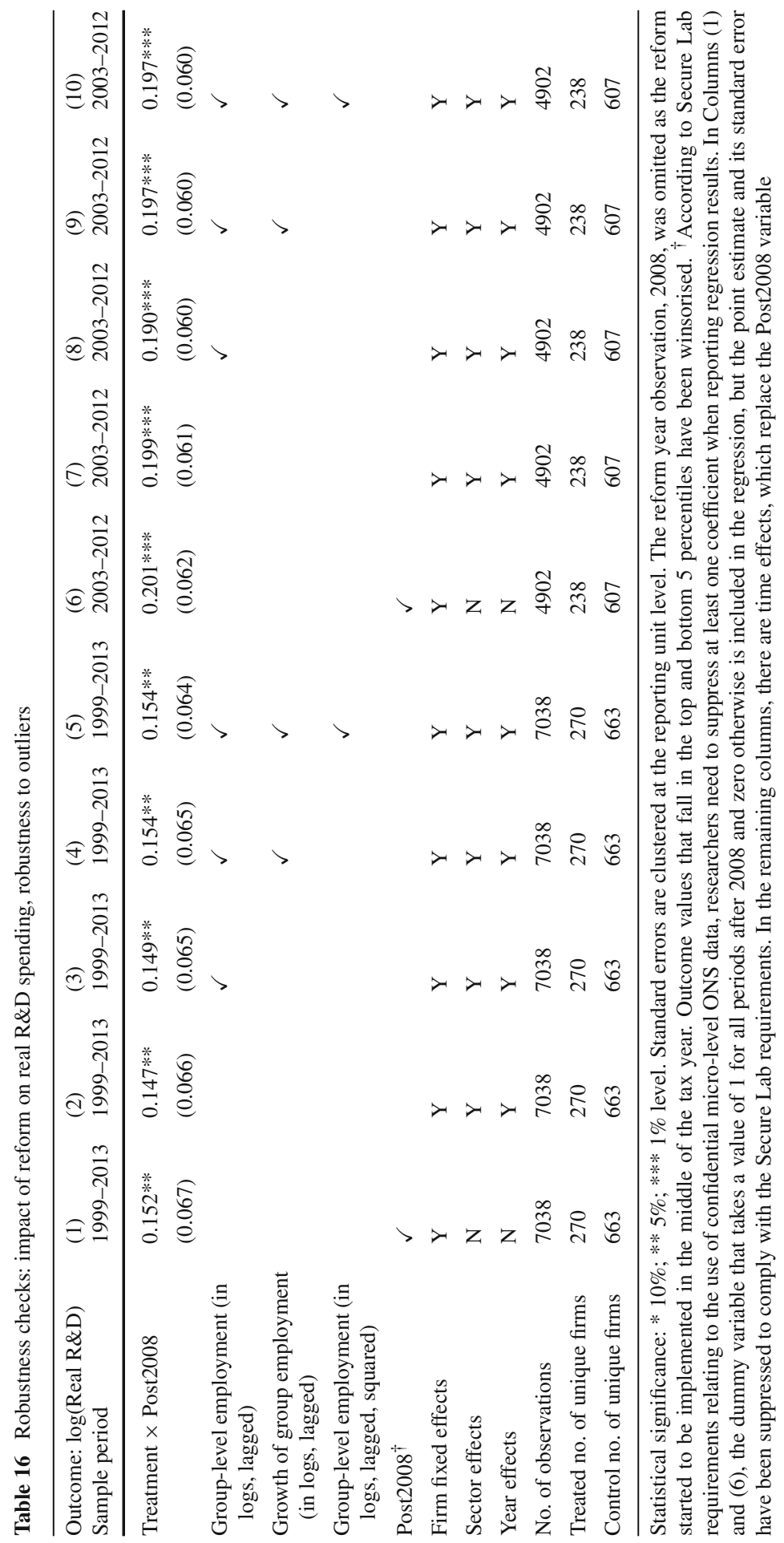




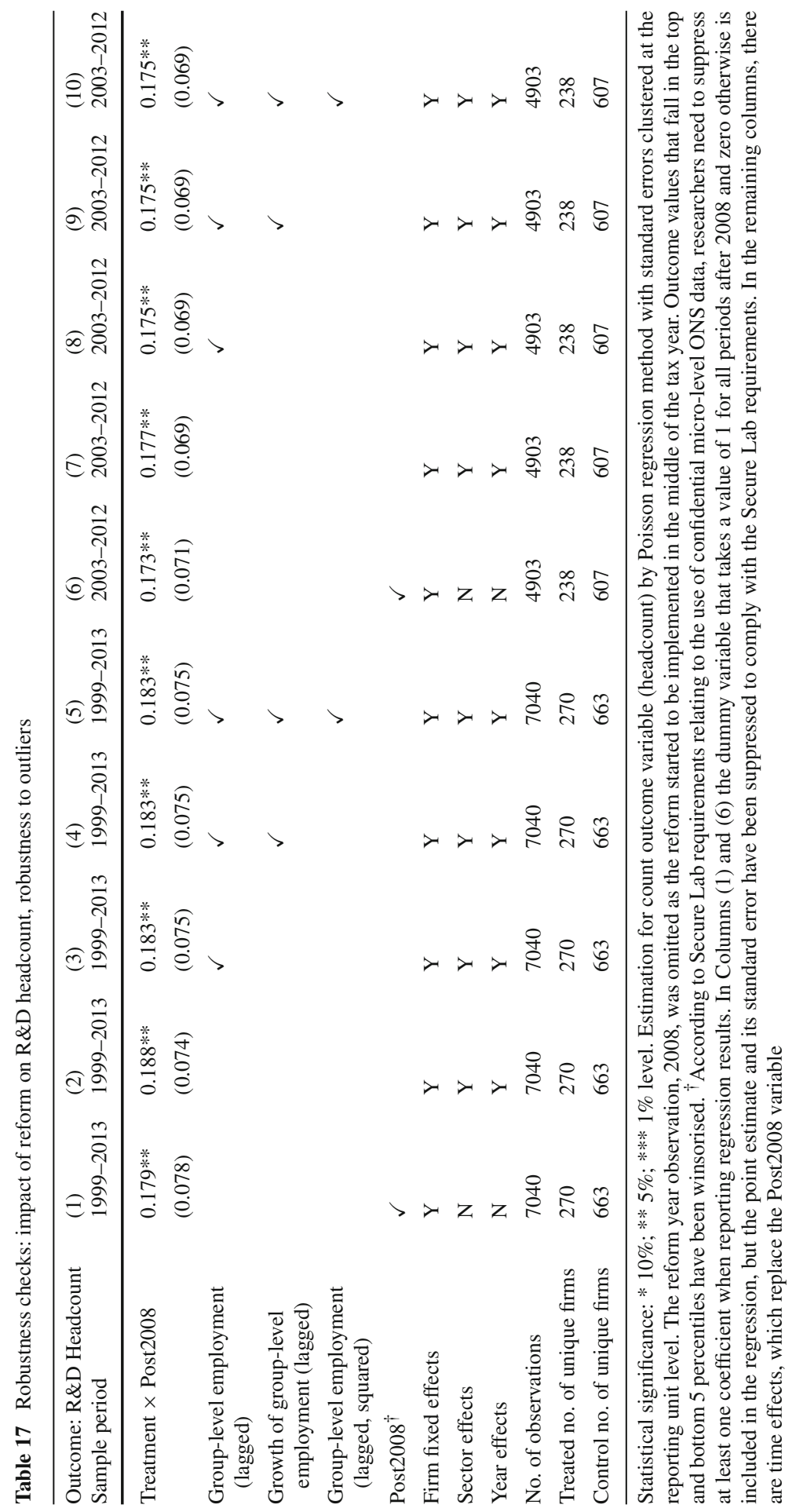


The Poisson regression method is commonly used in regressions with a count outcome variable (for examples and technical aspects, see Cameron and Trivedi 1998). However, the Poisson method relies on the assumption that the mean of the outcome variable is equal to its variance, which is often violated due to overdispersion. ${ }^{20} \mathrm{I}$ therefore check the robustness of the results to estimating an alternative count data model, which is the negative binomial model. In Table 18, I present the main regression results with $R \& D$ headcount variable as the dependent variable (Table 18). The results from negative binomial regressions indicate that the differential increase in R\&D headcount for the treated firms was between 17 and $20 \%$ and highly significant. Differently from the Poisson estimates, the results which use the 1999-2013 sample (Columns (1)-(5)) and the 2003-2012 sample (Columns (6)-(10)) are very similar in both magnitude and significance.

Identification using the diff-in-diff method requires that in the absence of the policy intervention, the treated and control group outcomes do not follow differential trends. I use placebo interventions in the pre-treatment periods as a robustness check to test pre-intervention period movements in the outcome variables. These are presented in Table 19 and 20. In both tables, Column (1) reports the results from a placebo test with 2003 as the placebo reform period with only firm, sector, and year fixed effects as controls. In Column (2), all size controls, namely the employment level, growth rate and squared employment level are included. Column pairs from Column (3) until Column (10) check the absence of a placebo effect for each of the pre-reform periods that follow. In each of these years, using the preferred specification, I find no significant differential change in any of the pre-reform periods. The confidence intervals around these placebo reform years are tight around zero.

\subsection{Did the reform come as a surprise?}

One question in a policy setting where the announcement of the policy predates implementation is whether beneficiaries adjust their investment behaviour after the announcement but prior to implementation of the policy. In the case of the R\&D Tax Relief schemes in the UK, the Chancellor announced the Government's intention to introduce the policy reform in the prior year's Budget before the reform took place, but enactment required EU State Aid clearance and implementation was at best uncertain from the perspective of potential beneficiaries. In this section, I present results from regressions which remove the years after the Chancellor's announcement prior to the reform, and the first period after reform.

The simplest way of assessing whether there has been any strategic delaying is to omit all the periods between announcement and the first period of implementation. Omission of the years 2007, 2008 and 2009 achieves this objective (Tables 21,22). The estimated impact of the introduction of the more generous tax relief for larger firms remains very similar to that obtained using the full sample, suggesting an increase in R\&D by around $17-19 \%$. The smaller sample size results in a marginal reduction in the statistical significance of the estimated coefficient on the diff-in-diff interaction

${ }^{20}$ Poisson Maximum Likelihood Estimator is still consistent in the presence of overdispersion. 


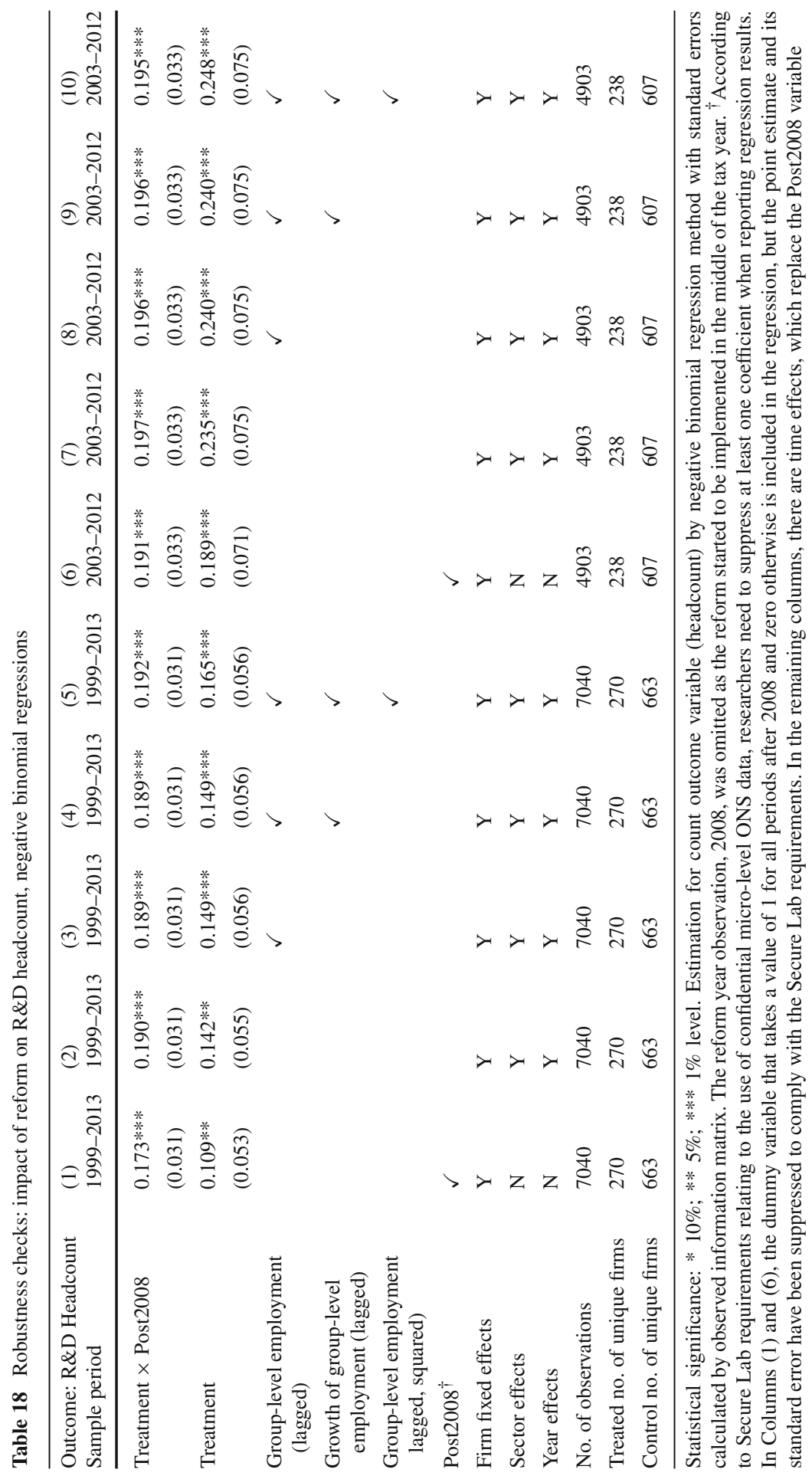




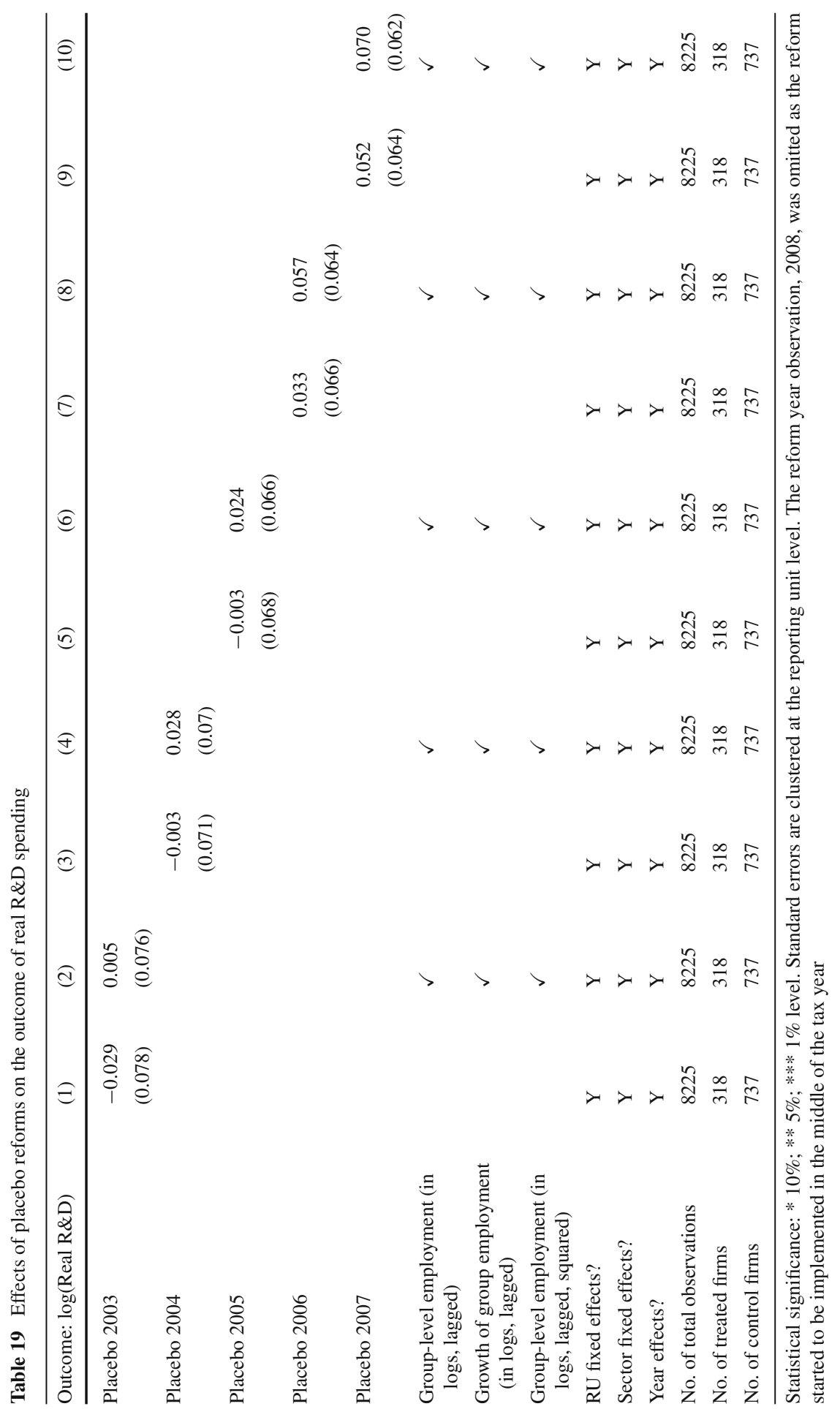




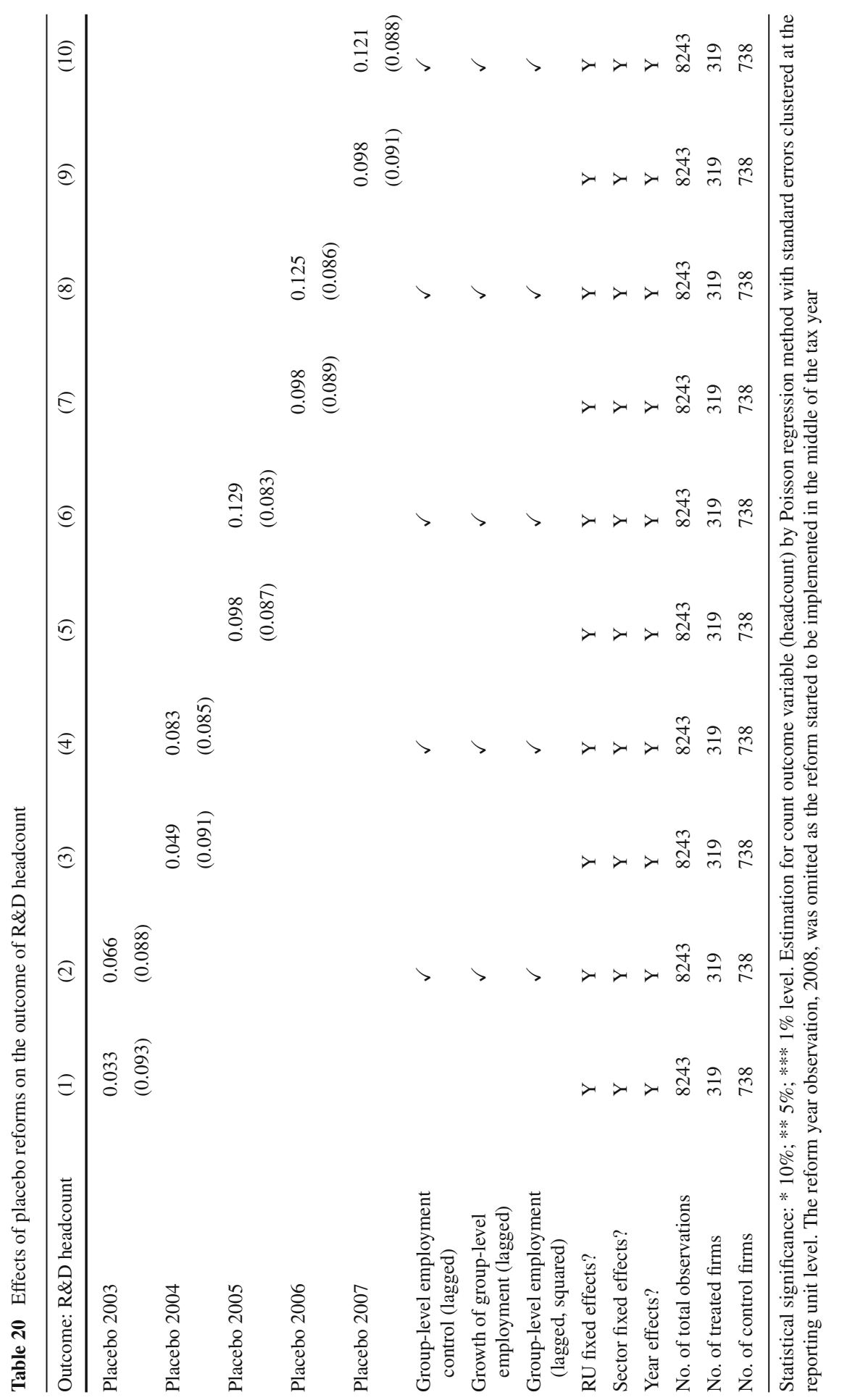




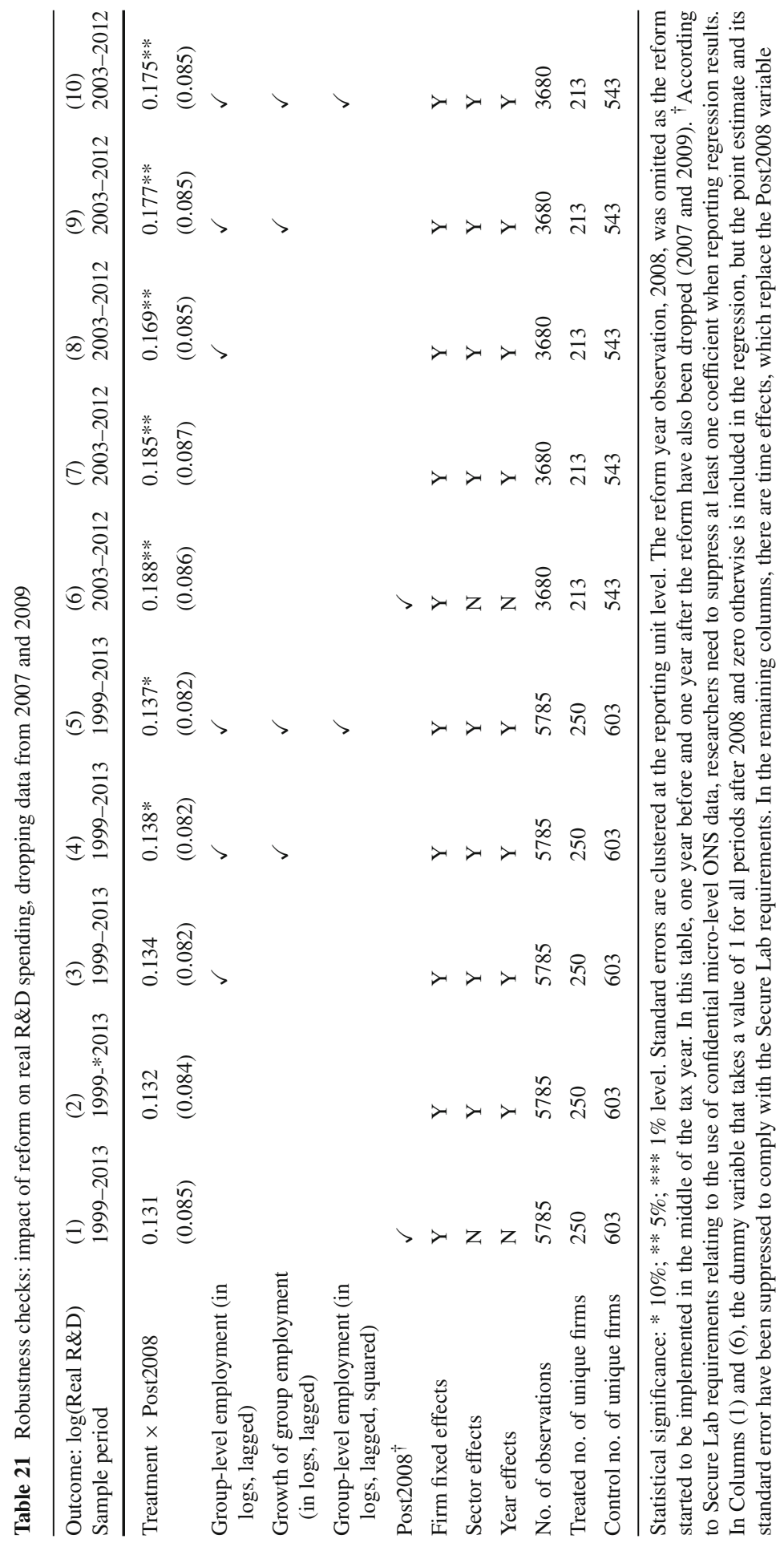




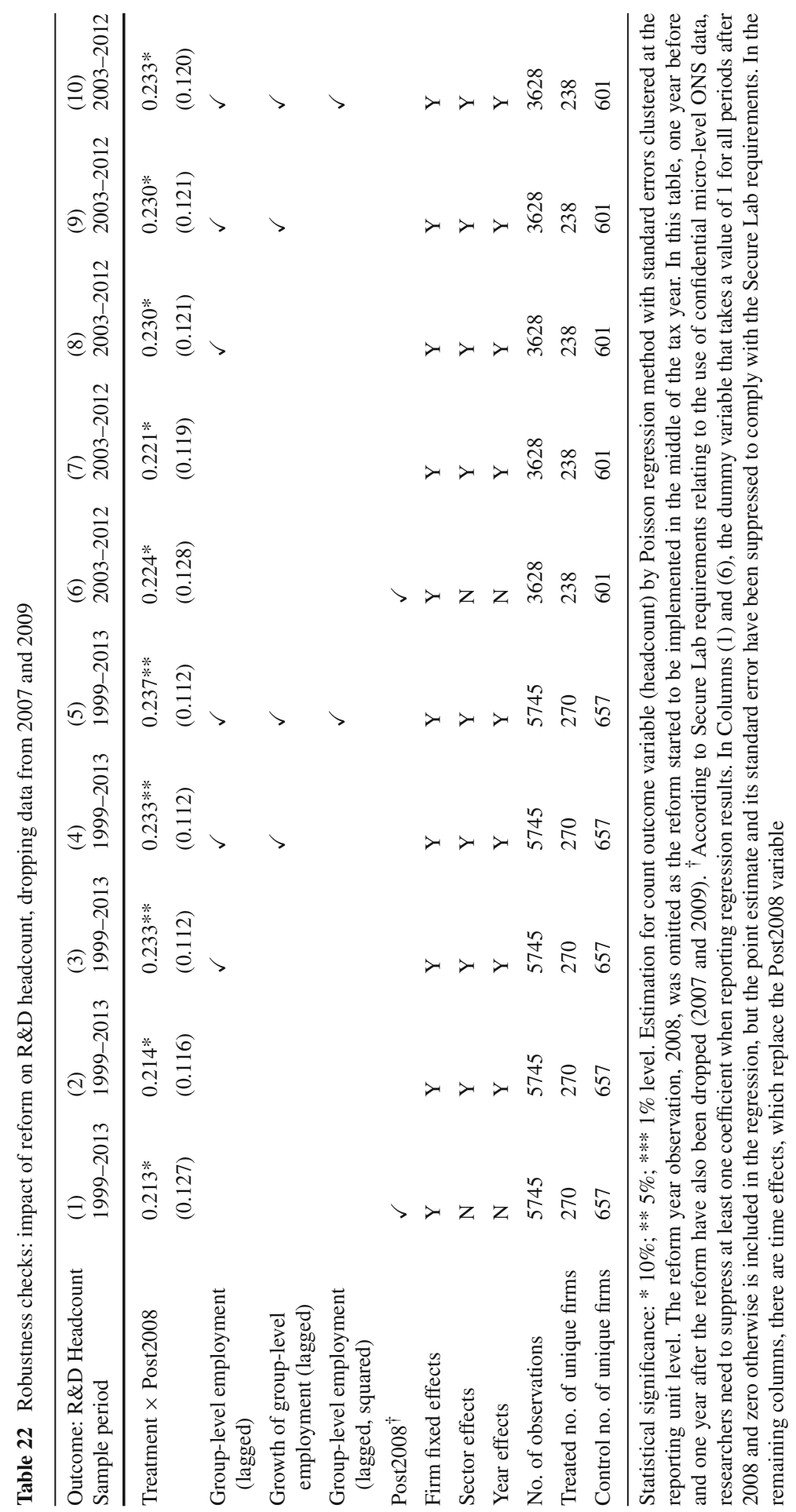


term, but there is no indication that our full sample results are seriously biased by firms postponing $R \& D$ expenditure until after the introduction of the change in the eligibility criteria in August 2008. Once again, the R\&D headcount results are stable, with the preferred specification (Column (10)) in the more restrictive sample of 2003-2012 yielding a significant diff-in-diff coefficient with a magnitude around $23 \%$.

\subsection{Is there reason to believe that there is no relabelling?}

An important concern in the study of the impact of R\&D tax incentives is the possibility that firms report a large chunk of administrative expenses as R\&D to benefit from the more generous tax treatment of their R\&D expenditures. In the BERD survey, firms should not have an incentive to lie about their R\&D spending, as ONS gives them information that their responses in the BERD survey is to be kept confidential (Fig. 9). Bloom et al. (2002) argues that the use of statistical offices' R\&D survey data, as opposed to the tax data, should alleviate any issues of relabelling. To the extent that firms keep their R\&D records for the purpose of responding to ONS's BERD Survey separate from their tax records, we should not expect to observe relabelling of ordinary spending as R\&D in the BERD data. In terms of evidence for relabelling in firms' tax returns, the few studies which had suitable data so far did not find systematic relabelling, at least in developed countries (For example, based on evidence from the USA and Australia, Hall (1995) reports no substantive evidence for relabelling). In the UK context, HMRC set up Specialist R\&D units to reinforce compliance and take up of R\&D tax credits (National Audit Office 2014).

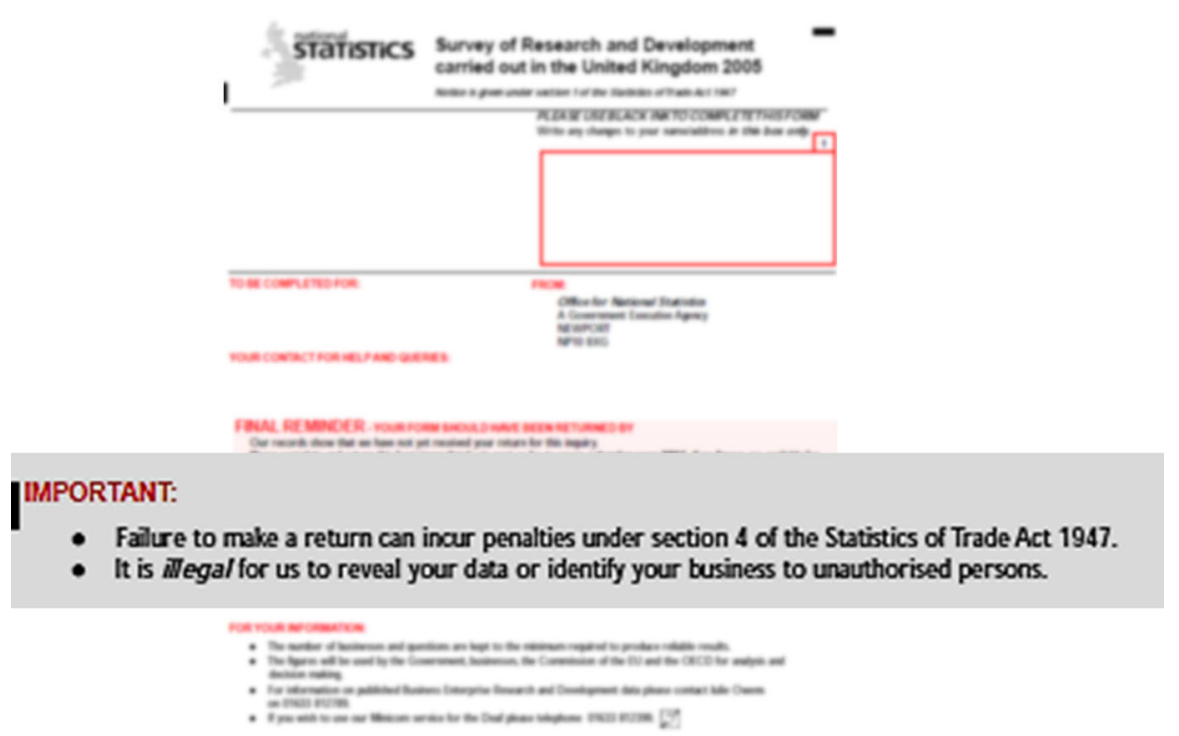

Fig. 9 Cover page remarks from the Office for National Statistics. Notes The figure shows a snapshot of the cover page of the BERD short form survey. The section that informs the respondents about the confidentiality of answers has been magnified. In addition to the confidentiality remark, ONS reminds the respondent here that filling out the firm is compulsory. The survey forms are similar across years, and the version displayed here is from 2006, requesting information from calendar year 2005 


\section{Discussion}

The UK R\&D tax incentive scheme has gradually become more generous, now with more than $£ 1$ billion cost to the Exchequer in foregone corporation tax revenue annually. The findings of this paper suggest that the reform in the R\&D tax relief that changed the status of the enterprises in the treatment group from 'large' to 'SME' caused these firms to increase their R\&D spending by 15-20\%. Guceri and Liu (2015) estimate that the drop in the user cost of R\&D capital for the treated group of firms thanks to the 2008 reform of the SME tax relief eligibility criteria was around $17 \%$. In the BERD data, I do not have information on the tax position of each firm and therefore cannot calculate individual values for the user cost of R\&D, but in this section, I refer to the point estimate of $17 \%$ in order to infer the implied user cost elasticity.

From the main diff-in-diff point estimates of 20.4 and $14.9 \%$ (upper and lower bound estimates for preferred specifications in Table 5), one can back out the elasticity of $\mathrm{R} \& \mathrm{D}$ with respect to its user cost, based on the finding that the introduction of the change in the SME scheme eligibility criteria resulted in a reduction in the user cost of R\&D by about $17 \%$ in the UK. The 20.4 and $14.9 \%$ increase in spending therefore corresponds to a user cost elasticity estimate of about -1.18 and -0.88 , respectively. Using the BERD dataset, there is evidence that the increase in R\&D spending is attributable to an increase in $R \& D$ headcount rather than higher salaries for $R \& D$ personnel.

Based on the estimated additionality effect of the policy of 15-20\% and the corresponding cost of the R\&D tax relief to HMRC, it is possible to calculate an estimate for the return for every pound of HMRC's foregone corporation tax revenue. The reform increased the burden of each unit of a medium-sized firm's R\&D on the Exchequer from $0.30 \times \tau$ to $0.75 \times \tau$, where $\tau$ is the statutory tax rate that applied to each firm. ${ }^{21}$ In addition to this extra cost per unit of $R \& D$, treated firms increase their R\&D spending by about $20 \%$ in response to the policy reform, and hence, the cost to the Exchequer increases indirectly as well. For a firm that pays taxes at the main rate of $28 \%$ in the $2008-2010$ period, every $£ 1$ R\&D generated by the policy reform of $20 \%$ results in HMRC to forego $£ 0.23$ of tax revenue. Similarly, for a firm that pays taxes at the small profits rate of $21 \%$, after the reform, HMRC loses $£ 0.17$ of tax revenue due to the reclassification of treated firms as SME and not large for the purpose of the R\&D tax relief. These two estimates result in an estimated bang-for-the-buck ranging between $£ 0.9$ and $£ 1$. 2 . The same calculations based on a $15 \%$ increase in $R \& D$ spending leads to bang-for-the-buck estimates between $£ 0.75$ and $£ 0.9$. Based on the simple calculation without considering any spillovers that may be generated by the policy, the results suggest that the Exchequer recovers its cost.

Throughout the paper, I assume that the firms' measured response to the increased generosity of tax incentives is a long-run effect. Prior evidence suggests that firms take a few years to adjust to the new equilibrium level of R\&D after an increase

\footnotetext{
${ }^{21}$ The calculation assumes away the firm specific discounting of losses carried forward and the value of cash claims. The calculation can be thought of as one where all the firms pay taxes, at least at the small profits rate.
} 
in the generosity of R\&D tax incentives (Bloom et al. 2002). In the current quasiexperimental setup, one way of exploring any adjustment issues is to introduce yearby-year treatment interaction terms for each of the years in the post-treatment period and pin down the year(s) in which the policy effect becomes more apparent. The results in Table 23 (Columns (6)-(10)) show that on average, R\&D spending seems to have responded relatively quickly, but with gradual adjustment over time. R\&D headcount seems to have responded with some lag, which may be attributable to frictions in the supply of scientists and engineers (Table 24).

\section{Conclusion}

The number of countries which offer R\&D tax incentives to stimulate business R\&D spending has been increasing rapidly in the past few decades. After a long period of relative decline in aggregate R\&D intensity, the UK joined the group of countries which offer generous fiscal incentives for R\&D in 2000. The first reform in 2000 was the introduction of the SME Tax Relief Scheme, followed by the introduction of the large company scheme in 2002, which was less generous than the SME scheme. In 2008, the definition of an 'SME' for the purpose of the R\&D Tax Relief expanded to include a group of medium-sized companies with up to 500 employees. ${ }^{22}$ In this study, I exploited the reduction in the user cost of R\&D for medium-sized companies in comparison with their slightly larger counterparts to obtain difference-in-differences estimates of the impact of R\&D tax incentives.

Tax credits have a direct effect on the firms' cost of investing in R\&D. Motivated by a simple neoclassical theoretical framework, the empirical specifications in this paper examined the effects of the change in the eligibility thresholds to the SME tax relief scheme on R\&D spending and on R\&D employment at the micro-level.

Controlling for firm size and growth using firm-level employment information from the business register, I have found that treatment group companies which started to benefit from the SME scheme after the 2008-2009 fiscal year increased their R\&D spending by around $15-20 \%$ in comparison with the control group after the introduction of the policy. The robust estimate of the $20 \%$ increase over the counterfactual scenario of less generous tax credits for treated firms translates to an elasticity of R\&D with respect to its user cost of around $-1.18 .^{23}$ The corresponding bang-for-the-buck estimates of $£ 0.75-£ 1.2$ suggest that the tax authority roughly recovers its additional cost of implementing the new policy.

The BERD survey does not give any incentives to its respondents to relabel ordinary spending as R\&D. I therefore argue that, differently from the studies that use administrative data, there is no reason for the magnitude of the effect found in this study to be affected by concerns related to relabelling.

Many young innovative start ups incur frequent losses. The UK R\&D tax relief allows firms to receive a cash refund when in a loss-making position. In comparison

\footnotetext{
22 Employment is the binding threshold. There are other thresholds based on turnover and size, which are discussed in detail in Sect. 2.

23 The lower bound estimate of $15 \%$ increase translates to a user cost elasticity of -0.88 .
} 


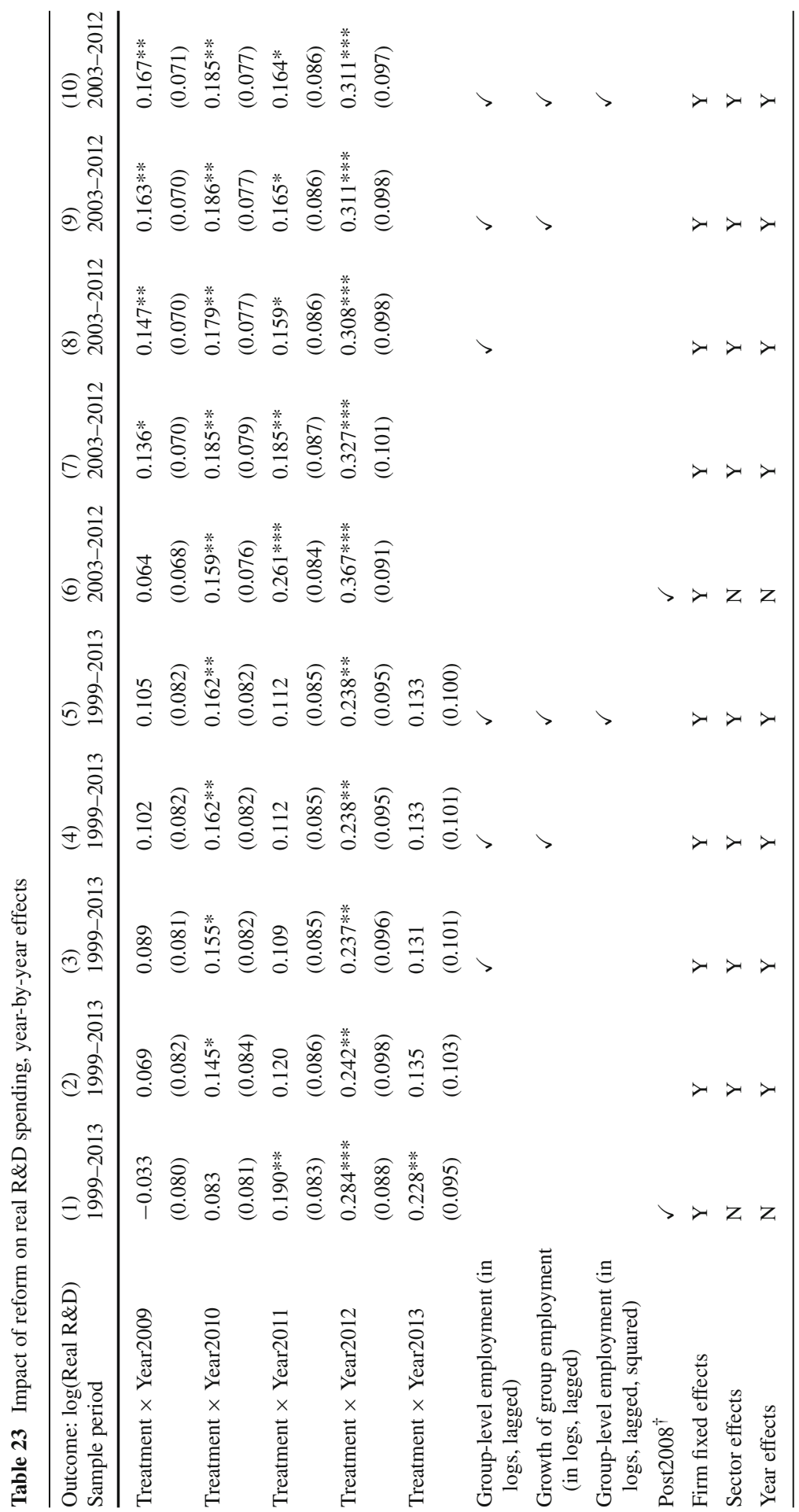




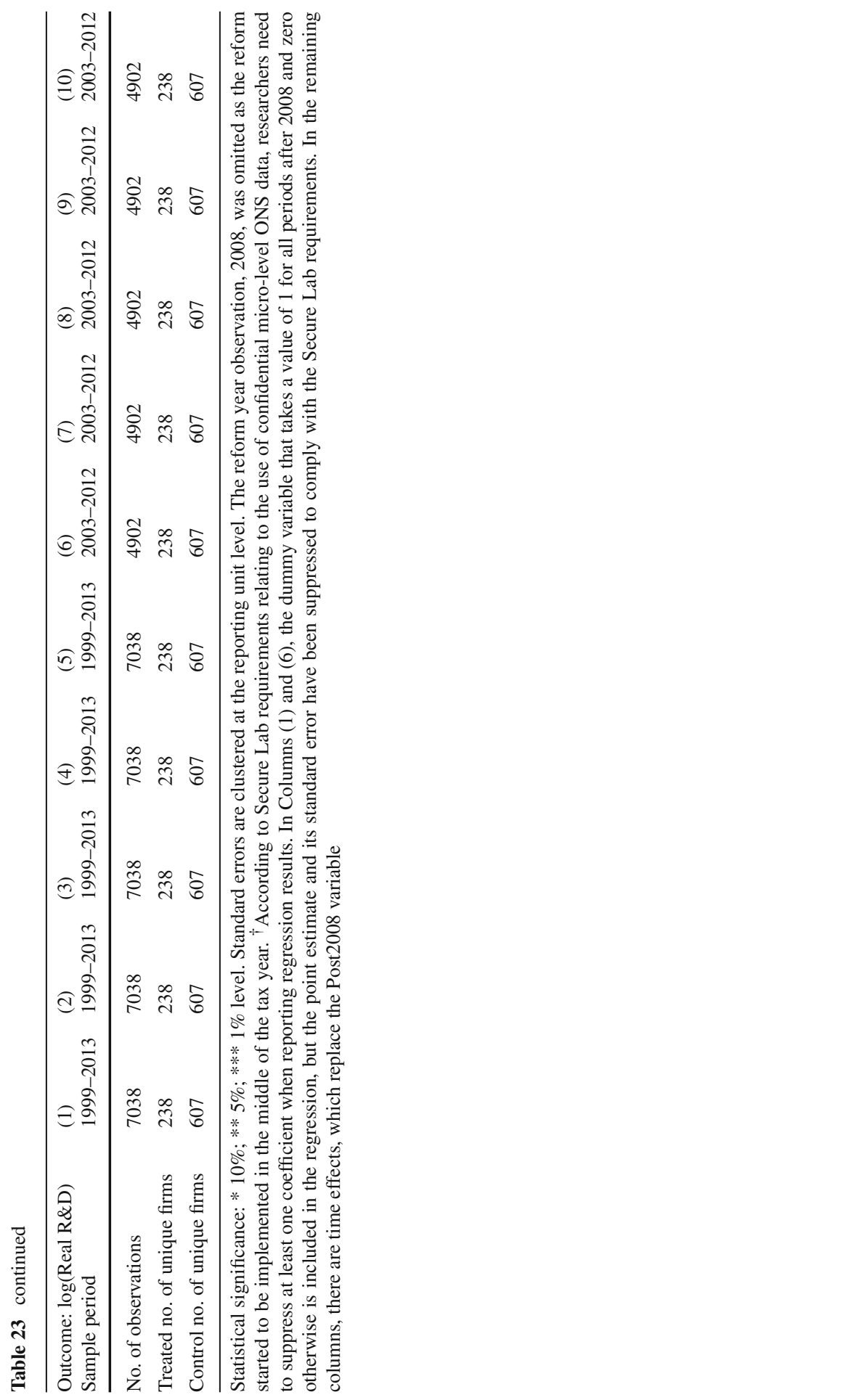




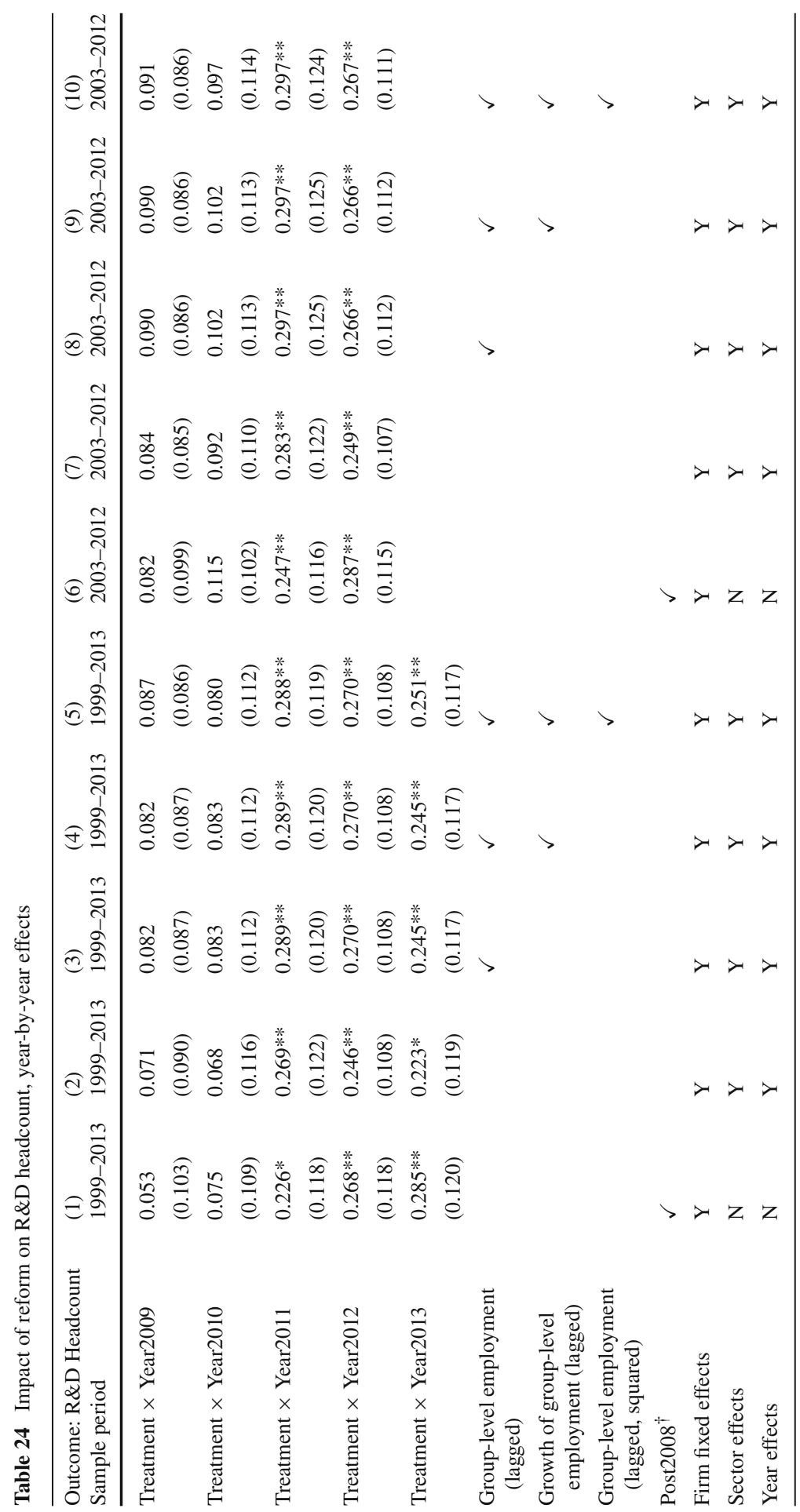




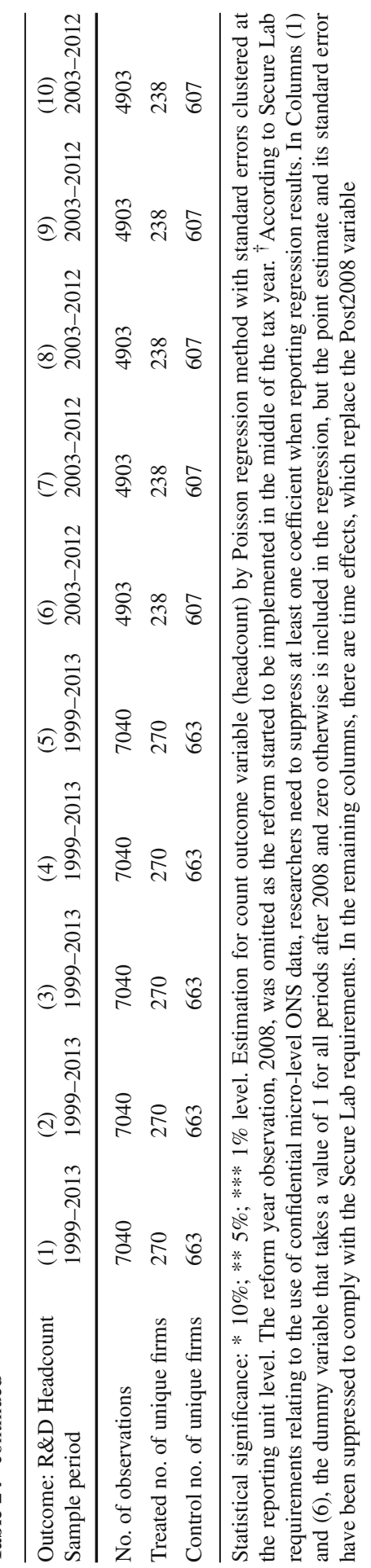


with $R \& D$ tax incentive schemes in many other countries, the effectiveness of the tax incentive on R\&D spending and headcount in the UK may be positively influenced by the more symmetric treatment of losses and profits in the context of the R\&D tax relief. This is an important design aspect in the UK context that policymakers around the world may need to consider in benchmarking the relative performance of R\&D tax relief schemes.

I find evidence that the increase in R\&D spending may have been driven by an increase in $R \& D$ headcount in response to the policy, instead of an increase in the 'price' of R\&D or scientists' salaries. Policymakers may be interested in scaling up a certain type of spending within business $R \& D$, and in the policy design, they may consider differentiating between R\&D spending items such as headcount, salaries or materials. The findings here suggest that the quantity effects dominate even in the absence of such differentiation.

Acknowledgements I am grateful for helpful comments from Steve Bond, Michael Devereux, Paul Hunermund, Molly Saunders-Scott, Helen Simpson, Joel Slemrod, Daniel Wilson and two anonymous referees, as well as seminar and conference participants at CBT, ZEW, Max Planck Institute for Tax Law and Public Finance, Koc University, Bilkent University, Ozyegin University, the National Tax Association Annual Congress and the International Institute for Public Finance. I thank the Office for National Statistics and Secure Data Service (UK Data Archive) for providing the data and for financial support from ESRC under Grant ES/L000016/1 and from Argela through the doctoral studentship agreement between Oxford University and Argela. Disclaimer: This work contains statistical data from the Office for National Statistics which is Crown copyright and reproduced with the permission of the controller of HMSO and Queen's Printer for Scotland, made available for use by the UK Data Archive. The Office for National Statistics, the UK Data Archive and Argela bear no responsibility for the analysis of the statistical data or the opinions presented in this paper.

Open Access This article is distributed under the terms of the Creative Commons Attribution 4.0 International License (http://creativecommons.org/licenses/by/4.0/), which permits unrestricted use, distribution, and reproduction in any medium, provided you give appropriate credit to the original author(s) and the source, provide a link to the Creative Commons license, and indicate if changes were made.

\section{Appendix}

\section{Data description and cleaning}

BERD data is available at the 'reporting unit' level, which corresponds to the geographical unit that has the postal address of the firm. The reporting unit may or may not be larger than a 'local unit'; therefore, it may be larger than a single plant or a single R\&D lab. It may be attached to the headquarters or can be a separate unit. A slightly larger statistical unit than the reporting unit is the 'enterprise,' which is defined in the EU Regulation on Statistical Units (EEC 696/93) as '....an organisational unit producing goods or services, which benefits from a certain degree of autonomy in decisionmaking, especially for the allocation of its current resources...'. BERD observations have the reporting unit as their identifier and most of them also contain the enterprise reference number.

An 'enterprise group' is defined as 'an association of enterprises bound together by legal and/or financial links. A group of enterprises can have more than one decision- 

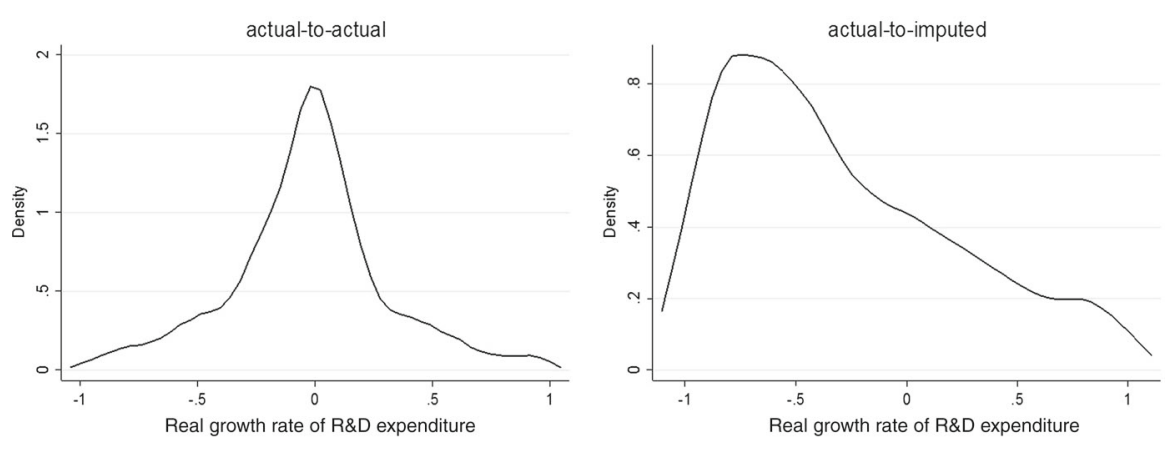

kernel $=$ epanechnikov, bandwidth $=0.0471$

kemel $=$ epanechnikov, bandwidth $=0.1055$
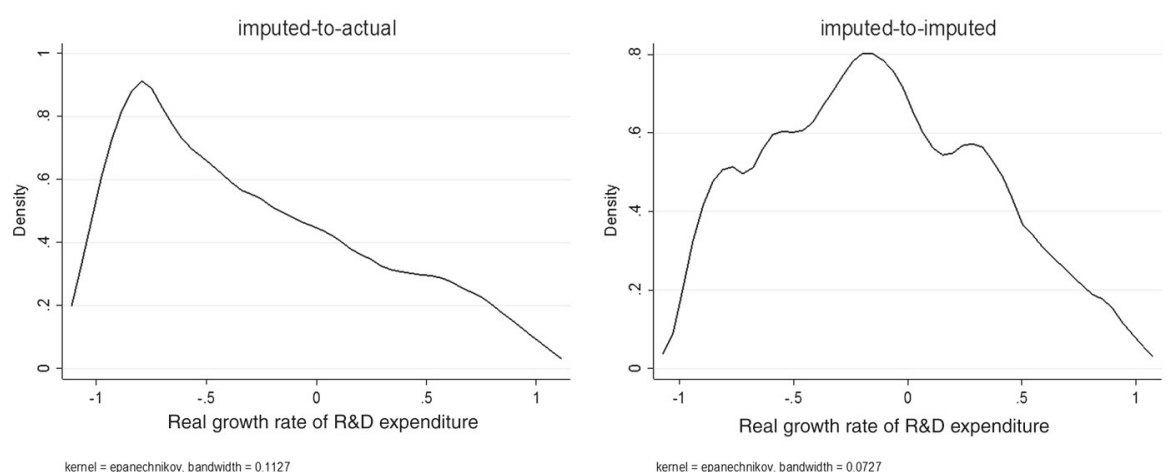

kernel $=$ epanechnikov, bandwidth $=0.1127$

kemel $=$ epanechnikov, bandwidth $=0.0727$

Fig. 10 Kernel density estimates for y-o-y real growth in R\&D, size band 100-399. Notes this figure presents the distribution of time differences between actual and imputed BERD values in the data. These figures have been taken from an earlier working paper on this topic (Guceri 2015). Therefore, the underlying data uses fewer years than those used in the present paper

making centre [...]. It constitutes an economic entity which is empowered to make choices, particularly concerning the units which it comprises (EEC 696/93).' The definition of an enterprise group is important for our purposes, as assignment to the treatment group depends on whether the group as a whole satisfies the criteria for eligibility to the SME scheme. Reporting unit-level R\&D data in BERD is matched to the BSD at the enterprise level. BERD provides information on both the reporting unit and enterprise references for each observation.

The ONS constructs the BERD dataset using the responses to two types of questionnaire forms sent out to firms: a long form and a short form. About 400 largest spenders (those who spent more than $£ 3$ million in a reference year) on $R \& D$ receive a long-form questionnaire, and the rest receive a short-form questionnaire. This latter form contains a small set of questions tracing basic information, namely, the unit's: (i) in-house $R \& D$ expenditure, (ii) extramural $R \& D$ expenditure, (iii) full time equivalent number of R\&D personnel and (iv) total headcount on R\&D. The long form collects a much wider set of variables, including a breakdown of R\&D expenditure to product groups; capital and current expenditure, broken down into salaries and other 


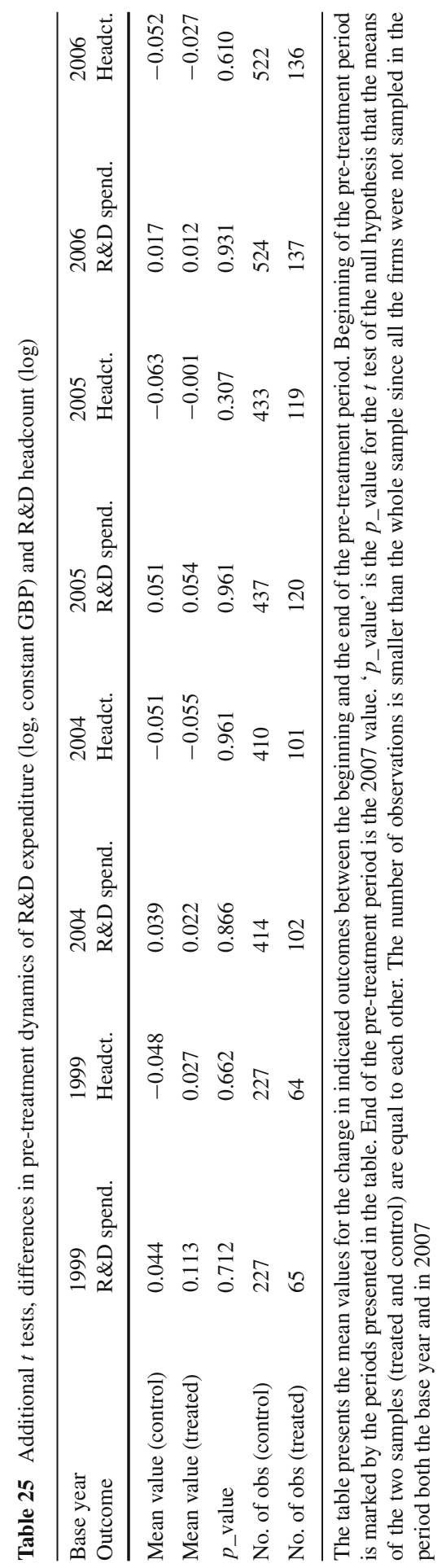



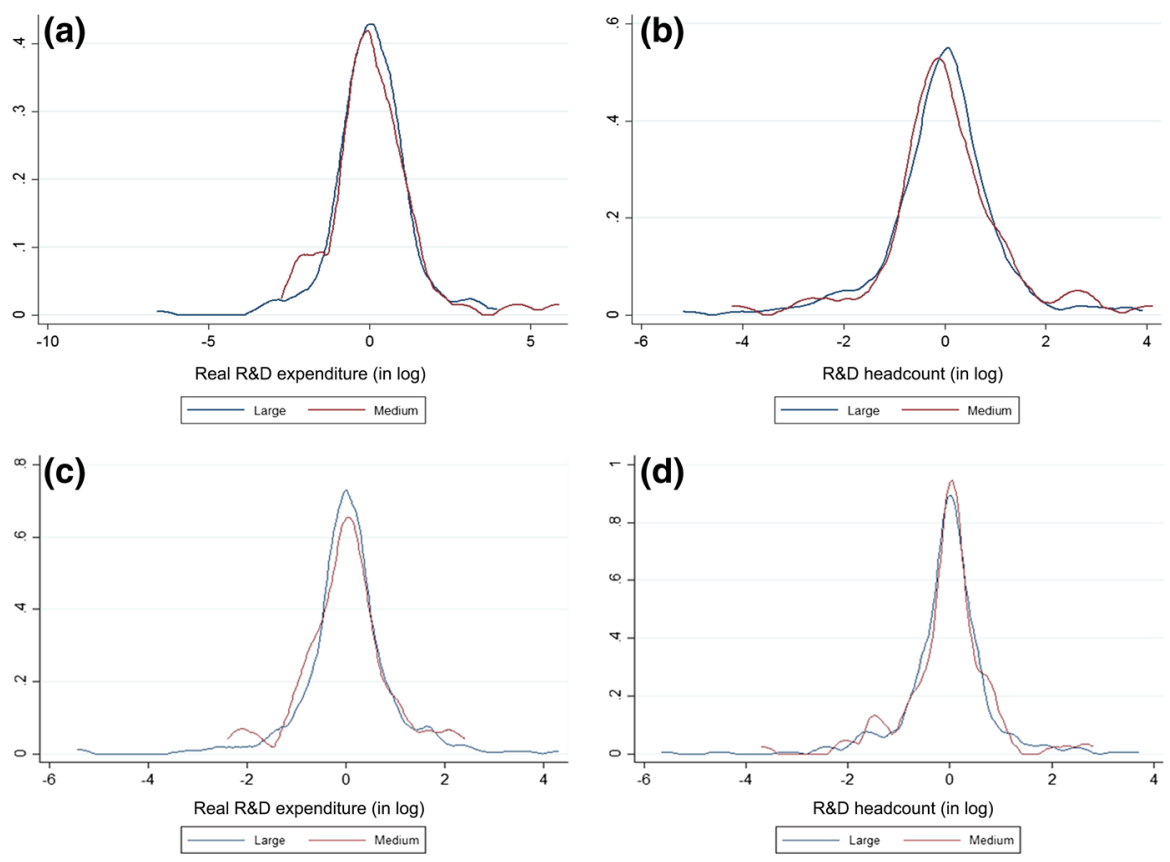

Fig. 11 Kernel densities, differences in pre-treatment dynamics of R\&D expenditure (log, constant GBP) and R\&D headcount $(\log )$. a Real R\&D expenditure $(\log )$, base year 1999. b R\&D headcount $(\log )$, base year 1999. c Real R\&D expenditure (log), base year 2004. d R\&D headcount (log), base year 2004. Notes the figures present the density of the changes between the beginning of the pre-treatment period (1999 or 2004) and the end of the pre-treatment period (2007) in key outcome variables. a shows the kernel density of the changes in the $\mathrm{R} \& \mathrm{D}$ spending variable in the treated and control groups. $\mathbf{b}$ shows the kernel density of the changes in the R\&D headcount variable in the treated and control groups

current expenditure; sources of funding for R\&D; a breakdown of the skills set for R\&D employment; and a breakdown of R\&D expenditure into geographic locations (UK postcodes). As smaller firms tend to spend less on R\&D than larger firms, the information available on SMEs is mostly limited to the questions asked in the short form.

The group of smaller firms (as they are less likely to be among the top 400 spenders) are subject to sampling at different sampling fractions depending on their size measured by employment. Since the stratified sampling procedure is repeated every year, this causes gaps in the time series data. Based on the publicly available BERD First Release data, ${ }^{24}$ the breakdown of participants to BERD Inquiry into long- and shortform recipients is around 4000 sampled firms, out of which around 400 are sent a long form and the rest are sent a short form. Out of the firms which receive short forms, all those with more than 400 employees are sampled. Within the size band of interest, there are firms with $250-400$ employees, for which the sampling ratio is 1:3. ${ }^{25}$ The

\footnotetext{
24 Until 2007, this publication was part of the MA14 Business Monitor.

25 Firms with 100-400 employees are sampled with this ratio.
} 

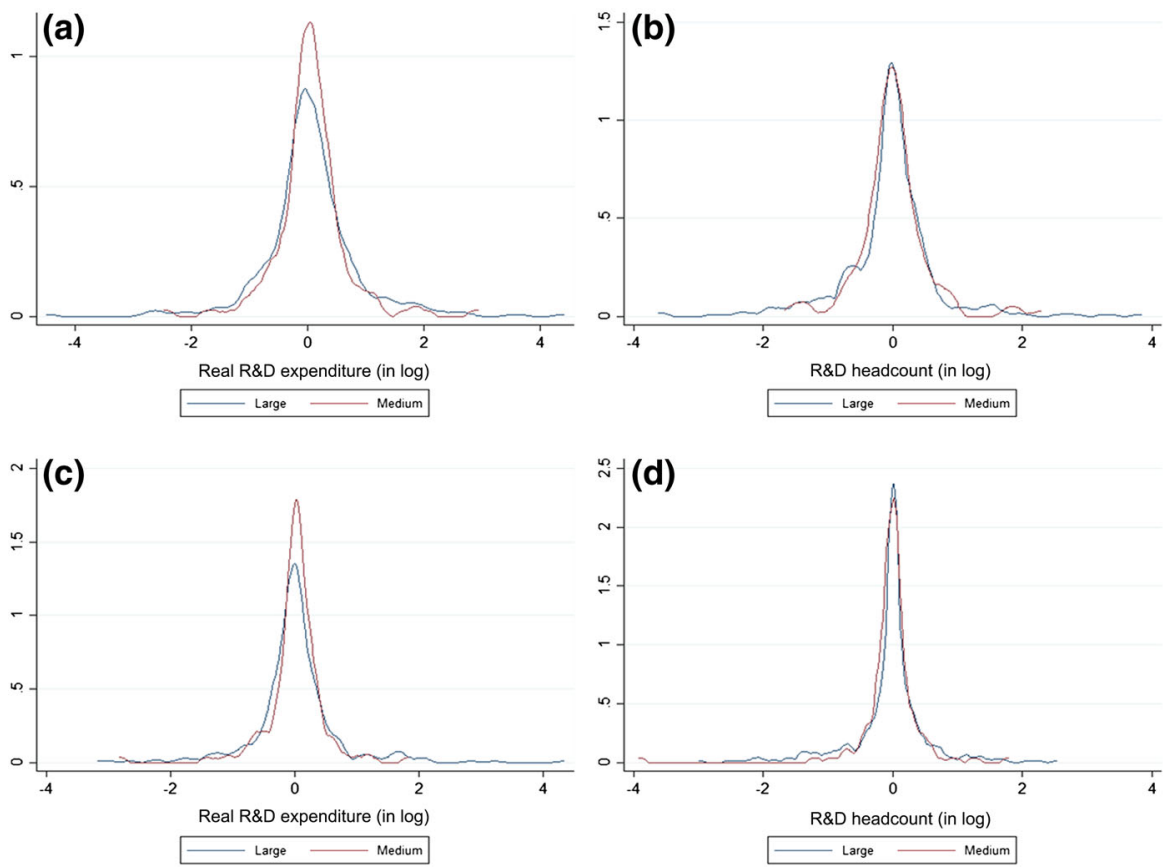

Fig. 12 Kernel densities, differences in pre-treatment dynamics of R\&D expenditure (log, constant GBP) and R\&D headcount $(\log )$. a Real R\&D expenditure (log), base year 2005. b R\&D headcount $(\log )$, base year 2005. c Real R\&D expenditure (log), base year 2006. d R\&D headcount (log), base year 2006. Notes the figures present the density of the changes between the beginning of the pre-treatment period (2005 or 2006) and the end of the pre-treatment period (2007) in key outcome variables. a shows the kernel density of the changes in the R\&D spending variable in the treated and control groups. b shows the kernel density of the changes in the R\&D headcount variable in the treated and control groups

smallest firms, that is, those with fewer than 100 employees are sampled with a 1:4 ratio.

When aggregating the data for the BERD publication, the ONS imputes the values for the unsampled firms based on their employment number and product group. In each of the 99 product group-size band 'cells' available (33 product groups over 3 size bands), the values for the unsampled observations are imputed using the average R\&D per worker value of those observations which are not imputed, with employment as the scaling variable. For instance, if an unsampled firm in sector $\mathrm{H}$ (Pharmaceuticals) and size band 2 (100-400 employees) has ' $x$ ' employees (this information is available through the IDBR for all firms), their unknown in-house R\&D spending is imputed as the mean R\&D per worker in that cell multiplied by the employment number ' $x$ ' of the observation. This imputation procedure introduces a high level of variation across years for a given reporting unit when the micro panel version of the dataset is used. The variance of the growth rate in $R \& D$ spending from one year to the next increases significantly between two years of data when these are imputed, and also when one of the two values is imputed. Figure 10 is taken from an earlier working paper on this topic (Guceri 2015), and demonstrates the uneven distribution of changes in 
R\&D over time when the observation moves from an actual value to an imputed value and vice versa. The distribution of R\&D growth rates is a smooth bell-shaped curve only for those observations which move from an actual value to another year's actual value.

\section{Additional $t$ tests for pre-treatment dynamics between treated and control groups}

In this section, I present further tests of pre-treatment dynamics between treated and control group outcomes. In Table 4 the reference period is 2003, which is the starting point of the preferred sample. Some firms were not included in the BERD sample for 2003, resulting in the number of firms in 2003 to be smaller than the number of firms in the main regression specification. In Table 25, I check differential changes between different base years and the last pre-treatment period to ensure that there are no differential time changes in the main outcome variables of interest between treated and control groups that are unrelated to the policy reform. None of the $t$ tests reject the null hypothesis of equal pre-treatment differences between the treated and control groups at conventional levels of significance (Figs. 11, 12).

\section{Further robustness checks to test for the effect of outliers}

See Tables 26, 27, 28, 29, 30 and 31. 


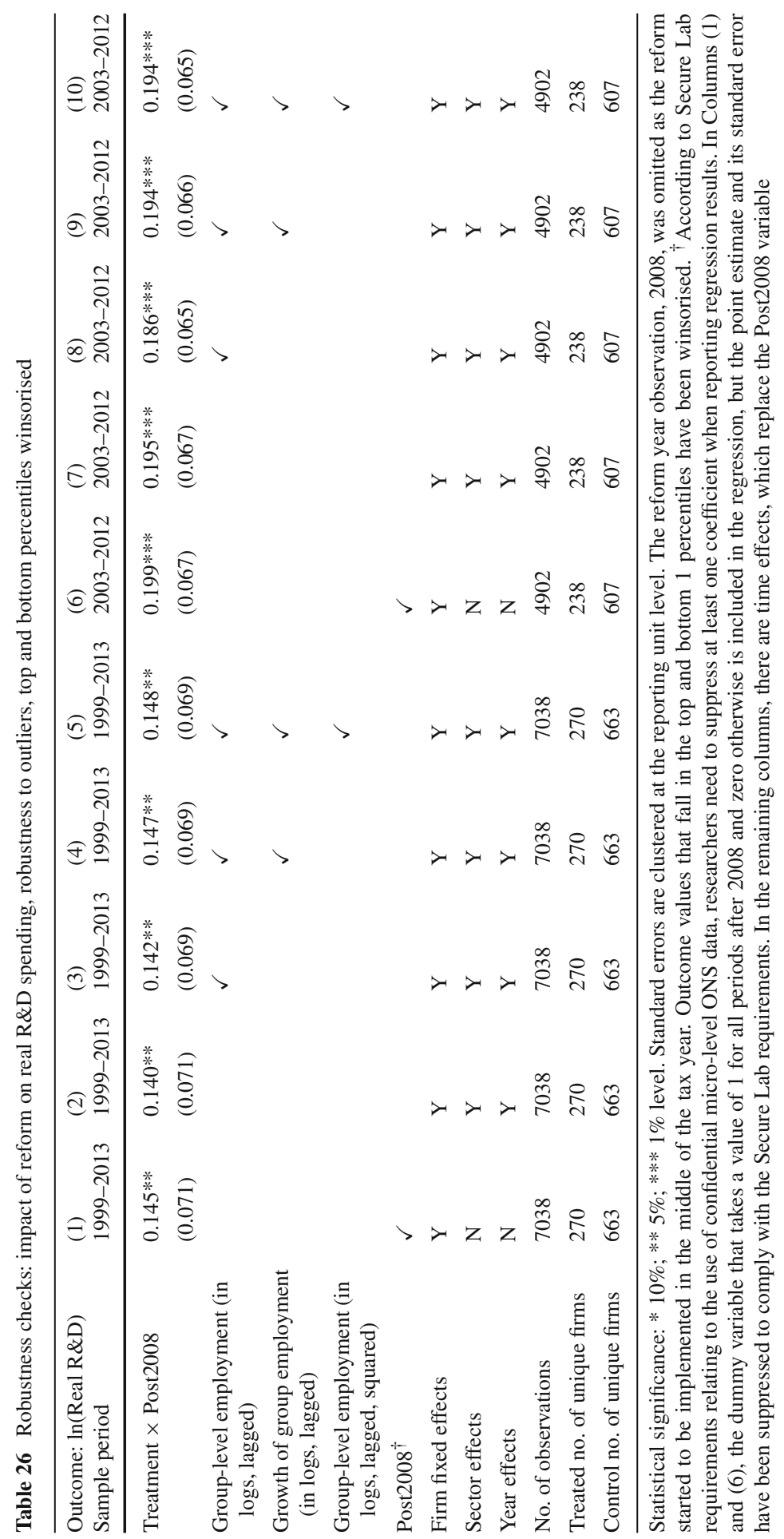




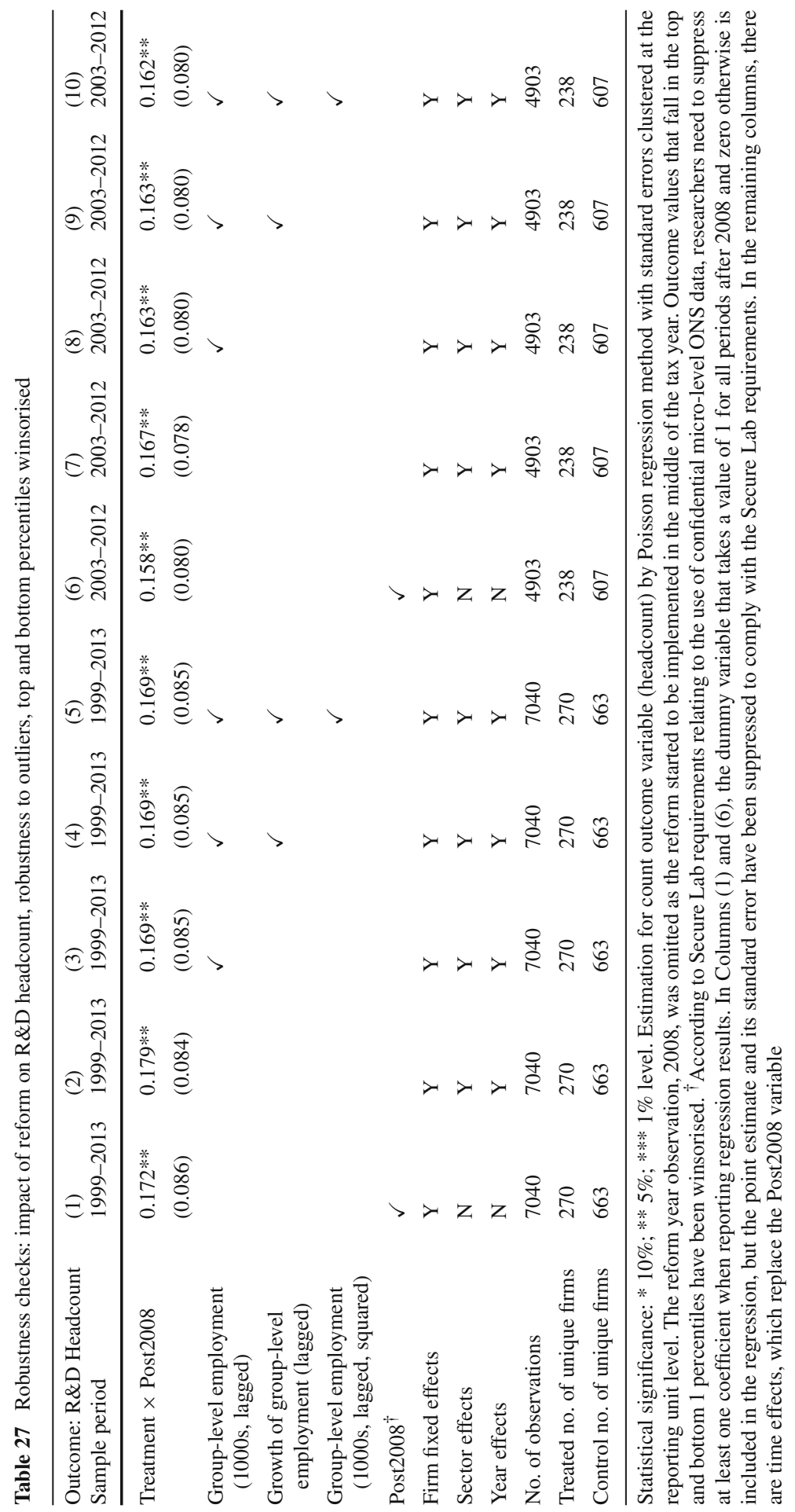




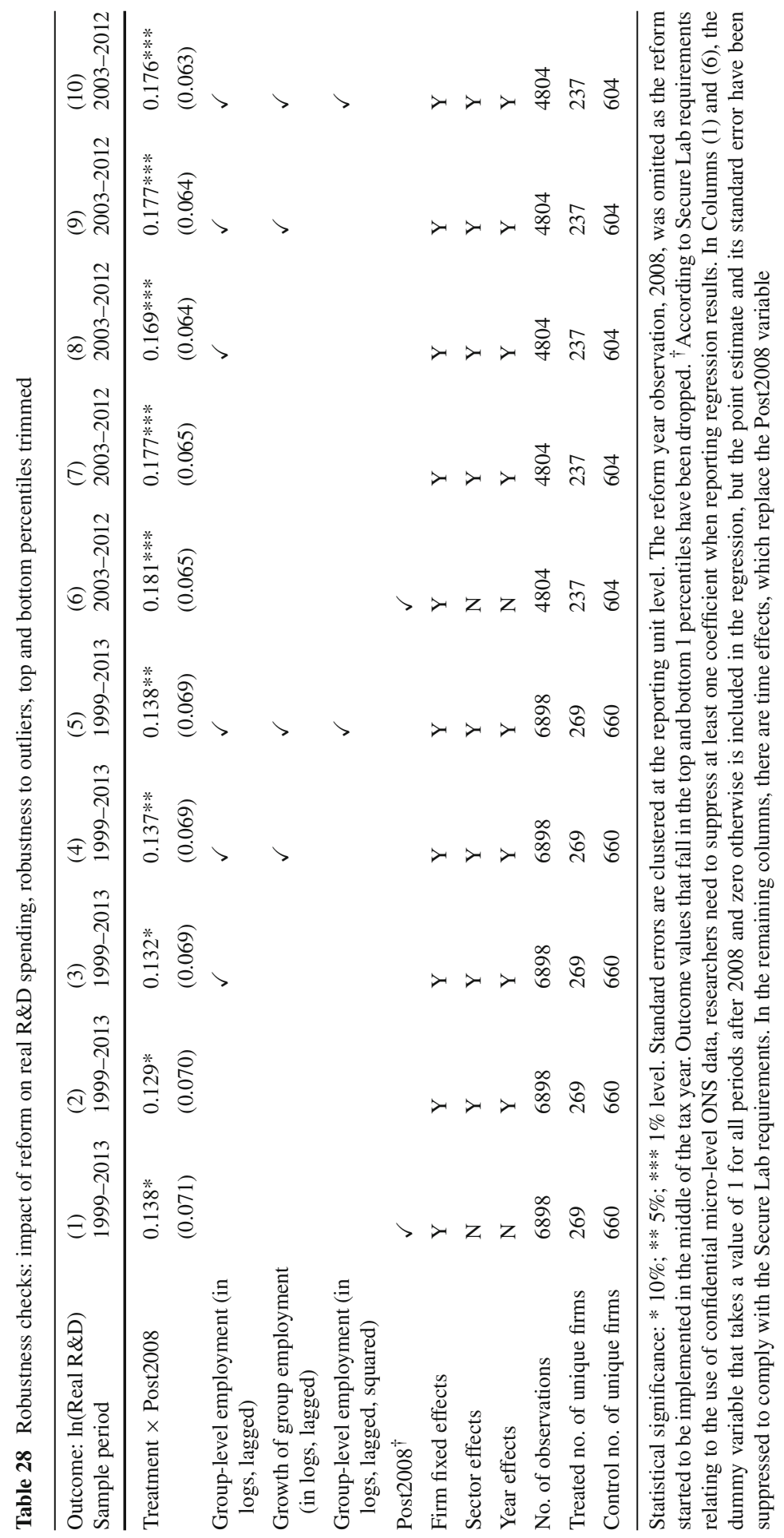




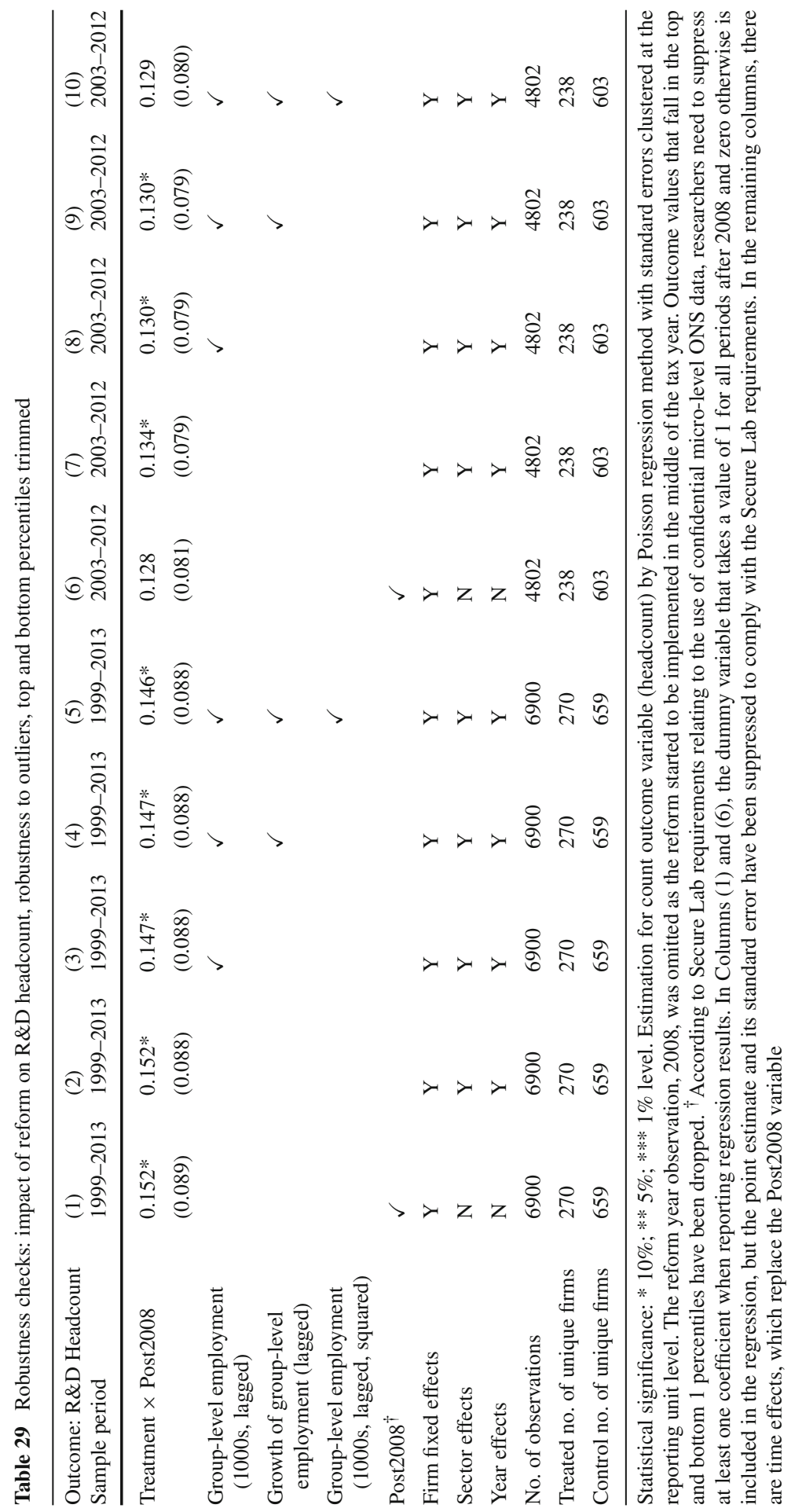




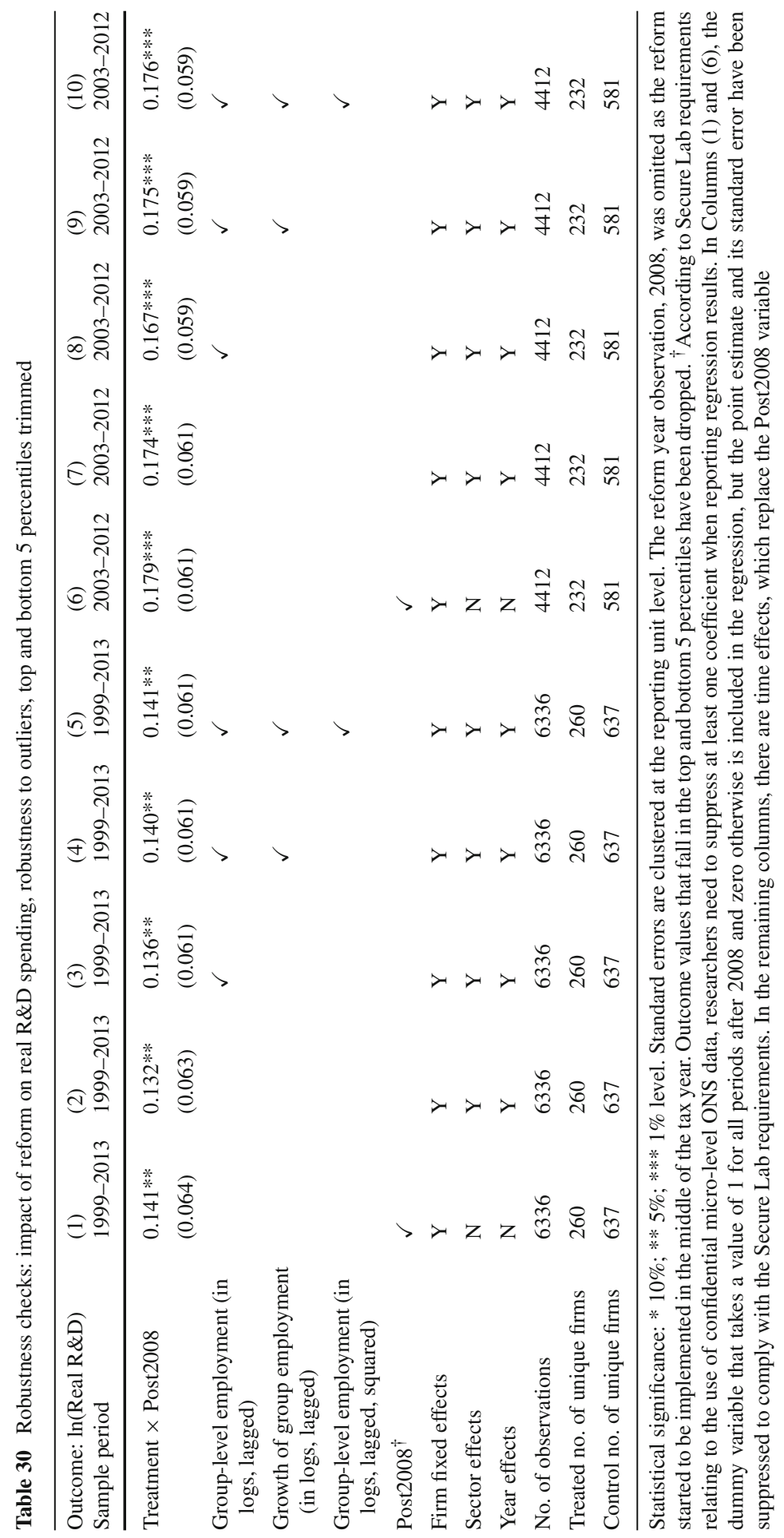




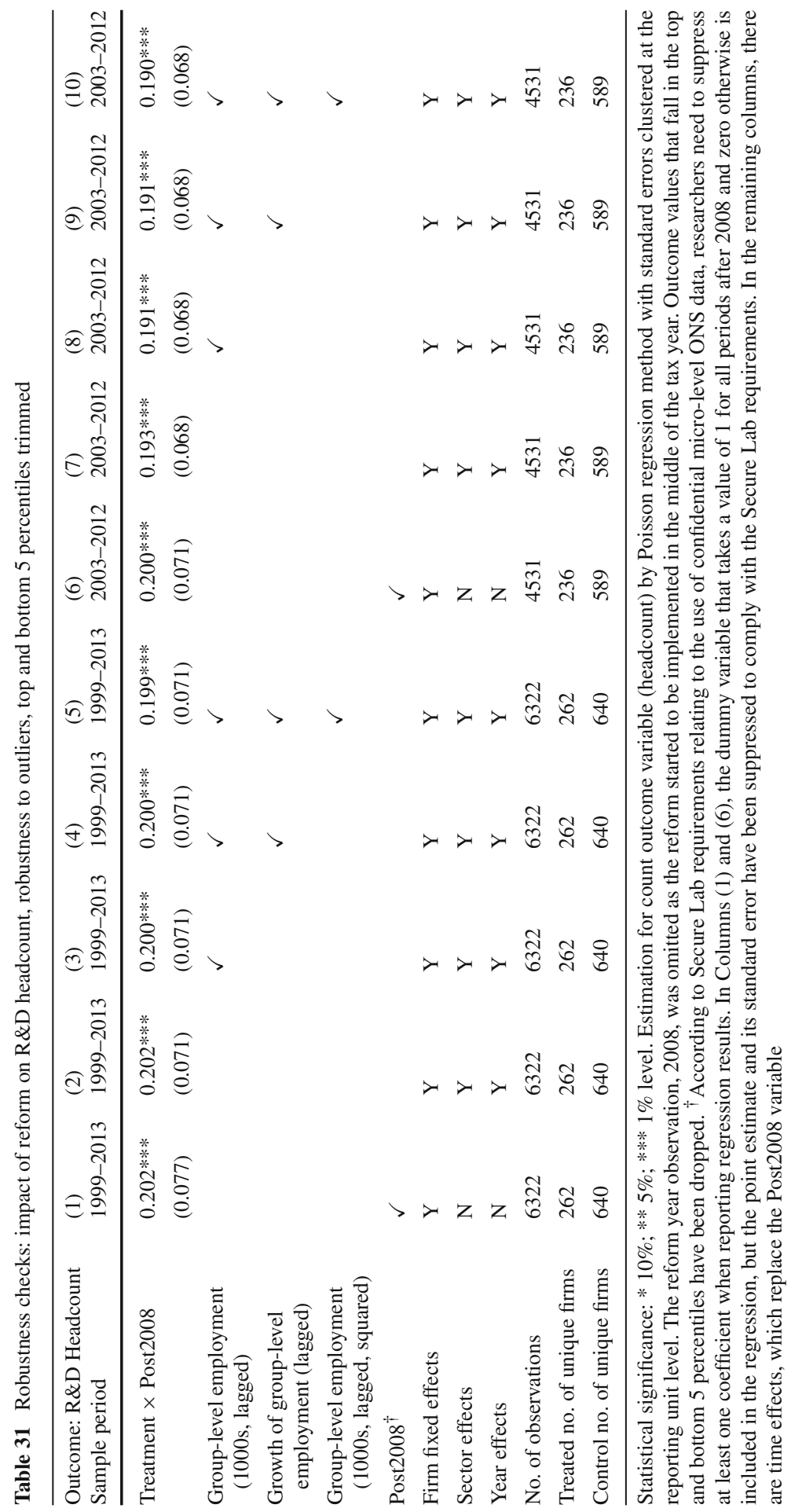




\section{References}

Aghion, P., \& Howitt, P. (1992). A model of growth through creative destruction. Econometrica, 60(2), 323-351.

Agrawal, A., Rosell, C., \& Simcoe, T. S. (2014). Do tax credits affect R\&D expenditures by small firms? Evidence from Canada. Working Paper 20615, National Bureau of Economic Research.

Altshuler, R. (1988). A dynamic analysis of the research and experimentation credit. National Tax Journal, 41(4), 453-466.

Arrow, K. (1962). Economic welfare and the allocation of resources for invention. In The rate and direction of inventive activity: economic and social factors, NBER Chapters (pp. 609-626). National Bureau of Economic Research, Inc.

Becker, B. (2015). Public R\&D policies and private R\&D investment: A survey of the empirical evidence. Journal of Economic Surveys, 29(5), 917-942.

Bloom, N., Griffith, R., \& Van Reenen, J. (2002). Do R\&D tax credits work? Evidence from a panel of countries 1979-1997. Journal of Public Economics, 85(1), 1-31.

Bond, S. R. \& Guceri, I. (2012). Trends in UK BERD after the introduction of R\&D tax credits. Working Papers 12/01, Oxford University Centre for Business Taxation.

Bronzini, R., \& Iachini, E. (2014). Are incentives for R\&D effective? Evidence from a regression discontinuity approach. American Economic Journal: Economic Policy, 6(4), 100-134.

Bronzini, R., \& Piselli, P. (2016). The impact of R\&D subsidies on firm innovation. Research Policy, 45(2), 442-457.

Cameron, C. A., \& Trivedi, P. K. (1998). Econometric society monographs: Regression analysis of count data. Cambridge, GB: Cambridge University Press.

Dechezlepretre, A., Einio, E., Martin, R., Nguyen, K.-T., \& van Reenen, J. (2016). Do tax incentives for research increase firm innovation? An RD design for $R \& D$. CEP Discussion Paper 1413, Centre for Economic Performance.

Ernst, C., Richter, K., \& Riedel, N. (2014). Corporate taxation and the quality of research and development. International Tax and Public Finance, 21(4), 694-719.

Evers, L., Miller, H., \& Spengel, C. (2014). Intellectual property box regimes: Effective tax rates and tax policy considerations. International Tax and Public Finance, 22(3), 502-530.

GAO. (1989). The research tax credit has stimulated some additional research spending. Technical Report GAO/GGD-89-114, US General Accounting Office.

GAO. (2009). The research tax credit's design and administration can be improved. Technical Report GAO-10-136, US Government Accountability Office.

Goolsbee, A. (1998). Does government R\&D policy mainly benefit scientists and engineers? American Economic Review: Papers and Proceedings, 88(2), 298-302.

Griffith, R., \& Harrison, R. (2003). Understanding the UKs poor technological performance. Technical report, Institute for Fiscal Studies

Griliches, Z. (1979). Issues in assessing the contribution of research and development to productivity growth. Bell Journal of Economics, 10(1), 92-116.

Guceri, I. (2015). Tax incentives and R\&D: Evaluation of an 2002 UK reform using BERD. Technical Report 15/11, Oxford University Centre for Business Taxation.

Guceri, I. \& Liu, L. (2015). Effectiveness of fiscal incentives for R\&D: A quasi-experiment. Technical Report $15 / 12$, Oxford University Centre for Business Taxation.

Hall, B., \& Van Reenen, J. (2000). How effective are fiscal incentives for R\&D? A review of the evidence. Research Policy, 29(4-5), 449-469.

Hall, B. H. (1995). Effectiveness of research and experimentation tax credits: Critical literature review and research design. Office of Technology Assessment, Congress of the United States: Report.

Hall, R. E., \& Jorgenson, D. W. (1967). Tax policy and investment behavior. The American Economic Review, 57(3), 391-414.

Jones, C. I., \& Williams, J. C. (1998). Measuring the social return to R\&D. The Quarterly Journal of Economics, 113(4), 1119-1135.

Jorgenson, D. W. (1963). Capital theory and investment behavior. The American Economic Review, 53(2), 247-259.

Kohler, C., Laredo, P., \& Rammer, C. (2012). The impact and effectiveness of fiscal incentives for R\&D. Working Paper 12/01, NESTA. 
Lokshin, B., \& Mohnen, P. (2013). Do R\&D tax incentives lead to higher wages for R\&D workers? Evidence from The Netherlands. Research Policy, 42(3), 823-830.

Mulkay, B., \& Mairesse, J. (2013). The R\&D tax credit in France: assessment and ex ante evaluation of the 2008 reform. Oxford Economic Papers, Oxford University Press, 65(3), 746-766.

National Audit Office. (2014). Tax reliefs. Report by the Comptroller and Auditor General HC 1256 Session 2013-14, National Audit Office.

OECD. (2002). OECD Frascati Manual (2002 ed.).

OECD. (2010). $R \& D$ tax incentives: Rationale, design, evaluation. Technical report, Organisation of Economic Co-operation and Development.

Rao, N. (2016). Do tax credits stimulate R\&D spending? The effect of the R\&D tax credit in its first decade. Journal of Public Economics. Forthcoming.

Rogers, M. (2010). R\&D and productivity: Using UK firm-level data to inform policy. Empirica, 37(3), 329-359.

Van Reenen, J. (1997). Why has Britain had slower R\&D growth? Research Policy, 26(4-5), 493-507.

Wilson, D. J. (2009). Beggar thy neighbor? The in-state, out-of-state, and aggregate effects of R\&D tax credits. The Review of Economics and Statistics, 91(2), 431-436.

Yagan, D. (2015). Capital tax reform and the real economy: The effects of the 2003 dividend tax cut. American Economic Review, 105(12), 3531-3563.

Zuniga-Vicente, J. A., Alonso-Borrego, C., Forcadell, F. J., \& Galan, J. I. (2014). Assessing the effect of public subsidies on firm R\&D investment: A survey. Journal of Economic Surveys, 28(1), 36-67.

Zwick, E., \& Mahon, J. (2017). Tax Policy and Heterogeneous Investment Behavior. American Economic Review, 107(1), 217-248.

\section{Datasets}

Office for National Statistics. (2015). Business Expenditure on Research and Development, 19942013: Secure Access. [data collection]. 4th Edition. UK Data Service. SN: 6690, doi:10.5255/ UKDA-SN-6690-4.

Office for National Statistics. (2015). Business Structure Database, 1997-2014: Secure Access. [data collection]. 5th Edition. UK Data Service. SN: 6697, doi:10.5255/UKDA-SN-6697-5.

Office for National Statistics. (2013). Annual Respondents Database, 1973-2009: Secure Data Service Access. 3rd Edition. Colchester, Essex: UK Data Archive, June 2012. SN: 6644, doi:10.5255/ UKDA-SN-6644-3. 